Aus dem Department für Nutztierwissenschaften

Lehrstuhl für Produktionssysteme der Nutztiere

\title{
Untersuchungen von klimatischen Einflüssen auf die Gesundheit und Milchleistung von Milchkühen in Niedersachsen
}

\author{
Dissertation \\ zur Erlangung des Doktorgrades \\ der Fakultät für Agrarwissenschaften \\ der Georg-August-Universität Göttingen
}

vorgelegt von

Christine Sanker

geboren in Bünde

Göttingen, Mai 2012 
1. Referent: Prof. Dr. Dr. Mathias Gauly

2. Korreferent: Prof. Dr. Sven König

Tag der mündlichen Prüfung: 20. Juli 2012 
Für

meine Eltern

"Wege entstehen dadurch, dass man sie geht" 


\section{INHALTSVERZEICHNIS}

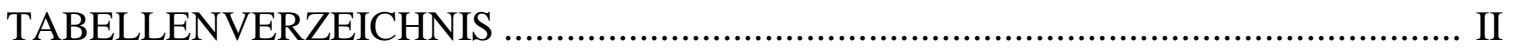

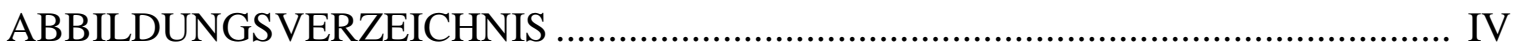

ZUSAMMENFASSUNG ................................................................................................................ 1

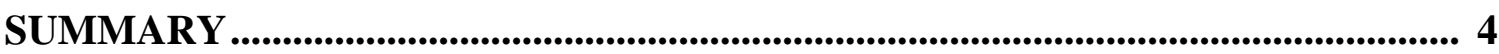

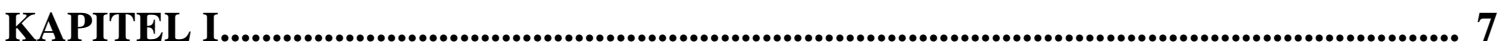

EINLEITUNG

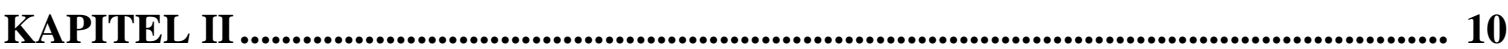

LITERATURÜBERSICHT

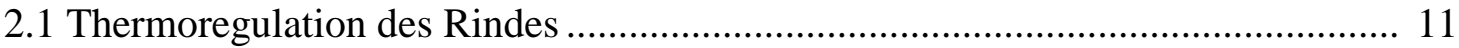

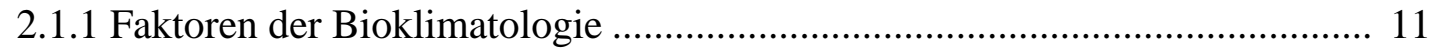

2.1.2 Anpassungsmechanismen an Umgebungstemperaturen .............................. 13

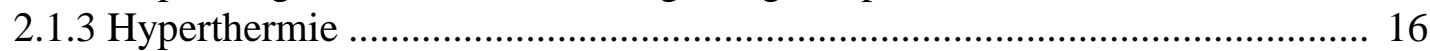

2.2 Wechselwirkungen zwischen klimatischen Bedingungen und Wohlergehen von

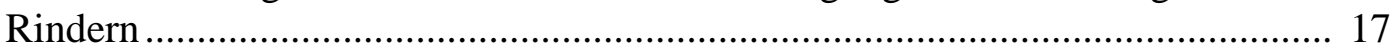

2.2.1 Klimatische Hitzestressfaktoren ............................................................ 17

2.2.1.2 Temperatur-Humiditäts Index ........................................................ 19

2.2.2 Auswirkungen von thermischen Belastungen............................................ 22

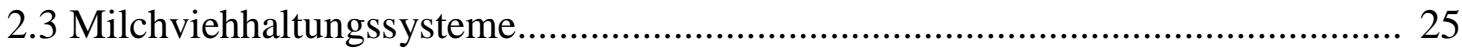

2.3.1 Strategien zur Reduzierung von Hitzestress ............................................ 26

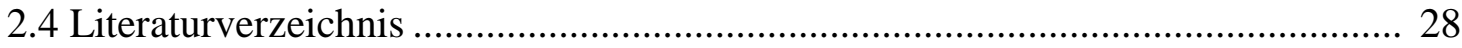

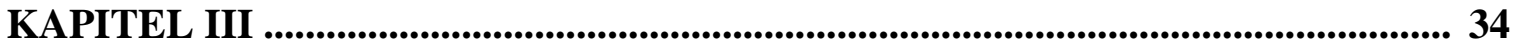

CLIMATIC EFFECTS IN CENTRAL EUROPE ON THE FREQUENCY

OF MEDICAL TREATMENTS OF DAIRY COWS

KAPITEL IV

CLIMATIC EFFECTS ON LACTATING HOLSTEIN COWS IN DIFFERENT HUSBANDRY SYSTEMS:

I. BULK MILK COMPONENTS AND SOMATIC CELL COUNT

KAPITEL V

CLIMATIC EFFECTS ON LACTATING HOLSTEIN COWS IN DIFFERENT HUSBANDRY SYSTEMS:

II. MILK YIELD, MILK COMPONENTS AND SOMATIC CELL SCORE

KAPITEL VI.

ALLGEMEINE DISKUSSION

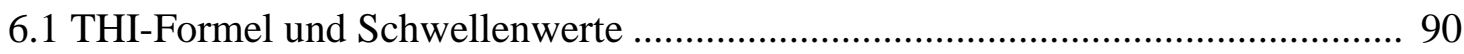

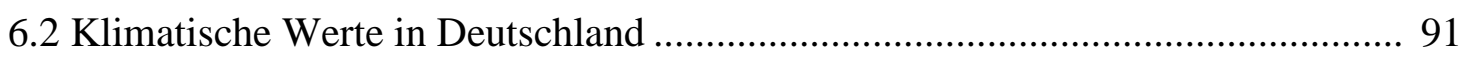

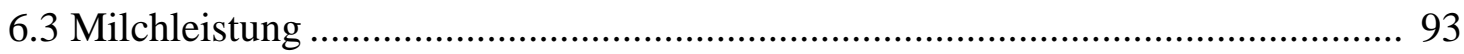

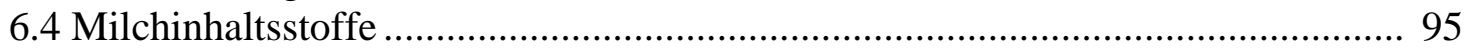

6.5 Eutergesundheit und somatischer Zellgehalt ...................................................... 97

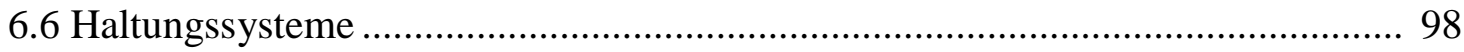

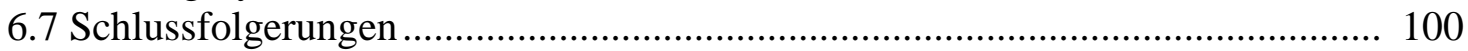

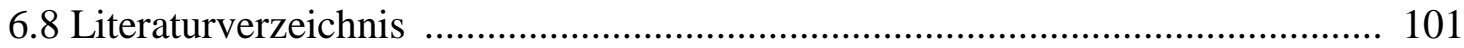




\section{TABELLENVERZEICHNIS}

\section{KAPITEL II:}

Tabelle 1: Maßnahmen der Temperaturregulation (WITTKE, 1972)

Tabelle 2: Indikatoren des Stallklimas und deren Auswirkung auf das Tier (BOCKISCH et al., 1999)

Tabelle 3: Unterschiedliche Formeln zur Berechnung des THIs (modifiziert nach BOHMANOVA et al., 2007 und WALTER UND LÖPMEIER, 2010).

Tabelle 4: Darstellung unterschiedlicher Schwellenwerte und Belastungsbereiche des Temperatur-Humiditäts Index (modifiziert nach WALTER und LÖPMEIER, 2010).

Tabelle 5: Gefährdungskategorien für Rinder in Freilandhaltung auf der Grundlage von THI-Auswertungen einer Hitzeperiode in den USA (nach HAHN et al., 1999)

Tabelle 6: Wasseraufnahme (in 1) pro Kuh und Tag bei unterschiedlichen Milchleistungen und Umgebungstemperaturen nach MACGREGOR (1995).. 23

Tabelle 7: Einfluss von Temperatur, relativer Luftfeuchtigkeit und THI auf die Milchleistung (modifiziert nach AMMER, 2011) 24

\section{KAPITEL III:}

Table 1: Monthly mean \pm standard deviation (SD), minimum, and maximum temperature-humidity index (THI) averaged over six meteorological stations from Lower Saxony, Germany, from the years 2003 and 2005 and the CLINO knowlegde (1961-1990; German MeteOrologiCAL SERVICE, 2012) 40

Table 2: Incidence of veterinary-treated cases according to four different diagnostic keys and different diagnoses using 5,547 records from eight dairy herds distributed over Lower Saxony, Germany, from the years 2003 and 2005 ... 41

\section{KAPITEL IV:}

Table 1: Monthly mean and maximum barn THI by the four different housing clusters throughout the experimental period (April 2010 to March 2011) 55 


\section{KAPITEL V:}

Table 1: Least square means (standard error) of $4 \%$ fat-corrected milk for temperature-humidity index (THI) classes in four different housing systems from April 2010 to March 2011

Table 2: Least square means (standard error) of milk fat yield $(\mathrm{kg} / \mathrm{d})$ for temperaturehumidity index (THI) classes in four different housing systems from April 2010 to March 2011 80

Table 3: Least square means (standard error) of milk protein yield $(\mathrm{kg} / \mathrm{d}$ ) for temperature-humidity index (THI) classes in four different housing systems from April 2010 to March 2011 81

Table 4: Least square means (standard error) of somatic cell score for temperaturehumidity index (THI) classes in four different housing systems from April 2010 to March 2011 82

Table 5: Linear Regression coefficients between THI (THI above 60) and milk production (FCM kg/day), milk components (milk fat and protein yield (kg/day)), and somatic cell score (SCS) at different stages of lactation (early: 0-100 DIM; mid: 101-200 DIM; late 201-305 DIM) in four loose-housing systems ( $\mathrm{n}=5,470)$ from April 2010 to March 2011 84

\section{KAPITEL VI:}

Tabelle 1: Auswirkungen von Hitzestress auf die jährliche Milchleistung pro Kuh (4\%fettkorrigierte Milch) in den unterschiedlichen Haltungssystemen im Bezug auf die „Anzahl THI Punkte über den THI Schwellenwert (THI $\geq 60$ )“ während der Versuchslaufzeit vom 1. April 2010 bis 30. März 2011 .99 


\section{ABBILDUNGSVERZEICHNIS}

\section{KAPITEL II:}

Abbildung 1: Zonen der Thermoregulation und deren Auswirkungen auf das Tier in Abhängigkeit von der Umgebungstemperatur (nach BIANCA, 1976) ... 12

Abbildung 2: Relative Veränderungen der unterschiedlichen Wärmeabgabemechanismen in Abhängigkeit von der Stalltemperatur (nach STROM UND FEENSTRA, 1980) 15

\section{KAPITEL III:}

Figure 1: Course of the daily mean temperature-humidity index (THI) values averaged over six meteorological stations from Lower Saxony, Germany, from the years 2003 and 2005

Figure 2: $\quad$ Least square means ( \pm standard error) of udder, fertility, metabolic, and foot/leg incidence $(\mathrm{N}=5,547)$ from eight dairy herds distributed over Lower Saxony, Germany, from the years 2003 and 2005 according to four THI-classes

Figure 3: Seasonal effects of udder, fertility, metabolic, and foot/leg incidences (Least square means \pm standard error; $\mathrm{N}=5,547$ ) from eight dairy herds distributed over Lower Saxony, Germany, from the years 2003 and 2005

\section{KAPITEL IV:}

Figure 1: Monthly average bulk fat percentages with standard error for the warm loose-housing system without access to pasture (WI, $\mathrm{N}=4, \mathrm{n}=192$ ), warm loose-housing system access to pasture (WP, $\mathrm{N}=4, \mathrm{n}=228$ ), cold loose-housing system without access to pasture $(\mathrm{CI}, \mathrm{N}=4, \mathrm{n}=254)$ and cold loose-housing system with access to pasture $(\mathrm{CP}, \mathrm{N}=4, \mathrm{n}=195)$ from April 2010 until March 2011 ( $\mathrm{N}=$ number of farms; $\mathrm{n}=$ number of records within cluster) 
Figure 2: Relationship of maximum THI during the last 3-days preceding milk sampling to fat content for $\mathbf{A}$ warm loose-housing system without access to pasture $(\mathrm{N}=4), \mathbf{B}$ warm loose-housing system with access to pasture $(\mathrm{N}=4), \mathbf{C}$ cold loose-housing system without access to pasture $(\mathrm{N}=4)$ and $\mathbf{D}$ cold loose-housing system with access to pasture $(\mathrm{N}=4) \ldots \ldots \ldots . . .58$

Figure 3: Relationship of 3-days maximum THI to milk protein content for $\mathbf{A}$ warm loose-housing system without pasturing $(\mathrm{N}=4)$, B warm loosehousing system with pasturing $(\mathrm{N}=4), \quad \mathrm{C}$ cold loose-housing system without pasturing $(\mathrm{N}=4)$ and $\mathbf{D}$ cold loose-housing system with pasturing $(\mathrm{N}=4)$ 61

Figure 4: $\quad$ Relationship of 3-days average THI to bulk milk somatic cell count (in thousands) for A warm loose-housing system without access to pasture ( $\mathrm{N}$ $=4), \mathbf{B}$ warm loose-housing system with access to pasture $(\mathrm{N}=4), \mathbf{C}$ cold loose-housing system without access to pasture $(\mathrm{N}=4)$, and $\mathbf{D}$ cold loosehousing system with access to pasture $(\mathrm{N}=4)$.

\section{KAPITEL V:}

Figure 1: $\quad$ Least square means ( \pm standard errors) for barn temperature-humidity index (THI) in warm loose-housing system without pasturing (black column), warm loose-housing system with pasturing (light grey column), cold loose-housing system without pasturing (dark grey column) and cold loose-housing system with pasturing (white column) from April 2010 to March 2011 (dashed line: heat stress threshold by BRÜGEMANN et al., 2010) 76

\section{KAPITEL VI:}

Abbildung 1: Monatliche Mittelwerte ( \pm Standardabweichung) des TemperaturHumiditäts Index (THI) für den Versuchszeitraum 2010/2011 und den CLINO Referenzen (1961 - 1990) von Niedersachsen 92 


\section{ZUSAMMENFASSUNG}

Die Ziele der vorliegenden Arbeit lagen in der Abschätzung der Folgen des Klimawandels (insbesondere Hitzeperioden) auf das Leistungsvermögen und die Gesundheit von Milchkühen in Niedersachsen, Deutschland. Hierfür wurden drei Versuchsansätze ausgewählt. Im ersten Versuch stand die Wechselwirkung zwischen klimatischen Bedingungen und der Behandlungsfrequenz von Milchkühen im Vordergrund. Hierfür wurden die Daten aus den Bestandsbüchern von 2003 und 2005 von acht Milchviehbetrieben ausgewertet. Die im zweiten und dritten Versuch analysierten Daten wurden im Rahmen eines einjährigen Feldversuches vom April 2010 bis März 2011 aufgenommen. Hierfür wurden aus einem Pool von niedersächsischen Milchviehbetrieben 20 Betriebe mit unterschiedlichen Haltungssystemen ausgewählt. Auf diesen Betrieben wurden klimatische Werte (Stalltemperatur und relative Stallluftfeuchtigkeit) als auch Herden- bzw. tierindividuelle Leistungsdaten anhand von Tankmilchproben bzw. Einzeltiermilchproben im Rahmen der Milchleistungsprüfung erfasst.

Im ersten Versuch (zweites Kapitel) wurden die Wechselwirkung zwischen dem Temperatur-Humiditäts-Index (THI) und der Behandlungsfrequenz von laktierenden Milchkühen analysiert. Es wurden die Behandlungsdaten von 2 Jahren (2003 und 2005) von acht Milchviehbetrieben mit Laufstallhaltung (55 bis 170 Kühe je Herde) erfasst. Nach der Eliminierung von Management abhängigen und Klima unabhängigen Einflüssen wurden insgesamt 5.547 Behandlungen analysiert. Die Behandlungen wurden in vier Komplexe unterteilt: Stoffwechsel, Fruchtbarkeit, Euter und Klauen. Es gehörten 37,4\% der Behandlungen zum Stoffwechsel-, 32,9\% zum Euter-, 21,6\% zum Fruchtbarkeits- und $8,1 \%$ zum Klauenkomplex. Die meteorologischen Daten wurden von der nächstgelegenen Wetterstation dem jeweiligen Betrieb zugeordnet (mittlere Distanz \pm Standardabweichung: $39 \pm 13 \mathrm{~km}$ ). Die Daten wurden mittels eines gemischten Modells analysiert, welches THI Klasse, Saison und Jahr als fixen und Betrieb als zufälligen Effekt berücksichtigte. Hierbei ergab sich, dass die Behandlungsfrequenzen nicht vom Jahr $(P>0,05)$, von der Saison $(P>0,05)$ und von den THI Klassen $(P>0,05)$ beeinflusst wurden, obwohl während der Sommermonate moderate Hitzestresskonditionen herrschten. Es zeigte sich ein tendenzieller Anstieg der Stoffwechselinzidenzen mit steigendem THI und ein nicht signifikanter Anstieg von Euterbehandlungen mit abfallendem THI.

Im zweiten Versuch (drittes Kapitel) wurde der Effekt vom Stall-THI auf den Milchfettund Milchproteingehalt (\%) sowie den somatischen Zellgehalt (SCC) in der Tankmilch 
von 16 Betrieben aus vier unterschiedlichen Haltungssystemen untersucht. Die Haltungssysteme wurden wie folgt unterteilt: (1) gedämmter Laufstall mit Weidegang; (2) gedämmter Laufstall ohne Weidegang; (3) Außenklimastall mit Weidegang und (4) Außenklimastall ohne Weidegang. Es standen für jedes System jeweils vier Betriebe zur Verfügung. In diesen 16 Betrieben wurde der THI mithilfe von Klimadatenloggern über einen Zeitraum von 12 Monaten erfasst. Die Tankmilchproben (SCC, Milchfett- und Milchproteingehalt) wurden während dieser Zeit vier bis sechs Mal pro Monat erfasst. Mit Hilfe eines gemischten Modells und einer Regressionsanalyse wurden die Effekte auf den SCC, Milchfett- und Milchproteingehalt analysiert. Es zeigten sich mit steigendem 3Tages-Maximum THI sinkende Milchfettgehalte, wobei sie um $0,012 \%$ und $0,01 \%$ für die gedämmten Laufstallsysteme mit und ohne Weidegang und um 0,004\% und 0,008\% für die Außenklimaställe mit und ohne Weidegang sanken. Beim Milchproteingehalt ergaben sich mit steigendem 3-Tages-Maximum THI die stärkeren Rückgänge in gedämmten Systemen im Gegensatz zu den Außenklimasystemen. Beim Saisonvergleich stieg der SCC vom Winter zum Sommer signifikant an $(215.400 \pm 74.400$ somatische Zellen/ml vs. $270.600 \pm 91.600$ somatische Zellen $/ \mathrm{ml} ; \quad P<0,001)$. Insgesamt wies die Studie unterschiedlich hohe Hitzestresseffekte auf die Inhaltsstoffe und den SCC in den Tankmilchproben der verschiedenen Haltungssysteme auf. Die deutlichsten Effekte von steigenden Klimawerten auf die Tankmilchinhaltsstoffe und SCC zeigten sich in den gedämmten Laufstallsystemen.

Im dritten Versuch (viertes Kapitel) wurde der Effekt vom THI auf die individuelle Milchmenge, Milchinhaltsstoffe (Fett und Eiweiß) und den somatischen Zellscore (SCS) in den im dritten Kapitel genannten vier Haltungssystemen analysiert. Pro Haltungssystem standen jeweils fünf Betriebe zur Verfügung. Die Klimadaten (Temperatur und relative Luftfeuchtigkeit) wurden in jedem Stall mit Datenloggern erfasst. Anhand der stündlichen Temperatur- und relativen Luftfeuchtigkeitswerte wurden 3-Tages-THI-Mittelwerte kalkuliert. Die Leistungsdaten beinhalteten 21.546 Testtagsdatensätze für Milchmenge, Milchfett- und Milchproteinmenge und SCS und wurden vom April 2010 bis März 2011 erfasst. Für die statistische Auswertung wurden gemischte Modelle und Regressionsanalysen genutzt. Insgesamt zeigte sich ein signifikanter Abfall von 0,78 kg, $0,04 \mathrm{~kg}$ und $0,03 \mathrm{~kg}$ bei der Milch-, Milchfett- und Milchproteinmenge und ein signifikanter SCS Anstieg von 0,15 bei einem Anstieg der THI Klasse 60-65 auf $\geq 65$. Bei weidebasierenden Haltungssystemen zeigten sich die höchsten Leistungsabfälle in der Milch-, Milchfett- und Milchproteinmenge bei einer Änderung der THI Klasse von 55-60 
auf $\geq 65$. Im Gegensatz dazu waren der SCS am höchsten in den Stallhaltungssystemen im THI Bereich $\geq 65$, wobei bei den Weidesystemen keine Hitzestresseffekte ersichtlich waren. Die Regressionsanalysen wurden mit den Daten durchgeführt, bei denen der THI Wert über 60 lag. Für die Milchmenge ergaben sich Regressionskoeffizienten von $-0,12 \mathrm{~kg}$ FCM/THI und -0,11 kg FCM/THI bei gedämmten Laufställen ohne und mit Weidegang sowie -0,21 kg FCM/THI für Außenklimaställe ohne und mit Weidegang. Für den SCS ergaben sich bei den Stallhaltungssystemen Regressionskoeffizienten von +0.03 SCS/THI für gedämmte Systeme $(P<0,05)$ und $+0,07$ SCS/THI für Außenklimaställe $(P<0,001)$. Zusammenfassend zeigten sich differenzierte THI Effekte auf die Milchproduktionsmerkmale zwischen den Haltungs- und Produktionssysteme.

Basierend auf den Ergebnissen der Arbeit kann geschlussfolgert werden, dass Milchkühe in Niedersachsen während der Sommermonate Hitzestress ausgesetzt sind, wohingegen sich die Auswirkungen je nach Haltungssystem differenziert darstellten. Des Weiteren konnte gezeigt werden, dass in dem System mit gedämmtem Dach niedrigere Auswirkungen mit steigendem THI zu finden waren. Für eine endgültige Empfehlung eines Haltungssystems sollte zusätzlich noch der Einfluss der Windgeschwindigkeit mit berücksichtigt werden. 


\section{SUMMARY}

The objectives of the present study were to determine the impact of climate change on the performance and health of dairy cows in Lower Saxony, Germany. Therefore, three experimental approaches were performed and as an indicator of heat stress the temperature-humidity index (THI) was used. The objective of the first study was the relationship between climatic conditions and the incidence of medical treatments of dairy cows. For this study, records of all veterinary-treated cases from the years 2003 and 2005 of eight dairy farms were used. For the second and third study a field experiment was conducted from April 2010 to March 2011. A total number of 20 dairy farms with four different housing systems in Lower Saxony was selected. Climatic conditions (temperature, relative humidity) and performance data using bulk and individual milk samples, respectively, were recorded on each farm.

In the first study (Chapter III) the relationship between the THI and the incidence of medical treatments in lactating dairy cows in Lower Saxony, Germany, was investigated. Records of all veterinary-treated cases over two years (2003 and 2005) from eight Holstein-Friesian dairy herds raised in loose-housing systems (55 to 170 cows per herd) were evaluated. After exclusion of management-dependent and climate-independent cases, a total of 5,547 treatments were analyzed. Treatments were clustered into the following groups: metabolism, fertility, udder, and foot/leg. Meteorological data were compiled from the nearest weather station (average distance \pm standard deviation: $39 \pm 13 \mathrm{~km}$ ). Hourly temperatures and relative humidity values were used to calculate the THI which was divided into classes. Out of the total number of treatments, 37.4, 32.9, 21.6, and 8.1\% belonged to metabolism, udder, fertility, and foot/leg, respectively. Data were analyzed with a mixed model that included THI class, season, and year as fixed effects and farm as random effect. In general, incidences were neither affected by the year $(P>0.05)$ and season $(P>0.05)$ nor by THI classes $(P>0.05)$. In tendency incidences of metabolic treatments increased with increasing THI and incidences of udder treatments increased with decreasing THI.

The aim of the second study (Chapter IV) was to compare the effect of the THI on fat and protein percentage, and somatic cell count (SCC) in bulk milk of dairy cows raised in four different housing systems: (1) warm loose-housing with access to pasture (WP); (2) warm loose-housing without access to pasture (WI); (3) cold loose-housing with access to pasture (CP); and (4) cold loose-housing without access to pasture (CI). This study was conducted 
for four farms of each housing system located in Lower Saxony. Air temperature and relative humidity were recorded by data loggers in these farms over a period of 12 months. Maximum THI values (averaged over three days) were calculated. Bulk milk samples (SCC, fat and protein percentage) were taken four to six times per month. Data were analyzed with a mixed model and a regression analysis. In July in each housing system heat stress conditions were found with maximum temperatures above $30^{\circ} \mathrm{C}$ and maximum THI values above 80 . In the warm loose-housing systems the highest environmental data (mean air temperature and THI) was recorded compared to cold loose-housing systems. With increasing 3-days maximum THI the fat percentage decreased by $0.012 \%$ and $0.01 \%$ per THI unit in the pasture-based and indoor warm loose-housing system, respectively. In the cold loose-housing system the fat percentages decreased by $0.004 \%$ per THI unit with access to pasture and by $0.008 \%$ per THI unit without pasturing. In the warm loosehousing systems a more distinct decline of protein percentages with increasing 3-days maximum THI was recorded than in the cold loose-housing system. A significant difference of bulk milk SCC between winter and summer $(215,400 \pm 74,400$ somatic cells $/ \mathrm{ml}$ vs. $270,600 \pm 91,600$ somatic cells $/ \mathrm{ml} ; P<0.001)$ was observed. In conclusion, the effect of heat stress conditions on bulk milk components and SCC differed between husbandry systems. With increasing THI more distinct decreases in the proportions of the different bulk milk components and increases in bulk milk SCC were recorded in the warm loose-housing system than in the cold loose-housing system.

The objective of the third study (Chapter IV) was to compare the effect of the THI on milk yield, milk components (milk fat and protein yield) and somatic cell score (SCS) of dairy cows in the same husbandry systems as in the second study. The performance data included 21,546 test-day records for milk, fat and protein yield and SCS. Data were recorded from April 2010 to March 2011 and analyzed with a mixed model and regression analysis. In each of the housing systems monthly THI values above 60 indicating heat stress were recorded between June and September. Compared to cold loose-housing systems average annual THI values were higher in warm loose-housing systems (WI: 56.3 \pm 0.7 , WP: $56.8 \pm 0.7$ vs. CI: $53.9 \pm 0.7, \mathrm{CP}: 54.7 \pm 0.7 ; P<0.001)$. Averaged over all housing systems, a significant difference of $0.78 \mathrm{~kg}, 0.04 \mathrm{~kg}$, and $0.03 \mathrm{~kg}$ in milk, fat and protein yield was calculated between the lowest and the highest THI class. For SCS a significant increase of 0.15 score units from THI class $60-65$ to $\geq 65$ was calculated. In pasture-based housing systems the highest milk, fat, and protein yield was observed in THI class 55-65. Above THI values of 65 yields decreased. Regarding SCS, the indoor systems 
had significantly higher values in the THI class $\geq 65$ compared to THI classes $<65$. However, for pasture-based systems large THI values did not affect SCS. The regression analysis was carried out for THI values above 60 and showed similar results of decreasing yields with increasing THI. Regression coefficients of fat corrected milk yield (FCM) on THI were $-0.12 \mathrm{~kg}$ for indoor, $-0.11 \mathrm{~kg}$ for pasture-based warm loose-housing systems, and $-0.21 \mathrm{~kg}$ for indoor and pasture-based cold loose-housing systems. In indoor systems the regression coefficients of SCS on THI were +0.03 for warm loose-housing $(P<0.05)$ and +0.07 for cold loose-housing $(\mathrm{P}<0.001)$. In conclusion, the effect of THI on milk production treatments differed between housing systems.

It can be concluded that in Lower Saxony dairy cows are exposed heat stress during the summer months. These effects have to be differentiated by the housing system. In the loose-housing system with isolated roofs lower effects with increasing THI were identified. 
KAPITEL I

EINLEITUNG 
Das Wohlbefinden und das Leistungsvermögen von landwirtschaftlichen Nutztieren hängen mit einer Vielzahl von Faktoren zusammen. Dieser Zusammenhang ergibt sich aus der komplexen Wechselbeziehung zwischen dem einzelnen Tier und der Umwelt mit ihren verschiedenen Faktoren wie z.B. dem Außen- bzw. Stallklima und den unterschiedlichen Haltungsbedingungen. Anhand von Regulationsmechanismen kann sich das Tier an die herrschenden Umweltbedingungen anpassen, wobei insbesondere Klimaeinflüsse diese Adaptationsfähigkeit beeinflussen. Für diese Anpassung an die klimatische Umwelt stehen dem Rind verschiedene Möglichkeiten auf physiologischer, morphologischer und verhaltensbedingter Ebene zur Verfügung (BIANCA, 1976). Durch verschiedene Prozesse, wie beispielsweise Änderungen in Körpertemperatur, Herzfrequenz oder Verhaltensweisen, kann sich das Tier an Veränderungen der Klimaverhältnisse anpassen. Dies wird vom Organismus durch das Bestreben der Aufrechterhaltung des Optimalzustands durchgeführt (JESSEN, 2000). Situationen, die das Adaptationsvermögen überfordern, führen $\mathrm{zu}$ Leistungseinbrüchen und/oder gesundheitlichen Problemen (RENAUdEAU et al., 2012). Verschiedene Studien zeigten, dass Milchkühe unter Hitzestress ein Absinken der Milchleistung aufweisen (u.a. IGONO et al., 1992; BouRAOUI et al., 2002). Ebenso führen extreme Umgebungstemperaturen $\mathrm{zu}$ schlechteren Fruchtbarkeitskennzahlen, wie z. B. verminderten Konzeptionsraten und höheren Zwischenkalbezeiten (u.a. RAY et al., 1992; VILLA-MANCERA et al., 2011).

Unter dem Aspekt der zu erwartenden Klimaveränderungen, insbesondere durch eine Erhöhung der Temperaturen und einer Zunahme der Extremsituationen (Hitze- und Kälteperioden) (KLEIN TANK UND KÖNNEN, 2003), muss in Deutschland vermehrt über Effekte von Hitzestress auf das Wohlbefinden und Leistungsvermögen von Tieren nachgedacht werden. Durch fortlaufende Entwicklungen und Veränderungen in der Zucht und in den Haltungsbedingungen werden einzelne Faktoren zwischen Umwelt und Tier verändert, so dass eine einmalige Bewertung der Umweltverhältnisse kaum ausreicht. Vielmehr besteht die Notwendigkeit einer langfristigen Betrachtung und Erfassung der herrschenden Umwelt-Organismus-Situation. In der praktischen Milchviehhaltung sind unterschiedliche Systeme von Bedeutung (u.a. Warmstall, Außenklimastall, Umbauvarianten und Weidehaltungssysteme). So wirft die Entwicklung der verschiedenen Haltungssystemen und Stalleinrichtungen (u.a. Liegeboxensysteme, Lüftungssysteme, Ventilatoren) die Frage auf, ob die Belastungssituationen, die unter anderem durch das Stallklima verursacht werden, in den Systemen unterschiedlich stark ausgeprägt sind. 
Bisherige Untersuchungen zu Klimaeinflüssen auf landwirtschaftliche Nutztiere wurden häufig anhand von Klimadaten von Wetterstationen also anhand von Außenklimabedingungen ermittelt oder in Regionen mit nicht vergleichbaren klimatischen Bedingungen wie in Deutschland durchgeführt. Die Übertragbarkeit derartiger Ergebnisse auf praxisübliche Haltungsbedingungen ist fraglich, denn die unterschiedlichen Bauweisen der verschiedenen Haltungssysteme könnten das Stallklima beeinflussen, wodurch wiederum die Intensität des Hitzestresses auf das Tier verschieden ausgeprägt sein könnte.

Gegenstand der vorliegenden Arbeit war daher, den Einfluss von klimatischen Bedingungen (Temperatur und Temperatur-Humiditäts Index) auf die Gesundheit und das Leistungsvermögen von Milchkühen in Niedersachsen zu untersuchen. In der ersten Studie wurden die Auswirkungen des Temperatur-Humiditäts Index (THI) auf die Behandlungsinzidenzen ermittelt. In der zweiten Studie war es zum einen das Ziel die Effekte der Stalltemperatur und dem Stall-THI auf die Milchinhaltsstoffe (Fett- und Eiweißgehalt) und den somatischen Zellgehalt anhand von Tankmilchproben in vier verschiedenen Haltungssystemen abzuschätzen, zum anderen wurde der Einfluss des Stall-THI auf die Produktionsmerkmale (4\%-Fett korrigierte Milchmenge, Fett kg, Eiweiß kg) und den somatischen Zellscore (SCS) der Einzeltiere in diesen vier Haltungssystemen ermittelt. Anhand dieser Untersuchungen soll aufgezeigt werden, ob es unterschiedliche Ausprägungen von Hitzestress in den einzelnen Systemen gibt und ob eventuell ein System die klimatischen Bedingungen besser kompensiert als die anderen. 
KAPITEL II

LITERATURÜBERSICHT 


\subsection{Thermoregulation des Rindes}

Im Folgenden wird ein kurzer Überblick über einige Aspekte des Wärmehaushaltes und seine Regulationsmechanismen beim Rind dargestellt. Zunächst wird auf die Physiologie der Thermoregulation und die verschiedenen Anpassungsmechanismen eingegangen und im Anschluss die Hyperthermie und ihre Anzeichen dargestellt.

\subsubsection{Faktoren der Bioklimatologie}

Das Rind gehört zu den homiothermen Tieren und kann in gewissen Grenzen unabhängig von der klimatischen Umgebung die Körperkerntemperatur konstant halten. Eine relativ konstante Körpertemperatur ist für die vitalen und produktiven Prozesse notwendig, weshalb eine Aufrechterhaltung des Gleichgewichtes zwischen Wärmebildung und Wärmeabgabe erforderlich ist (RICHTER et al., 2006).

Die Körpertemperatur wird von verschiedenen Faktoren beeinflusst. Zum einen variiert sie mit der Tageszeit und zeigt den höchsten Anstieg nach der Fütterung (YousEF, 1985). Zum anderen variiert sie mit dem Laktationsstadium, dem Milchleistungsniveau und mit dem Zyklusstadium (zitiert nach BOHMANOVA, 2006). Des Weiteren haben klimatische Bedingungen Einfluss auf die Höhe der Körpertemperatur. Mit diesem Bereich setzt sich die Bioklimatologie auseinander, wobei sie die Einwirkungen des Klimas auf die Lebensvorgänge und Leistungen von Tieren analysiert (BIANCA, 1968). In der folgenden Abbildung werden die verschiedenen Anpassungswege von homiothermen Tieren auf unterschiedliche Temperaturen verdeutlicht.

Die Umgebungstemperatur kann anhand der Wirkung auf das Tier in vier Bereiche unterteilt werden (RICHTER et al., 2006). Zwischen den Punkten B und B' liegt die Zone der Thermoneutralität. In diesem Bereich erfordert die Thermoregulation keinen bzw. geringsten energetischen Aufwand. Innerhalb der Zone der Thermoneutralität befindet sich die Behaglichkeitszone (A-A'), in der das Tier keine Wärme oder Kälte empfindet, weshalb sie ebenfalls als Bereich der thermischen Indifferenz bezeichnet wird (BIANCA, 1971). In diesem Modell wird ausschließlich die Temperatur als Klimafaktor berücksichtigt und nicht andere Klimaparameter wie die relative Luftfeuchtigkeit oder die Windgeschwindigkeit. 


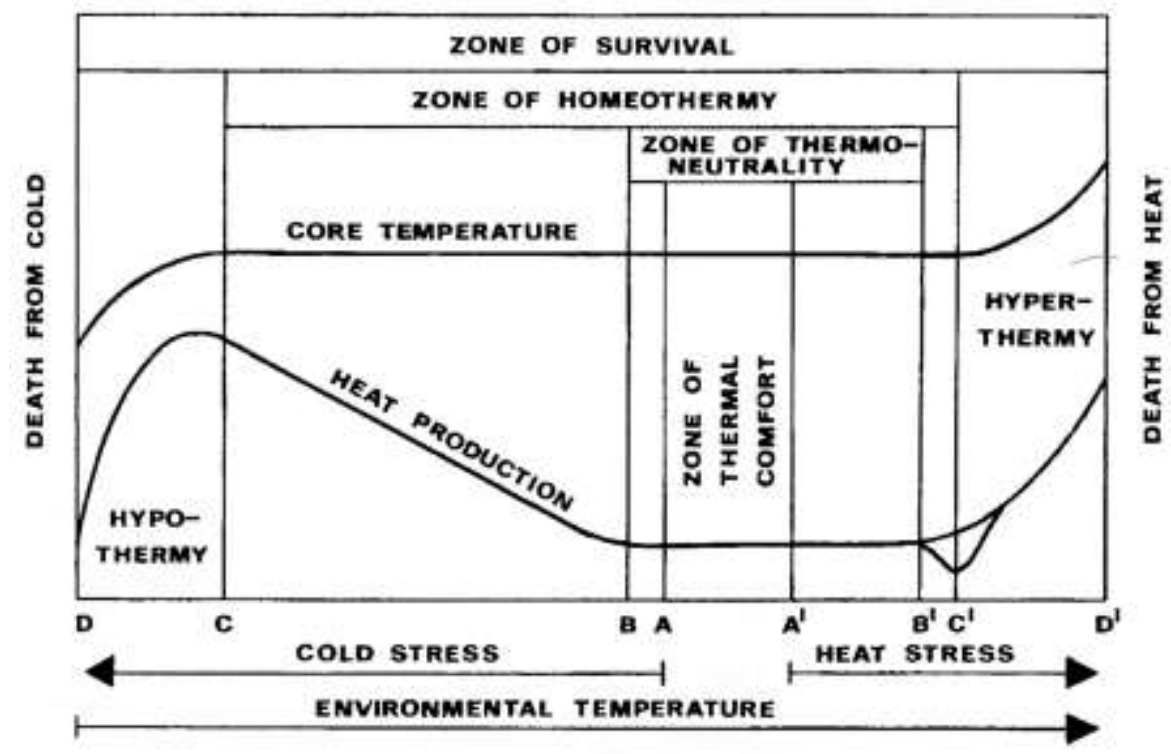

Abbildung 1. Zonen der Thermoregulation und deren Auswirkungen auf das Tier in Abhängigkeit von der Umgebungstemperatur (nach BIANCA, 1976).

Bei Absinken der Temperatur unterhalb der unteren kritischen Temperatur (B) muss mit Hilfe von erhöhter Stoffwechselaktivität und Kältezittern die Körperkerntemperatur aufrechterhalten werden. Mit Anstieg der Umgebungstemperatur über die obere kritische Temperatur (B') versucht der Organismus durch vermehrtes Schwitzen und Reduzierung der metabolischen Wärmeproduktion die Belastung auszugleichen. Je höher jedoch die Umgebungstemperatur ansteigt, desto mehr Energie wird für die Thermoregulation benötigt, um das Ansteigen der Körperkerntemperatur zu verhindern (KHALIFA, 2003). Dieser Bereich befindet sich bei Umgebungstemperaturen ab $23-26^{\circ} \mathrm{C}$ bei Holstein Kühen (IGONO et al., 1992; HAHN, 1999). Bei steigenden Temperaturen versucht der Organismus die Wärmeproduktion zu reduzieren, indem die Futteraufnahme verringert wird und das Leistungsvermögen sinkt (WEST, 2003). Reichen diese Mechanismen nicht aus, beginnt die Körperkerntemperatur anzusteigen und es kommt zu einer Hyperthermie (C'-D'; ROBERTSHAW, 1981). Nach JESSEN (2000) können Umgebungstemperatur zwischen $42^{\circ} \mathrm{C}$ und $43^{\circ} \mathrm{C}$ zu einem Hitzeschlag führen, welches in den meisten Fällen tödlich endet.

Bei Milchkühen wird der Temperaturbereich der Thermoneutralität je nach Autor unterschiedlich beschrieben. BIANCA (1971) und YOUSEF (1985) definieren diesen bei Umgebungstemperaturen von 0 bis $16^{\circ} \mathrm{C}$ und MALKOW-NERGE et al. (2005) von $-7^{\circ} \mathrm{C}$ bis $17^{\circ} \mathrm{C}$. Die thermoneutrale Zone wird von verschiedenen Faktoren beeinflusst. Hierzu gehören das Leistungs- und Fütterungsniveau, Rasse/Genetik, Tieralter, Geschlecht, Haut und Haarkleid (WEST et al., 2003). 


\subsubsection{Anpassungsmechanismen an Umgebungstemperaturen}

Wie im vorherigen Abschnitt beschrieben, besitzen homoiotherme Tiere die Fähigkeit ihren Wärmehaushalt zu regulieren und somit das Ausmaß ihrer Wärmeproduktion zu variieren. Hierbei muss beachtet werden, dass unabhängig von den klimatischen Bedingungen und von dem Tier nicht beeinflussbar, ein Mindestmaß an Wärme produziert wird, da für die Erhaltung von Lebensfunktionen ein Mindestenergieumsatz notwendig ist, welcher mit Wärmebildung verbunden ist (JESSEN, 2000). Beispielsweise wird bei Rindern in Abhängigkeit von der Futteraufnahme durch Pansenmikroben Wärmeenergie produziert (NiCHELMANN, 1971).

Es gibt verschiedene Thermoregulationsmechanismen, welche sich in physiologische und morphologische Anpassungsmechanismen und Verhaltensänderungen zur Wärmeregulation unterteilen lassen (Tabelle 1).

Tabelle 1. Maßnahmen der Temperaturregulation (WITTKE, 1972).

\begin{tabular}{llll}
\hline Klima & \multicolumn{2}{c}{ Maßnahmen zur Temperaturregulation } \\
\hline & \multicolumn{1}{c}{ Autonome Regelung } & \multicolumn{1}{c}{ Verhaltensregelungen } \\
physikalisch & chemisch & \\
\hline Hitze & Steigerung der & Verminderung der & z.B.: Aufsuchen von Schatten \\
& Hautdurchblutung & Wärmebildung & Benetzung mit Wasser \\
& Wärmehecheln, & & Einschränkung der Bewegung \\
& Schwitzen & & und der Futteraufnahme \\
Kälte & Verminderung der & Steigerung der & z.B. Zusammenstellen mehrerer \\
& Hautdurchblutung & Wärmebildung & Tiere (kollektive \\
& & & Temperaturregelung) \\
& Aufstellen der Haare & & Aufsuchen von Windschatten \\
\hline
\end{tabular}

Die Umgebungsbedingungen wie Temperatur, Luftfeuchtigkeit, Luftbewegung, sowie Wärmestrahlung können im wesentlich den Wärmeaustausch und das Ausmaß der Regulationsmechanismen beeinflussen. Ebenso nehmen sie Einfluss auf die physikalischen Wärmeabgabemechanismen (Leitung, Konvektion, Strahlung und Verdunstung). Wenn sich ein homoiothermer Organismus im Gleichgewicht mit seiner Umgebung befindet, trifft folgende Formel zu (BERMAN et al., 1985): 


$$
Q_{m}=Q_{h s}+Q_{k}+Q_{c}+Q_{r}+Q_{e}
$$

$Q_{m}=$ metabolische Wärmeproduktion, $Q_{h s}=$ gespeicherte Wärme, $Q_{k}=$ Wärmeaustausch durch Konduktion, $Q_{c}=$ Wärmeaustausch durch Konvektion, $Q_{r}=$ Wärmeaustausch durch Radiation, $Q_{e}=$ Wärmeaustausch durch Evaporation.

Sobald dieses Gleichgewicht durch eine längerfristige Überschreitung der endogenen Wärmeproduktion und der exogenen Wärmeeinträge gegenüber der Wärmeabgabe des Rindes gestört wird, hat es Folgen auf das Wohlbefinden und die Gesundheit des Tieres (BICKHARDT, 1992).

\section{Konduktion}

Die Wärmeleitung (Konduktion) beschreibt die Wärmeabgabe durch den direkten Kontakt zwischen Körperoberfläche und kälteren Flächen (z.B. Liegebox, Stallwand). Der Wärmetransport findet wie bei allen Arten der Wärmeübertragung durch die Übertragung von Wärmeenergie von Teilchen höherer auf Teilchen geringerer Temperatur statt (JESSEN, 2000; HoY et al., 2006).

\section{Konvektion}

Die Wärmeströmung (Konvektion) ist ein Wärmeübertragungsweg der hauptsächlich die Wärme innerhalb des Tierkörpers überträgt. Hierbei wird die Wärmeenergie, welche an das strömende Medium Blut gebunden ist, aus dem Körperinnern bis zur Epidermis bzw. Körperoberfläche transportiert, wodurch der Zusammenhang zwischen Wärmeabgabe und Windgeschwindigkeit deutlich wird (JESSEN, 2000). Muskelzittern verursacht z.B. eine erhöhte Hautdurchblutung. Dieser Mechanismus steigert den inneren Wärmestrom zur Peripherie (nach BAROw, 1998).

\section{Radiation}

Die Wärmestrahlung (Radiation) beschreibt die Wärmeübertragung durch elektromagnetische Wellenstrahlen von der Körperoberfläche zu kälteren Flächen der Umgebung ohne direkten Kontakt zwischen den Flächen (ScHÖNMUTH et al., 1986). Die Ausmaße der Radiation können in gewissen Massen direkt vom Tier beeinflusst werden, 
indem sie durch Ausstrecken bzw. Einrollen ihre Ausstrahlungsfläche vergrößern oder verringern können (PENZLIN, 1991).

\section{Evaporation}

Die Wärmeabgabe durch Verdunstung von Wasser (Evaporation) über die Haut und die Atemwege stellt einen effizienten Weg der Wärmeabfuhr dar. Die Evaporation ist abhängig von der Differenz der Wasserdampfpartialdrücke und nicht von den Temperaturdifferenzen, wodurch sie insbesondere in sehr warmen und trockenen Klimazonen von Bedeutung ist (MCARTHUR UND CLARK, 1988). Unter thermischer Belastung können die Wärmeabgabe über die autonomen Effektoren (Hecheln und Schwitzen) deutlich gesteigert werden (zitiert nach BRÜSER-PIEPER, 2006). HARRIS (1992) und Webster (1991) sehen eine Steigerung der Atemfrequenz über 60 Atemzüge pro Minute als Reaktion auf gestiegene Umgebungs- und Körpertemperaturen. Beim erwachsenen Rind werden Atemzüge über 80 pro Minute als Indikator für kritische Hyperthermie gesehen (MCDOwELL, 1972).

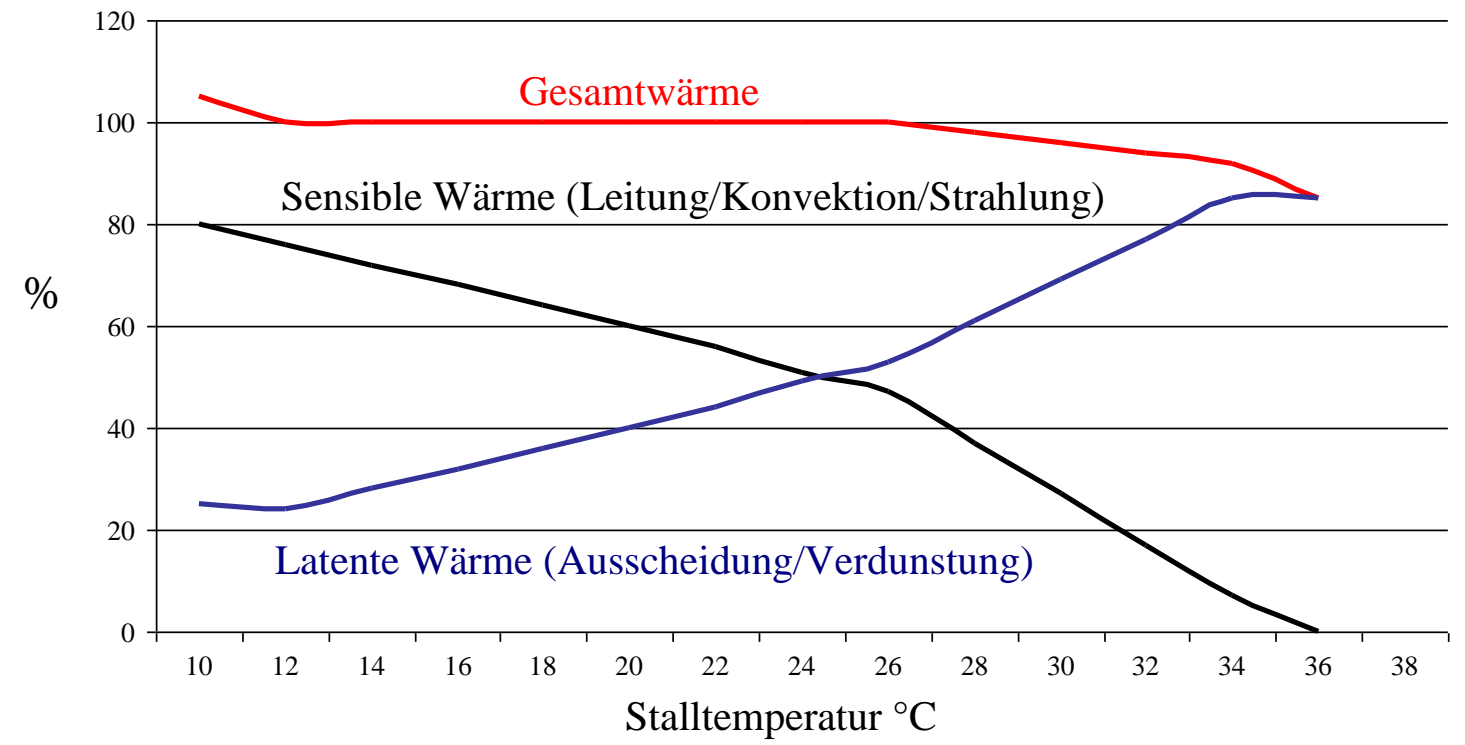

Abbildung 2: Relative Veränderungen der unterschiedlichen Wärmeabgabemechanismen in Abhängigkeit von der Stalltemperatur (nach STROM UND FEENSTRA, 1980).

Bei der Evaporation handelt es sich um eine indirekte (latente) Wärmeabgabe, wobei die Wärme i.d.R. nur vom Körper an die Umwelt abgegeben wird. Bei der direkten (sensible) Wärmeabgabe durch die Konduktion, Konvektion oder Radiation verläuft es in beide Richtungen (HERZ Und STEINHAuf, 1974). Die Abbildung 2 verdeutlicht die Abhängigkeit 
der genannten Wärmeabgabemechanismen von der Umgebungstemperatur. Je höher die Temperatur steigt, desto weniger Gesamtwärme kann durch die sensiblen Wege abgegeben werden und desto mehr muss über Evaporation ausgeglichen werden. Neben der Temperatur werden die Abgabemechanismen zusätzlich durch andere Klimafaktoren, wie die Windgeschwindigkeit und die Strahlung beeinflusst. Der Anteil der Strahlung an der Gesamtwärmeabgabe nimmt mit zunehmender Windgeschwindigkeit ab. Gleichzeitig steigt die Wärmeabgabe durch die Strömung an. Im Allgemeinen sind die Möglichkeiten der Wärmestrahlung nach ScHÖNMUTH et al. (1986) im Freien für Rinder größer als im Stall. Die Strahlungstemperatur ist insbesondere bei bedecktem Himmel 10 bis $20^{\circ} \mathrm{C}$ geringer als die Lufttemperatur, wobei sie im Gebäude ungefähr der Umgebungstemperatur entspricht.

Neben den genannten physikalischen Mechanismen, mit denen sich das Tier an hohe und niedrige Umgebungstemperaturen anpassen kann, gibt es noch die Anpassungsmöglichkeit durch Verhaltensänderungen. Hier sind zum einen Anpassungen durch die Futteraufnahme und Leistungseinschränkungen zu nennen. Bei niedrigen Temperaturen wird unter anderem die Futteraufnahme erhöht, um mehr Körperwärme zu erzeugen. Bei hohen Temperaturen wird wiederum die Futteraufnahme gesenkt, um die Erzeugung der Körperwärme zu reduzieren. Zum anderen versuchen sie durch die Wahl ihres Aufenthaltsortes sich anzupassen, indem sie zum Beispiel bei hohen Temperaturen schattige Plätze aufsuchen und sich weniger bewegen (WITTKE, 1972).

\subsubsection{Hyperthermie}

Die Überhitzung (Hyperthermie) bezeichnet den Zustand des Ansteigens der Temperatur über die normale Körperkerntemperatur. Um diesen Zustand zu vermeiden, reagiert der Körper auf seine Umwelt mit den im vorherigen Kapitel genannten Mechanismen. Je höher die Umgebungstemperatur, desto schwieriger wird die Wärmeabgabe für das Tier, da warme Umgebungsluft nur begrenzt die abzugebende Körperwärme aufnehmen kann. Aus diesem Grund sind Rinder in warmen Umgebungen bestrebt, ihre Wärmeproduktion auf ein Minimum zu reduzieren. Hierfür schränken sie ihre Futteraufnahme und Bewegungsaktivität ein. Nach WINTER et al. (1980) haben hohe Umgebungstemperaturen klare Auswirkungen auf das Weideverhalten von Rindern der Rasse Holstein und Jersey. Bei Temperaturen ab $27^{\circ} \mathrm{C}$ schränken sie das Grasen tagsüber zugunsten der Nachtgraszeit ein, womit sie ihre endogene Wärmebildung zu dieser Zeit reduzieren. 
Des Weiteren kann sich das Liege- und Stehverhalten im Rahmen der Thermoregulation verändern. In Untersuchungen von MULLER et al. (1994) verbrachten Holstein Kühe ohne Schattenmöglichkeiten mehr Zeit mit Stehen als Tiere mit Schatten (331,9 Minuten vs. 267,7 Minuten). Durch die längere Stehzeit vergrößern sie ihre wärmeabgebende Körperoberfläche und vermeiden den zusätzlichen Wärmeeintrag durch den Kontakt mit dem warmen Boden.

\subsection{Wechselwirkungen zwischen klimatischen Bedingungen und Wohlergehen von}

\section{Rindern}

Neben der Temperatur beeinflussen auch andere klimatische Faktoren die Thermoregulation von Rindern. $\mathrm{Zu}$ diesen gehören neben der Temperatur die Luftfeuchtigkeit, der Wind sowie die Strahlungsintensität. Im Folgenden wird ein kurzer Überblick über die einzelnen Klimaindikatoren gegeben, wobei insbesondere auf den Temperatur-Humiditäts Index (THI) eingegangen wird, welcher als Indikator für Wärmekomfort gesehen wird. Anschließend wird dargestellt wie man anhand des THI Hitzestress bzw. den Beginn von Hitzestress quantifizieren kann und welche Auswirkungen von thermischen Belastungen anhand des THI bislang untersucht wurden.

\subsubsection{Klimatische Hitzestressfaktoren}

Das Stallklima fasst die physikalische Beschaffenheit und den chemischen Zustand der Stallluft zusammen. Hierbei sind insbesondere die Temperatur, die relative Feuchte, die Luftgeschwindigkeit und -strömung, sowie der Anteil gasförmiger Verbindungen wie Ammoniak, Schwefelwasserstoff, Kohlendioxid, Methylamine, Lachgas und Methan zu nennen (Hoy et al., 2006; RICHTER et al., 2006).

BOCKISCH et al. (1999) weisen auf die Wechselwirkungen zwischen dem Tier und den Indikatoren des Stallklimas in der Rinderhaltung hin (Tabelle 2). Die Temperatur und die Luftfeuchte sind die Stallklimakomponenten, die am häufigsten und am einfachsten zu erfassen sind (UNRATH, 2004). Die Thermoregulation wird maßgeblich durch die Umgebungstemperatur des Tieres beeinflusst und wirken somit auf das Wohlbefinden des Tieres. Je nach Veröffentlichung werden Optimalbereiche zwischen $-7^{\circ} \mathrm{C}$ und $20^{\circ} \mathrm{C}$ angegeben (BIANCA, 1971; JESSEN, 2000; MALKOW-NERGE et al., 2005).

Die Luftfeuchtigkeit im Stall wird anhand unterschiedlicher Faktoren wie direkt (Atemluft, Schwitzen) und indirekt durch das Tier sowie durch die Außenluft und durch Tränken, 
Reinigung und Desinfektion beeinflusst. Der empfohlene Luftfeuchtigkeitsbereich liegt zwischen 50 und $80 \%$ (RICHTER et al., 2006).

Tabelle 2. Indikatoren des Stallklimas und deren Auswirkung auf das Tier (BOCKISCH et al., 1999).

\begin{tabular}{|c|c|}
\hline Indikator & Auswirkung auf das Tier \\
\hline Luftfeuchte und -temperatur & $\begin{array}{l}\text { - } \text { erheblicher Einfluss auf das Infektionspotenzial und das } \\
\text { Fruchtbarkeitsgeschehen } \\
\text { - kontinuierliche Messungen in relativen Zeitabständen zur } \\
\text { Einschätzung der tatsächlichen Verhältnisse erforderlich }\end{array}$ \\
\hline Staubbelastung und Schadgase & $\begin{array}{l}\text { O belastende Wirkung auf die Atmungsorgane der Nutztiere als } \\
\text { Fremdpartikel sowie als Träger von Keimen }\end{array}$ \\
\hline $\begin{array}{l}\text { Lichtintensität und -dauer } \\
\text { sowie UV-Strahlung }\end{array}$ & $\begin{array}{l}\text { - hohe Einflussnahme auf die Fruchtbarkeit, die Stoffwechsel- } \\
\text { aktivitäten und die tierische Leistungen }\end{array}$ \\
\hline Wärmedämmung & $\begin{array}{l}\text { ○ Vermeidung von z.B. zu hohen Stalltemperaturen durch eine } \\
\text { geeignete Wärmedämmung der raumumschließenden Bauteile }\end{array}$ \\
\hline
\end{tabular}

Die Thermoregulation und somit die mögliche Höhe von Hitzestress wird durch die Temperatur $\left({ }^{\circ} \mathrm{C}\right)$, Luftfeuchtigkeit, Wind- bzw. Luftbewegung und Strahlungsintensität bzw. Sonnenstrahlung beeinflusst, so dass nicht nur anhand von einem Klimaparameter für die Beurteilung von der thermischen Umwelt eines Tieres genutzt werden sollte, sondern eine Kombination mehrerer Parameter. Um Effekte von Hitzestress beurteilen zu können, wurden anhand von Korrelationen zwischen Leistungs- bzw. funktionalen Merkmalen und verschiedenen Klimafaktoren (Temperatur, relative Luftfeuchtigkeit, Wind, Luftbewegung und Sonneneinstrahlung) unterschiedliche Indices entwickelt (RENAUDEAU et al., 2012). Im nachfolgenden Kapitel wird hierbei insbesondere auf den Temperatur-Humiditäts Index eingegangen. 


\subsubsection{Temperatur-Humiditäts Index}

Der Temperatur-Humiditäts Index (THI) ist ein Indikator für Wärmekomfort, der sich aus der Temperatur und relativer Luftfeuchtigkeit zusammensetzt. In verschiedenen Studien wurden unterschiedliche Indices mit verschieden Gewichtungen der Klimaparameter und spezifischen Schwellenwerten entwickelt.

Je nach Klimazone bzw. Breitengrad wurde dementsprechend eine optimale Gewichtung von Temperatur und relativer Luftfeuchtigkeit mit spezifischen Schwellenwerten entwickelt. Bei feuchteren Klimata wird die Luftfeuchte höher gewichtet und in arideren Klimazonen die Temperatur höher. In Tabelle 3 sind unterschiedliche Formeln zur Berechnung des THI zusammengefasst. Diese Formeln sind zum Teil für Menschen, Mastrinder oder Milchkühe entwickelt worden. So ergibt es sich, dass jede THI-Formel je nach Kimazone, Leistungsniveau, Versuchsdauer bzw. Zeitpunkt und Genetik eine unterschiedliche Eignung aufweisen. 
Tabelle 3: Unterschiedliche Formeln zur Berechnung des THIs (modifiziert nach BOHMANOVA et al., 2007 und WALTER und LÖPMEIER, 2010).

\begin{tabular}{|c|c|c|}
\hline $\begin{array}{l}\text { Formel } \\
\end{array}$ & Verwendungsbereich & Quelle \\
\hline $\mathrm{THI}_{1}=0,8 \mathrm{~T}_{\mathrm{db}}+\mathrm{RH}\left(\mathrm{T}_{\mathrm{db}}-14,4\right)+46,4$ & & Tном, 1959 \\
\hline $\mathrm{THI}_{2}=\left[0,4\left(\mathrm{~T}_{\mathrm{db}}+\mathrm{T}_{\mathrm{wb}}\right)\right] \times 1,8+32+15$ & Mensch & Тном, 1959 \\
\hline $\mathrm{THI}_{3}=\left(0,15 \times \mathrm{T}_{\mathrm{db}}+0,85 \times \mathrm{T}_{\mathrm{wb}}\right) \times 1,8+32$ & Mensch & BIANCA, 1962 \\
\hline $\mathrm{THI}_{4}=\left(0,35 \times \mathrm{T}_{\mathrm{db}}+0,65 \times \mathrm{T}_{\mathrm{wb}}\right) \times 1,8+32$ & Rind & BIANCA, 1962 \\
\hline $\mathrm{THI}_{5}=1,8 \times \mathrm{T}_{\mathrm{a}}-(1-\mathrm{RH}) \times\left(\mathrm{T}_{\mathrm{a}}-14,3\right)+32$ & Milchvieh & KIBLER, 1964 \\
\hline $\mathrm{THI}_{6}=\left(0,55 \times \mathrm{T}_{\mathrm{db}}+0,2 \times \mathrm{T}_{\mathrm{dp}}\right) \times 1,8+32+17,5$ & & NATIONAL RESEARCH COUNCIL, 1971 \\
\hline $\left.\mathrm{THI}_{7}=\left(1,8 \times \mathrm{T}_{\mathrm{db}}+32\right)-[0,55-0,0055 \times \mathrm{RH}) \times\left(1,8 \times \mathrm{T}_{\mathrm{db}}-26\right)\right]$ & Rind mit Außenhaltung & NATIONAL RESEARCH COUNCIL, 1971 \\
\hline $\mathrm{THI}_{8}=\left(\mathrm{T}_{\mathrm{db}}+\mathrm{T}_{\mathrm{wb}}\right) \times 0,72+40,6$ & Mensch & NATIONAL RESEARCH COUNCIL, 1971 \\
\hline $\mathrm{THI}_{9}=\mathrm{T}_{\mathrm{db}}+0,36 \times \mathrm{T}_{\mathrm{db}}+41,2$ & Rind & YousEF, 1985 \\
\hline $\begin{aligned} \mathrm{THI}_{10}= & 0,8 \times \text { (Maximale Tagestemp. }+32)-(0,55-0,0055 \mathrm{RH}) \\
& \mathrm{x} \text { (Maximale Tagestemp. }-26)\end{aligned}$ & Milchvieh & RAVAGNOLO UND MISZTAL, 2000 \\
\hline $\mathrm{THI}_{11}=\left(0,8 \times \mathrm{T}_{\mathrm{db}}\right)+\left[(\mathrm{RH} / 100) \times\left(\mathrm{T}_{\mathrm{db}}-14,4\right)\right]+46,4$ & & MADER et al., 2006 \\
\hline $\begin{aligned} \mathrm{THI}_{12}= & (49+0,75 \times \text { Max. Tagestemp }+0,2 \times \text { RH zum Zeitpunkt max. Tagestemp. }) \times 0,65 \\
& +(49+0,75 \times \text { min. Tagestemp. }+0,2 \text { RH zum Zeitpunkt min. Tagestemp }) \times 0,35\end{aligned}$ & Milchvieh & ROBINSON, 2006 \\
\hline
\end{tabular}


Neben den unterschiedlichen Gewichtungen der Temperatur und Luftfeuchtigkeit gibt es ebenfalls spezifische THI Schwellenwerte für Milchvieh (Tabelle 4). Bis zum Schwellenwert befinden sich die Tiere in der thermoneutralen Zone und bei der Überschreitung dieser leidet das Tier unter Hitzestress und es führt zu Einbußen in der Milchleistung, Fruchtbarkeit und zu Gesundheitsproblemen (RENAUdEAU et al., 2012). In dem Vergleich unterschiedlicher THI Formeln von BOHMANOVA et al. (2007) zeigten sich je nach THI Formel verschiedene Milchleistungsdepressionen pro THI Einheit. Bei dem Vergleich anhand der Klimawerte in Athen ergaben sich Leistungsrückgänge von 0,27 kg (Tabelle3: THI4) bis 0,4 kg (Tabelle 3: THI7) zwischen den einzelnen THI Gewichtungen und in Phoenix von 0,23 kg (Tabelle 3: THI8) bis 0,59 kg (Tabelle 3: THI3) bei unterschiedlichen Schwellenwerten.

Tabelle 4. Darstellung unterschiedlicher Schwellenwerte und Belastungsbereiche des TemperaturHumiditäts Index (modifiziert nach WALTER und LÖPMEIER, 2010).

\begin{tabular}{|c|c|c|c|c|}
\hline Autor & Schwelle & & Belastungsbereich & \\
\hline $\begin{array}{l}\text { BRÜGGEMANN } \\
\text { et al., } 2011\end{array}$ & 60 & $\begin{array}{l}\text { Leistungsdepression } \\
>60\end{array}$ & & \\
\hline Тном, 1959 & 69 & $\begin{array}{l}\text { Wenig Komfort } \\
\quad 70-74\end{array}$ & $\begin{array}{c}\text { Kein Komfort } \\
75-79\end{array}$ & $\begin{array}{c}\text { erheblicher Stress } \\
>80\end{array}$ \\
\hline $\begin{array}{l}\text { HOLTER et al., } \\
1996\end{array}$ & 70 & $\begin{array}{c}\text { Futteraufnahme- } \\
\text { depression } \\
71-73\end{array}$ & $\begin{array}{c}\text { Futteraufnahme- + } \\
\text { Leistungsdepression } \\
>74\end{array}$ & \\
\hline $\begin{array}{l}\text { WEST et al., } \\
2003\end{array}$ & 70 & $\begin{array}{c}\text { Futteraufnahme- + } \\
\text { Leistungsdepression } \\
\quad 71-81\end{array}$ & & \\
\hline HUTJENS, 2007 & 70 & & $\begin{array}{c}\text { belastend } \\
75-78\end{array}$ & $\begin{array}{c}\text { extrem belastend } \\
>79\end{array}$ \\
\hline $\begin{array}{l}\text { ARMSTRONG, } \\
1994\end{array}$ & 71 & $\begin{array}{c}\text { Geringer Stress } \\
72-79\end{array}$ & $\begin{array}{l}\text { moderater Stress } \\
\quad 80-89\end{array}$ & $\begin{array}{c}\text { erheblicher Stress } \\
>90\end{array}$ \\
\hline $\begin{array}{l}\text { BOHMANOVA et } \\
\text { al., } 2007\end{array}$ & 72 & $\begin{array}{l}\text { Hitzestress } \\
\quad>73\end{array}$ & & \\
\hline HUHNKE, 2001 & & & $\begin{array}{c}\text { Gefahrenbereich } \\
79-83\end{array}$ & $\begin{array}{c}\text { Kritischer Bereich } \\
>84\end{array}$ \\
\hline
\end{tabular}

Neben dem Schwellenwert ist auch die Dauer der Hitzeperiode von Bedeutung (Tabelle 5). Verschiedene Studien zeigten höhere Korrelationen zwischen THI Werten über mehrere Tage gegenüber einzelnen Tagen (BouraOu et al., 2002; BoHMANOvA et al., 2008). Des Weiteren definierten HAHN et al. (1999) Risikokriterien anhand der Dauer der Hitzeperioden in Tagen, der Anzahl der Stunden pro Tag mit einem THI von mehr als 79, der Anzahl der Stunden pro Tag mit einem THI von mehr als 84 und der Anzahl der 
Stunden pro Nacht mit einem THI unter 72, den „Livestock Weather Safety Index“. Die verwendeten THI-Stunden errechnen sich aus dem durchschnittlichen THI für eine Stunde minus den jeweiligen Grenz-THI (z.B.: eine Stunde THI mit durchschnittlich 81 entspricht 2 THI-Stunden in der Kategorie THI-hrs $\geq 79$ ).

Tabelle 5. Gefährdungskategorien für Rinder in Freilandhaltung auf der Grundlage von THIAuswertungen einer Hitzeperiode in den USA (nach HAHN et al., 1999).

\begin{tabular}{|c|c|c|c|c|}
\hline \multirow[t]{2}{*}{ Kriterien } & \multicolumn{4}{|c|}{ Beschreibende Merkmale } \\
\hline & Dauer & THI-hrs $\geq 79$ & THI-hrs $\geq 84$ & $\begin{array}{l}\text { nächtliche } \\
\text { Abkühlungszeit } \\
\text { (hrs } \leq 72 \text { THI) }\end{array}$ \\
\hline 1. geringfügig & $\begin{array}{l}\text { begrenzt: } \\
\text { 3-4 Tage }\end{array}$ & $10-25 \mathrm{hrs} / \mathrm{d}$ & nichts & $\begin{array}{l}\text { gut: } \\
\text { 5-10 hrs/Nacht }\end{array}$ \\
\hline 2. leicht & $\begin{array}{l}\text { begrenzt: } \\
\text { 3-4 Tage }\end{array}$ & $18-40 \mathrm{hrs} / \mathrm{d}$ & $\leq 5 \mathrm{hrs} / \mathrm{d}$ & $\begin{array}{l}\text { etwas: } \\
\text { 3-8 hrs/Nacht }\end{array}$ \\
\hline 3. mäßig & $\begin{array}{l}\text { beständig: } \\
\text { 4-6 Tage }\end{array}$ & $25-50 \mathrm{hrs} / \mathrm{d}$ & $\leq 6 \mathrm{hrs} / \mathrm{d}$ & $\begin{array}{l}\text { reduziert: } \\
1-6 \text { hrs/Nacht }\end{array}$ \\
\hline 4. stark & $\begin{array}{l}\text { erhöhte Persistenz: } \\
\text { 5-7 Tage }\end{array}$ & $33-65 \mathrm{hrs} / \mathrm{d}$ & $\leq 6 \mathrm{hrs} / \mathrm{d}$ & $\begin{array}{l}\text { begrenzt: } \\
0-4 \text { hrs/Nacht }\end{array}$ \\
\hline 5. akut & $\begin{array}{l}\text { erhöhte Persistenz: } \\
\text { 6-8 Tage }\end{array}$ & $40-80 \mathrm{hrs} / \mathrm{d}$ & $\begin{array}{l}3-15 \mathrm{hrs} / \mathrm{d} \text { an } 3 \\
\text { oder mehr } \\
\text { aufeinander } \\
\text { folgenden Tagen }\end{array}$ & $\begin{array}{l}\text { sehr begrenzt: } \\
0-2 \text { hrs/Nacht }\end{array}$ \\
\hline 6. extrem & $\begin{array}{l}\text { erhöhte Persistenz: } \\
6-10 \text { Tage oder } \\
\text { länger }\end{array}$ & $50-100 \mathrm{hrs} / \mathrm{d}$ & $\begin{array}{l}15-30 \mathrm{hrs} / \mathrm{d} \text { an } 3 \\
\text { oder mehr } \\
\text { aufeinander } \\
\text { folgenden Tagen }\end{array}$ & $\begin{array}{l}\text { nichts: } \leq 1 \text { hrs für } 3 \\
\text { oder mehr } \\
\text { aufeinander } \\
\text { folgenden Tagen }\end{array}$ \\
\hline
\end{tabular}

Diese Risikoklassifizierung ist nicht vollständig, da anhand des THI nur die Temperatur und Luftfeuchtigkeit berücksichtigt werden. Die Wärmeabgabewege der Radiation und Konvektion sind hierbei nicht eingeschlossen und können die Belastung für das Tier erhöhen. Insbesondere in den Kategorien 5 und 6 können hohe Sonneneinstrahlungen und geringe Luftbewegungen zu akuter Lebensgefahr führen.

\subsubsection{Auswirkungen von thermischen Belastungen}

Die Auswirkungen von Hitzestress wirken sich auf unterschiedliche Bereiche von Milchkühen aus. Zum einen beeinflussen sie physiologische Prozesse und Parameter, wie z.B. die Wasser- und Futteraufnahme und Atem- und Herzschlagfrequenz. Zum anderen 
wirkt sich Hitzestress auf die Milchleistung sowie Reproduktion aus. Diese Bereiche hängen z.T. zusammen und können sich gegenseitig beeinflussen (FAROOQ et al., 2010).

\section{Physiologie}

In dem vorherigen Kapitel Anpassungsmechanismen an Umgebungstemperaturen wurde z.T. bei der Erläuterung der Thermoregulationsmechanismen schon auf physiologische Veränderung eingegangen. Physiologische Reaktionen auf Hitzebelastungen sind Schwitzen, eine erhöhte Atemfrequenz, eine Erweiterung der Blutgefäße (Vasodilatation) mit einer gesteigerten Durchblutung zur Hautoberfläche, reduzierte Stoffwechselraten sowie geringere Trockensubstanzaufnahmen und ein veränderter Wasserhaushalt (FAROOQ et al., 2010). Bei erhöhten klimatischen Konditionen steigt zum einen die Flüssigkeitsaufnahme, wobei die reine Wasseraufnahme um 29\% ansteigt und die Flüssigkeitsaufnahme übers Futter durch die Hitzestress bedingte reduzierte Futteraufnahme um $14 \%$ sinkt (STAPLES UND THATCHER, 2011).

Tabelle 6. Wasseraufnahme (in 1) pro Kuh und Tag bei unterschiedlichen Milchleistungen und Umgebungstemperaturen nach MACGREGOR (1995).

\begin{tabular}{lccccc}
\hline Umgebungstemperatur & \multicolumn{5}{c}{ kg Milch pro Kuh und Tag } \\
& $\mathbf{1 3 , 6 k g}$ & $\mathbf{2 2 , 7} \mathbf{k g}$ & $\mathbf{3 1 , 7 k g}$ & $\mathbf{4 0 , 8 k g}$ & $\mathbf{4 9 , 9 k g}$ \\
\cline { 2 - 6 } & 58,5 & 77,6 & 96,7 & 115,3 & 134,3 \\
$\mathbf{4 , 4}{ }^{\circ} \mathbf{C}$ & 63,5 & 85,3 & 107,1 & 129,3 & 151,1 \\
$\mathbf{1 5 , 6}^{\circ} \mathbf{C}$ & 70,3 & 96,7 & 123,0 & 149,8 & 176,1 \\
\hline $\mathbf{2 6 , 7 ^ { \circ }} \mathbf{C}$ & & & & & \\
\hline
\end{tabular}

Neben der Umgebungstemperatur wird der Wasserverbrauch pro Kuh zusätzlich von dem Leistungsniveau der Kuh beeinflusst (Tabelle 6). Nach MACGREGOR (1995) erhöht sich die Wasseraufnahme pro Kuh und Tag um 17\%, 21\% und 24\% bei einer niederleistenden, mittelleistenden und hochleistenden Milchkuh bei einer Erhöhung der Umgebungstemperatur um $22^{\circ} \mathrm{C}$ von $4^{\circ} \mathrm{C}$ auf $26,7^{\circ} \mathrm{C}$. Verschiedene Studien beschreiben neben der erhöhten Wasseraufnahme eine reduzierte Futteraufnahme. Zum Beispiel ermittelten BOURAOUI et al. (2002) eine negative Korrelation zwischen dem täglichen THI und der Futteraufnahme von -0,24. In dieser Untersuchung sank die Trockensubstanzaufnahme um 9,6\% bei einem THI Anstieg von 68 auf 78. Durch die reduzierte Futteraufnahme verringert sich ebenfalls die Stoffwechseltätigkeit. Diese physiologischen Auswirkungen 
haben einen negativen Einfluss auf die Produktions- und Reproduktionsleistungen von Milchkühen (WEST, 1999).

\section{Milchleistung}

Neben den Auswirkungen auf die Futter- und Flüssigkeitsaufnahme von Milchkühen zeigen sich ebenfalls Einflüsse auf die Produktionsmerkmale. Nach Young (1981) liegt die kritische obere Temperatur für hochleistende Tiere bei $25^{\circ} \mathrm{C}$. JOHNSON (1987) und RAVAGNOLO UND MisZTAL (2000) zeigten Hitzestressauswirkungen ab einem THI von 72 anhand eines kontinuierlichen Absinkens der Milchmenge. In Tabelle 7 sind Ergebnisse von unterschiedlichen Studien zusammengestellt, welche die Zusammenhänge zwischen Klimafaktoren (Temperatur, relative Luftfeuchtigkeit und THI) und der Milchleistung erforscht haben. Je nach Studie ergaben sich Milchleistungsdepressionen unter Hitzestress

Tabelle 7. Einfluss von Temperatur, relativer Luftfeuchtigkeit und THI auf die Milchleistung (modifiziert nach AMMER, 2011).

\begin{tabular}{|c|c|c|c|}
\hline Parameter & Umweltbedingung & Milchleistungsdepression & Quelle \\
\hline Temperatur & 6 Wochen bei $30^{\circ} \mathrm{C}$ & $\varnothing 60 \%$ & RICHTER et al. 2006 \\
\hline $\begin{array}{l}\text { Temperatur \& } \\
\text { Luftfeuchte }\end{array}$ & $\begin{array}{l}29^{\circ} \mathrm{C} \& 40 \% \mathrm{RH} \\
29^{\circ} \mathrm{C} \& 90 \% \mathrm{RH}\end{array}$ & $\begin{array}{l}\text { 93-98\% Milchleistung } \\
\text { 69-83\% Milchleistung }\end{array}$ & BIANCA, 1965 \\
\hline $\begin{array}{l}\text { Temperatur } \\
\text { THI }\end{array}$ & $\begin{array}{l}\varnothing 28^{\circ} \mathrm{C} \\
\varnothing 76,5\end{array}$ & $\varnothing 4,5 \mathrm{~kg}$ & SPERONI et al., 2006 \\
\hline THI & $\varnothing 70-75$ & $\varnothing 0,32 \mathrm{~kg} / \mathrm{THI}$ & INGRAHAM et al., 1979 \\
\hline THI & $\geq 72$ & $\varnothing 0,2 \mathrm{~kg} / \mathrm{THI}$ & RAVAGNOLO et al., 2000 \\
\hline THI & $>72$ & $0,26 \mathrm{~kg} / \mathrm{THI}$ & JOHNSON, 1987 \\
\hline THI & $>69$ & $0,41 \mathrm{~kg} / \mathrm{THI}$ & BOURAOUI et al., 2002 \\
\hline THI & $>60$ & $\begin{array}{c}0,08 \mathrm{~kg} / \mathrm{THI} \text { bis } \\
0,26 \mathrm{~kg} / \mathrm{THI}\end{array}$ & BRÜGEMANN et al., 2012 \\
\hline THI & $\geq 80$ & $\varnothing 10$ bis $>25 \%$ & CHASE, 2006 \\
\hline
\end{tabular}

von 4,5 kg bei einem Vergleich zwischen einer Periode mit Hitzestress und einer ohne Hitzestress (SPERONI et al., 2006) bzw. Leistungsrückgänge von 0,08 kg/THI (BRÜGEMANN et al., 2012) bis 0,41 kg/THI (BOURAOUI et al., 2002) bei der Überschreitung der Hitzestressschwellenwerte. 
Neben der Milchleistung wird ebenfalls die Höhe der Milchinhaltsstoffe vom Hitzestress beeinflusst (WEST, 2003). Die Studie von BOURAOUI et al. (2002) zeigte signifikante Veränderungen in der Zusammensetzung der Milch und des Zellgehaltes bei dem Vergleich der Frühjahrs- und Sommermonate. Der Milchfettgehalt sank um 0,34\% und der Proteingehalt um 0,08\%, während der somatische Zellgehalt um 450.000 Zellen anstieg. Vergleichbare Auswirkungen konnten in anderen Studien ebenfalls gezeigt werden (u.a. OLDE RIEKERINK et al., 2007; QUIST et al., 2008).

\section{Reproduktion}

Im Bereich der Reproduktion konnten unterschiedliche Studien den Einfluss von Hitzestress auf die Kennzahlen der Reproduktionsleistungen darlegen. Bei einem Saisonvergleich von RAY et al. (1992) zeigte sich eine zwei Wochen kürzere Zwischenkalbezeit (ZKZ) bei Kühen, die im Winter und Frühling abgekalbt haben gegenüber Kühen mit Sommer- und Herbstabkalbungen. Ebenfalls hatten die im Winter und Frühjahr abgekalbten Kühe bessere Besamungserfolge mit 0,4 bis 0,5 weniger Besamungen. Im Hinblick auf die Konzeptionsrate verdeutlichten die Studien von GARCIAISPIERTO et al. (2007) und VILLA-MANCERA et al. (2011) eine verringerte Konzeptionsrate mit steigendem THI. Ebenfalls demonstrierten diese Untersuchungen, dass zwei bzw. drei Tage vor der Besamung die Klimaverhältnisse den größten Einfluss auf die Konzeptionsrate aufwiesen. RAVAGNOLO UND MiszTAL (2002) beschrieben zusätzlich einen negativen Einfluss von hohen THI Werten auf die Non-Return-Rate.

\subsection{Milchviehhaltungssysteme}

In Europa werden landwirtschaftliche Tiere überwiegend in Ställen gehalten, wobei man nach NARDONE et al. (2010) die Produktionssysteme in drei Hauptkategorien unterteilen kann. Diese Kategorien sind: weidebasierte Systeme, gemischte Systeme (Tierhaltung und Ackerbau) und industrielle Systeme. Das gemischte System ist in Zentraleuropa das dominierende Verfahren, wobei Weidesysteme eher untergeordnet sind.

Neben den genannten Produktionssystemen werden verschiedene Haltungssysteme für die Aufstallung von Milchkühen genutzt. Zum einen können diese in Anbinde- und Laufstallsysteme unterteilt werden (RICHTER et al., 2006). In Niedersachsen werden zwei Drittel der Milchkühe in Laufstallsystemen gehalten (DEUTSCHES BUNDESAMT FÜR STATISTIK, 2011), wobei dieser Anteil ansteigend ist (ZÄHNER et al., 2004). Zum anderen 
können die Haltungssysteme anhand ihres Stallklimas bzw. der Konstruktion der Stallhülle in Warm- und Außenklimaställe differenziert werden (SCHNIER et al., 2004; PACHE et al., 2007). Die Lüftung findet in diesem System zunächst über Trauf-First Lüftung statt. In den letzten Jahren ging der Trend eher zu Außenklimaställen. In Außenklimaställen sind die mikroklimatischen Konditionen im Stall ähnlich den makroklimatischen Konditionen außerhalb des Stalles (SCHNIER et al., 2003). Außenklimaställe sind oft offen und mit freier Lüftung konzipiert. Sie bieten Milchkühen gute Haltungsbedingungen bezüglich Temperatur, Luftfeuchte und Umgebungsgase. Probleme werden bei dieser Haltungsform in den Sommermonaten gesehen. Insbesondere aufgrund der hohen Temperaturen und der geringen Möglichkeit der Thermoregulation. Trotz der Bedürfnisanpassungen des Stalles an das Tier bestehen Unterschiede zwischen dem Stallklima und dem Außenklima bezüglich Temperatur, relativer Luftfeuchtigkeit, Umgebungsgase, Staubgehalte in der Luft, Licht, Luftbewegung und Geräuschpegel. Aus Tierschutzsicht und zum Schutz der Tiere müssen solche Extremsituationen vermieden werden. Ziel muss es sein das Wohlbefinden der Tiere zu sichern (UNRATH, 2004).

Neben den verschiedenen Haltungssystemen ist in Niedersachsen auch die Weidehaltung von Bedeutung und weit verbreitet. Über zwei Drittel der 783.000 Milchkühe wurden 2009 durchschnittlich für 24 Wochen auf der Weide gehalten (DEUTSCHES BUNDESAMT FÜR STATISTIK, 2010). Abhängig von den klimatischen Bedingungen zeigen sich bei Milchkühen unterschiedliche Leistungen zwischen Weide- und Stallhaltung (LEGRAND et al., 2009; KROHN et al., 1992).

\subsubsection{Strategien zur Reduzierung von Hitzestress}

Zur Reduzierung von thermischen Belastungen stehen verschiedene Möglichkeiten wie ausreichende Belüftung (Erhöhung der Luftwechselraten, z.B. durch Ventilatoren), evaporative Kühlungen (Wassersprühnebel), Dämmung des Dachs, Schatten und verschiedene Kombinationen dieser zur Verfügung (ARMSTRONG, 1994; West, 2003; SMITH et al., 2006).

Eine ausreichende Belüftung kann sowohl passiv durch ausreichend große Seitenöffnungen und die Querlüftung oder aktiv durch unterstützende Lüftung mittels Ventilatoren erreicht werden, wobei BRANDES (1999) 60 bis 100 Luftwechsel pro Stunde empfiehlt. Zur Wasserkühlung gehören zwei Varianten. Zum einen die Vernebelung von Wasser, um die Luft durch die Verdunstung des Wassers zu kühlen, wobei diese Variante nur für Länder 
mit niedrigeren Luftfeuchtigkeiten und hohen Temperaturen geeignet ist. Zum anderen besteht die Möglichkeit durch die Benetzung der Tiere mit Wasser eine ähnliche kühlende Wirkung wie bei der Schweißbildung zu generieren. Der kühlende Effekt ergibt sich durch die Verdunstung des Wassers auf der Körperoberfläche (ARMSTRONG, 1994). IGONO et al. (1985) untersuchten die Auswirkungen der evaporativen Kühlung auf die Milchleistung, Milchtemperatur und Rektaltemperatur. Die Untersuchung zeigte geringere thermische Belastungen anhand von niedrigeren Milch- und Rektaltempertur und höhere Milchleistung (+0,7kg/Kuh und Tag) der Kühe unter gekühlten Konditionen gegenüber der Kontrollgruppe. Bei einer Untersuchung des Einflusses von einer kombinierten Variante aus der Erhöhung der Luftgeschwindigkeit und der Benetzung der Luft mit Wasser zeigten sich eine geringere thermische Belastung durch eine signifikante Senkung der Rektaltemperatur um $1,5^{\circ} \mathrm{C}$ und einer nicht signifikanten Senkung der Respirationsrate und des Pulses (KoubKovÁ et al., 2002).

Betriebe mit Weidehaltung bzw. mit Weidegang haben nur einen begrenzten Einfluss auf die Gestaltung des Klimas und können somit nur geringfügig Einfluss auf die Reduzierung von klimatischen Belastungen nehmen. Durch die Wahl des Weidezeitpunktes kann z.T. Einfluss genommen werden, indem man z.B. die kühleren Nachtstunden nutzt. Eine Untersuchung in den USA in unterschiedlichen Haltungssystemen zeigte die höchsten Milchleistungen bei Stallhaltung mit $15,6 \mathrm{~kg}$ FCM und die niedrigsten bei reiner Weidehaltung mit 14,2 kg FCM bei einem THI von 69. Bei Stallhaltung mit Weidegang von 24 bis 12 Uhr ergaben sich Milchleistungen von 15,0 kg FCM und mit Weidegang von 12 bis 24 Uhr 14,5 kg FCM (THATCHER, 1974). Bei den Fruchtbarkeitsdaten zeigten sich bei der Stallung und bei nächtlicher Weidezeit Trächtigkeitsraten von $40 \%$ und bei ganztägiger bzw. über den Tag verteilter Weidehaltung 28\%. Eventuelle Anpassung der Futterzeiten können ebenso zu einer Reduzierung von Hitzestress führen. MERLKOWNERGE et al. (2005) ermittelten höchste Futteraufnahmen in den Abendstunden. 


\subsection{Literaturverzeichnis}

AMMER S. 2011. Vergleich der klimatischen Bedingungen in verschiedenen Stallsystemen für Milchkühe. Masterarbeit an der Georg-August Universität Göttingen.

Armstrong D.V. 1994. Heat stress interaction with shade and cooling. J. Dairy Sci. 77: 2044-2050.

BAROW U. 1998. Methodische Untersuchungen zur Erfassung der Thermoregulationbei Mutterkühen unter Feldbedingungen. Dissertation an der Georg-August Universität Göttingen.

Berman A., Y. Folman, M. Kaim, M. Mamen, Z. Herz, D. Wolfenson, A. Arieli und Y. GRABER 1985. Upper critical temperatures and forced ventilation effects for high-yielding dairy cows in a subtropical climate. J. Dairy Sci. 68: 1488-1495.

BIANCA W. 1962. Relative importance of dry- and wet-bulb temperatures in causing heat stress in cattle. Nature 195: 251-252.

BIANCA W. 1965. Review of the progress of dairy science. Section A. Physiology. Cattle in a hot environment. J. Dairy Res. 32: 294-345.

BIANCA W. 1968. Neuzeitliche Ergebnisse und Aufgaben der Bioklimatologie bei Haustieren. Der Tierzüchter 20: 438-442.

BiANCA W. 1971. Die Akklimatisation von Haustieren. Der Tierzüchter 7: 187-189.

BIANCA W. 1976. The significance of meterology in animal production. Int. J. Biometeor. 20: 139-156.

BICKHARDT K. 1992. Kompendium der allgemeinen inneren Medizin und Pathophysiologie für Tierärzte. Paul Parey Verlag, Berlin, Hamburg.

Bockisch F.J., T. Jungbluth Und A. RudovsKy 1999. Technische Indikatoren für die Beurteilung einer tiergerechten Haltung von Rindern, Schweinen und Legehennen. Züchtungskunde 71: 38-63.

Bohmanova J. 2006. Studies on genetics of heat stress in US Holsteins. Dissertation an der University of Georgia.

Bohmanova J., I. Misztal Und J.B. Cole 2007. Temperature-humidity indices as indicators of milk production losses due to heat stress. J. Dairy Sci. 90: 1947-1956.

Bohmanova J., I. MiszTal, S. Tsuruta, H.D. Norman und T.J. Lawlor 2008. Short communication: Genotype by environment interaction due to heat stress. J. Dairy Sci. 91:840-846.

Bouraoui R., M. Lahmar, A. Majdoub, M. Djemali, and R. Belyea 2002. The relationship of temperature-humidity index with milk production of dairy cows in a Mediterranean climate. Anim. Res. 51: 479-491.

BRANDES C. 1999. Kuhkomfort ist Voraussetzung für hohe Leistungen. In Fütterung der 10000-Liter-Kuh. DLG-Verlag, Frankfurt. 
BRÜGEMANN K., E. GERNAND, U.U. vON BORSTEL UND S. KÖNIG 2011. Genetic analyses of protein yield in dairy cows applying random regression models with time and temperature x humidity dependent covariates. J. Dairy Sci. 94: 4129-4139.

Brügemann K., E. Gernand, U. König von Borstel, And S. König S 2012. Defining and evaluating heat stress thresholds in different dairy cow production systems. Arch. Tierz. 55: 13-24.

BRÜSER-PIEPER C. 2006. Untersuchungen zur thermischen Belastung von Schlachtrindern beim Straßentransport auf Langstrecken. Dissertation der tierärztliche Hochschule, Hannover.

CHASE L. 2006. Climate change impacts on dairy cattle. abgerufen am 15. Mai 2012 unter http://www.climateandfarming.org/pdfs/FactSheets/III.3Cattle.pdf.

DEUTSCHES BUNDESAMT FÜR STATISTIK 2011. abgerufen am 18. Januar 2012 unter http://www.destatis.de/jetspeed/portal/cms/Sites/destatis/Internet/DE/Content/Publi kationen/Fachveroeffentlichungen/LandForstwirtschaft/Landwirtschaftzaehlung/Sta llhaltung_Weidehaltung2032806109004,property=file.pdf.

Faroog U., H.A. SAmad, F. ShehZAD Und A. QAYYUM 2010. Physiological Responses of Cattle to Heat Stress. World Appl. Sci. J. 8: 38-43.

García-Ispierto I., F. López-Gatius, G. Bech-Sabat, P. Santolaria, J.L. YÁniz, C. NogaredA, F. De RENSIS UND M. LÓPEZ-BÉJAR 2007. Climate factors affecting conception rate of high producing dairy cows in northeastern Spain. Theriogenology 67: 1379-1385.

HAHN G.L. 1999. Dynamic responses of cattle to thermal heat load. J. Anim. Sci. 77: 1020.

Hahn G.L., T.L. Mader, J.B. Gaughan, Q. Hu und J.A. NiEnaber 1999. Heat waves and their impacts on feedlot cattle. In Proc., Intern. Soc. Biometeorology Congress, Sydney, Australien, ICB Nr. 11.1, 353-357.

HARRIS B. 1992. Hot weather dairying: feeding to combat heat stress. Feed Intern. 13, 3032.

HERZ A. Und D. STEINHAUf 1974. Zur Reaktion landwirtschaftlicher Nutztiere auf Wärmebelastung. Z. Tierzüchtung Züchtungsbiologie 91: 145-154.

Holter J.B., J.W. West und M.L. McGilliard 1996. Predicting ad libitum dry matter intake and yields of Jersey cows. J. Dairy Sci. 79: 912-921.

Hoy S., M. GAUly UND J. KRIETER 2006. Nutztierhaltung und -hygiene. Ulmer, Stuttgart.

Huhnke R.L., L.C. McCowan, L.C. Meraz, S.L. Harp und M.E. Payton 2001. Determining the frequency and duration of elevated temperature-humidity index. ASAE Annu. Int. Mtg., Sacramento, CA. Am. Soc. Agric. Biol. Eng., St. Joseph, MI.

HutJens M.F. 2007. Heat stess strategies. Abgerufen am 15. April 2012 unter http://www.livestocktrail.illinois.edu/dairynet/paperDisplay.cfm?ContentID=9765. 
Igono M.O., B.J. Steevens, M.D. Shanklin und H.D. Johnson 1985. Spray cooling effects on milk production, milk, and rectal temperatures of cows during a moderate temperature summer season. J. Dairy Sci. 68: 979-985.

IgONO M.O., G. BJotvedT und H.T. SANFORD-Crane 1992. Environmental profile and critical temperature effects on milk production of Holstein cows in desert climate. Int. J. Biometeor. 36: 77-87.

InGRAhAM R.H., R.W. STANLEY UND W.C. WAGNER 1979. Seasonal effects of tropical climate on shaded and nonshaded cows as measured by rectal temperature, adrenal cortex hormones, thyroid hormone, and milk production. Am. J. Vet. Res. 40: 1792-1797.

JESSEN C. 2000. Wärmebilanz und Temperaturregulation. In Physiologie der Haustiere. (eds W.v. Engelhardt und G. BREVES), pp.446-460, 2. Auflage, Enke, Stuttgart.

JOHNSON H.D. 1987. Bioclimate effects on growth, reproduction and milk production. In Bioclimatology and the Adaptation of Livestock, World Animal Science, B5, Chapter 5 (eds H.D. Johnson), pp. 35-57, Elsevier Science Publishers B.V., Amsterdam, The Netherlands.

KHALIFA H.H. 2003. Bioclimatology and adaptation of farm animals in a changing climate. In Interactions between climate and animal production, EAAP Technical Series No 7, pp. 15-29, Wageningen Academic Publishers, Wageningen, Netherlands.

KIBLER H.H. 1964. Environmental physiology and shelter engineering, LXVII. Thermal effects of various temperature-humidity combinations on Holstein cattle as measured by eight physiological responses, Res. Bull. Missouri Agric. Exp. Station: 862.

KLEIN TANK A.M.G. UND G.P. KÖNNEN 2003. Trends in indices of daily temperature and precipitation extremes in Europe, 1946-99. J. Climate 16: 3665-3680.

Koubková M., I. KnížKovÁ, P. Kunc, H. HÄrtlová, J. Flusser und O. DoležAl 2002. Influence of high environmental temperatures and evaporative colling on some physiological, hematological and biochemical parameters in high-yielding dairy cows. Czech J. Anim. Sci. 47: 309-318.

Krohn C.C., L. MunKsgaARd und B. Jonasen. 1992. Behaviour of dairy cows kept in extensive (loose housing/pasture) or intensive (tie stall) environments I. Experimental procedure, facilities, time budgets - diurnal and seasonal conditions. Appl. Anim. Beh. Sci. 34: 37-47.

LEGRAND A.L., M.A.G. von KeYSERLINGK UND D.M. WEARY 2009. Preference and usage of pasture versus free-stall housing by lactating dairy cattle. J. Dairy Sci. 92: 36513658.

MADER T.L., M.S. DAVIS UND T. BROWN-BRANDL 2006. Envirnmental factors influencing heat stress in feedlot cattle. J. Anim. Sci. 84: 712-719.

Malkow-Nerge K., M. Tischer UND P. Ziegler 2005. Modernes Fruchtbarkeitsmanagement beim Rind. AgroConcept GmbH, Bonn.

MCARTHUR A.J. UND J.A. CLARK 1988. Body temperature of hoemothermes and the conservation of energy and water. J. Therm. Biol. 3: 9-13. 
MCDOWELL R.E. 1972. Improvement of livestock production in warm climates. W.H. Freeman and Company, San Francisco.

MACGREGOR C.1995. Directory of Feed and Feedinggrdients. Hoard's Dairyman.

MULLER C.J.C., J.A. BothA UND W.A. SMITH 1994. Effects of shade on various parameters of Friesian cows in a Mediterranean climate in South Africa. 3. Behaviour. S. Afr. J. Anim. Sci. 24: 61-66.

NARDONE A., B. Ronchi, N. LACETERA, M.S. RANIERI UND U. BERnABUCCI 2010. Effects of climate changes on animal production and sustainability of livestock systems. Livest. Sci. 130: 57-69.

NATIONAL RESEARCH COUNCIL 1971. A guide to environmental research on animals. NRC, National Academy of Sciences, Washington, DC, USA.

NiCHELMANN M. 1971. Der Wärmehaushalt beim Rind. In Der Wärmehaushalt landwirtschaftlicher Haustiere (eds L. LHYs), VEB Gustav Fischer Verlag, Jena.

Olde RieKERINK R.G.M., H.W. BARKEMA UND H. STRYhn 2007. The effect of season on somatic cell count and the incidence of clinical mastitis. J. Dairy Sci. 90: 17041715 .

PACHE H., S. RÖSSNER UND O. HÖRING 2007. Hitzestress bei Kühen - Anforderungen der Milchkühe an sommertaugliche Außenklimaställe. 8. Jahrestagung der wissenschaftlichen Gesellschaft der Milcherzeugerberater e.V., 17./18. Oktober 2007, Poing.

Penzlin H. 1991. Lehrbuch der Tierphsiologie. 5. Auflage. Gustav Fischer Verlag, Jena.

Quist M.A., S.J. LeBlanc, K.J. Hand, D. Lazenby, F. Miglior und D.F. Kelton 2008. Milking-to-Milking variability for milk yield, fat and protein percentage, and somatic cell count. J. Dairy Sci. 91: 3412-3423.

Ravagnolo O. und I. Misztal 2000. Genetic component of heat stress in dairy cattle, parameter estimation. J. Dairy Sci. 83: 2126-2130.

Ravagnolo O., I. MiszTAl und G. Hoogenboom 2000. Genetic component of heat stress in dairy cattle, development of heat index function. J. Dairy Sci. 83: 2120-2125.

RAVAGNOLO O. UND I. MisZTAL 2002. Effect of heat stress on nonreturn rate in Holsteins: fixed-model analyses. J. Dairy Sci. 85: 3101-3106.

RAY D.E., T.J. HalbaCh Und D.V. ARMSTRONG 1992. Season and lactation number effects on milk production and reproduction of dairy cattle in Arizona. J. Dairy Sci. 75: 2976-2983.

Renaudeau D., A. Collin, S. Yahav, V. De Basilio, J.L. Gourdine, R.J. Collier 2012. Adaptation to hot climate and strategies to alleviate heat stress in livestock production. Animal 6: 707-728.

Richter T., B. Busch, M. Karrer, A. Müller, S. Petermann und C. Renner 2006. Krankheitsursache Haltung, Beurteilung von Nutztierställen - Ein tierärztlicher Leidfaden. Enke, Stuttgart. 
ROBERTSHAW D. 1981. The environmental physiology of animal production. In Environmental aspects of housing for animal production. (eds J.A. Clark), pp. 3-17, Butterworth, London.

RoBINSON P.H. 2006. Excel Spreadsheets: PredDMI.xls and NRGREQ.xls. abgerufen am: 15.05.2012 unter http://animalscience.ucdavis.edu/faculty/robinson/Excel/default .htm.

SchÖNmuth G., D. Flade und G. SeEland 1986. Tierproduktion. Züchterische und ökologische Grundlagen. VEB Deutscher Landwirtschaftsverlag, Berlin.

SCHNIER C., S. HIElm UND H.S. SAlONIEMI 2003. Comparison of milk production of dairy cows kept in cold and warm loose-housing systems. Prev. Vet. Med. 61: 295-307.

SChNiER C., S. HiElm Und H.S. SAlONIEMI 2004. Comparison of the breeding performance of cows in cold and warm loose-housing systems. Prev. Vet. Med. 62: 135-151.

Smith T.R., A. Chapa, S. Willard, J.C. Herndon, R.J. Williams, J. Crouch, T. Riley UND D. POGUE 2006. Evaporative tunnel cooling of dairy cows in the southeast: II: Impact on lactation performance. J. Dairy Sci. 89: 3915-3923.

SPERONi M., G. PIRLO UND S. LOLLI 2006. Effect of automatic systems on milk yield in a hot environment. J. Dairy Sci. 89: 4687-4693.

STAPLES C.R. UND W.W. THATCHER 2011. Heat stress: effects on milk production and compostion. In Encyclopedia of Dairy Science (eds JW Fuquay, PF Fox, PLH McSweeney), 2nd Edition, pp. 561-566. Academic Press - Elsevier Science Ltd, Oxford, UK.

Strom J.S. und A. FeEnstra 1980. Heat loss from cattle, swine and poultry. Am. Soc. Agri. Eng., St. Joseph, Mich. Paper, 80-4021.

THATCHER W.W. 1974. Effects of season, climate, and temperature on reproduction and lactation. J. Dairy Sci. 57: 360-368.

THом E.C.1959. The discomfort index. Weatherwise 12: 57-59.

UnRATH J. 2004. Analyse und Bewertung von Parametern der Produktionsumwelt bei der Milchgewinnung mit automatischen Melksystemen (AMS). Dissertation an der Humboldt- Universität zu Berlin.

Villa-Mancera A., M. Méndez-Mendoza, R. Huerta-Crispín, F. VÁZquez-Flores UND A. CóRDOVA-IZQUIERDO A 2011. Effect of climate factors on conception rate of lactating dairy cows in Mexico. Trop. Anim. Health Prod. 43: 597-601.

WALTER K. UND F.J. LÖPMEIER 2010. Fütterung und Haltung von Hochleistungskühen 5. Hochleistungskühe und Klimawandel. vTI Agriculture and Forestry Res. 60: 17-34.

WEBSTER A.J.F. 1991. Metabolic responses of farm animals to high temperature. Eur. Assoc. Anim. Prod. 55: 15-22.

WEST J.W. 1999. Nutritional strategies for managing the heat-stressed dairy cows. J. Animal Sci. 14: 350-362.

WEST J.W. 2003. Effects of heat-stress on production in dairy cattle. J. Dairy Sci. 86: 2131-2144. 
WeST J.W., B.G. MULLINIX UND J.K. BERNARD 2003. Effects of hot, humid weather on milk temperature, dry matter intake, and milk yield of lactating dairy cows. J. Dairy Sci. 86: 232-242.

WitTKe G. 1972. Phsiologie der Haustiere. Paul Parey, Berlin und Hamburg.

Winter P., J.H. Weniger, J.E. Huhn UND E.S. TAWFIK 1980. Vergleichende Untersuchungen an taurinen und zebuinen Rindern und deren Kreuzungen bei Weide- bzw. Stallhaltung am tropischen Standort Bangladesh 4. Der Einfluss des Klimas auf Herz- und Atemfrequenz sowie Körper- und Hauttemperatur. Z. Tierzüchtg. Züchtungsbiol. 103: 307-318.

YounG B.A. 1981. Cold stress as it affects animal production. J. Ainm. Sci. 52: 154-163.

YouSEF M.K. 1985. Stress physiology in livestock. CRC Press, Boca Raton, Fla.

ZÄHNER M., L. Schrader, R. HAuser, W. LANGhans, M. KecK Und B. WeChSLER 2004. The influence of climatic conditions on physiological and behavioural parameters in dairy cows kept in open stables. Anim. Sci. 78: 139-47. 
KAPITEL III

CLIMATIC EFFECTS IN CENTRAL EUROPE ON THE FREQUENCY OF MEDICAL TREATMENTS OF DAIRY COWS 


\begin{abstract}
In the present study the relationship between the temperature-humidity index (THI) and the incidence of medical treatments in lactating dairy cows in Lower Saxony, Germany, was investigated. Records of all veterinary-treated cases over two years (2003 and 2005) from eight Holstein-Friesian dairy herds raised in loose-housing systems (55 to 170 cows per herd) were evaluated. After exclusion of management-dependent and climate-independent cases, a total of 5,547 treatments were analyzed. Treatments were clustered into the following groups: metabolism, fertility, udder, and foot/leg. Meteorological data were compiled from the nearest weather station (average distance \pm standard deviation $39 \pm 13$ $\mathrm{km}$ ). Hourly temperatures and relative humidity values were used to calculate the THI which was divided into classes. Out of the total number of treatments, 37.4, 32.9, 21.6, and $8.1 \%$ belonged to metabolism, udder, fertility, and foot/leg, respectively. Data were analyzed with a mixed model that included THI class, season, and year as fixed effects and farm as random effect. In general, incidences were neither affected by the year $(P>0.05)$ and season $(P>0.05)$ nor by THI classes $(P>0.05)$. In tendency incidences of metabolic treatments increased with increasing THI and incidences of udder treatments increased with decreasing THI. In conclusion, indications of moderate heat stress during summer months in Central Europe were found in the present study, though THI and season did not affect the different disease complexes significantly.
\end{abstract}

\title{
IMPLICATIONS
}

Increasing milk yields together with rising ambient temperatures due to climate change result in considerable heat stress for dairy cows. Particularly this heat stress affects animal welfare and health negatively. This study demonstrated to which extent the temperaturehumidity index as a measure of heat stress influences the incidence of veterinary treatments (metabolism, udder, fertility, and foot/leg).

\section{INTRODUCTION}

Increasing milk production of dairy cows, which was realized through rapid progress in genetics and management, results in an increased metabolic heat production. This will become even more important under the scenarios of climatic change which will impede 
heat dissipation as suggested by the Intergovernmental Panel on Climate Change (IPCC, 2007). Beside the ambient temperature the relative humidity plays a major role in evaluating the thermal environment an animal is exposed to (WEST, 2003). Combining effects of temperature and relative humidity, the temperature-humidity index (THI) is widely used to measure heat stress in animals (NATIONAL RESEARCH COUNCIL, 1971). Based on the THI, thresholds for heat stress in dairy cows have been established and were found to differ between regions and indices. Relative humidity is the major heat stress factor in humid climates, whereas air temperature is the major limiting factor in dry climates (BOHMANOVA et al., 2007). In a recent study, BRÜGEMANN et al. (2012) defined thresholds for heat stress by evaluating production traits of different production systems in Northern Germany. A THI of 60 was identified as a general threshold for a substantial decline in milk yield. Heat stress has not only significant impacts on the animal performance, but also impacts animal welfare and health negatively as it results in reduced fertility and increased disease susceptibility (AMUNDSON et al., 2006; HANSEN, 2007; PEGORER et al., 2007; Villa-MANCERA et al., 2011). In general, animals with the highest milk yield have the greatest risk to be affected by heat stress. Animal responses to thermal challenge vary according to its type. Short-term adaptive changes in behavioral, physiological, and immunological functions follow acute events, whereas impacts on the performance are shown after longer lasting challenges (NIENABER AND HAHN, 2007). For dairy cows heat loads increase to the point that body temperature rises, feed intake declines, and consequently, the productivity decreases (WEST, 2003). Through increased respiratory rates, decreased feed intake, increased water intake, and imbalances in blood gases and plasma electrolytes cattle try to counteract excessive heat loads (BEATTY et al., 2006).

The capacity to compensate climatic effects may vary with the housing system. So far only limited information on the interaction between different housing systems and heat stress is available under Central European environmental conditions, though heat stress in HolsteinFriesian dairy cows is of increasing concern. Analysis on seasonal THI dynamics pointed out that the overall warming in Europe will result in an increase of warm extremes rather than a decrease of cold extremes (HoLlwEG et al., 2008). Extreme summer THI values represent a major challenge for dairy production and lactating animals are likely to be exposed to severe heat stress during summer months. Therefore, the present study was conducted to assess the impact of the THI on the frequency of medical treatments under the climatic conditions of Lower Saxony, Germany. 


\section{MATERIALS AND METHODS}

\section{Animal herds and housing systems}

The present study included eight Holstein-Friesian dairy herds distributed over the whole region of Lower Saxony, Germany. Herd sizes varied between 55 and 170 dairy cows. Mean annual milk yields ranged from 8,000 to $10,000 \mathrm{~kg}$. In all farms cows were milked twice per day. The animals were kept in loose-housing systems with slatted floors. Three farms kept their cows on pasture during summer time, whereas in the other five farms the animals were kept indoor throughout the whole year. Two farms had a ventilation system. Rations were adjusted throughout the year as season and stage of lactation changed. Animals were bred all the year round and apart from one herd, artificial insemination was used. The percentage of replacement ranged between 10 and $30 \%$ in all farms.

\section{THI measurements}

Climate data including hourly mean temperature and relative humidity were obtained from the nearest meteorological station for the years 2003 and 2005. The six stations covered the whole region of Lower Saxony and were on average $39 \mathrm{~km}( \pm 13 \mathrm{~km}$; SD) away from the different farms. The maximum distance was $60 \mathrm{~km}$. From the hourly temperatures and relative humidity values the THI was calculated according to the following formula proposed by the NRC (1971):

$$
\mathrm{THI}=(1.8 * \mathrm{~T}+32)-(0.55-0.0055 * \mathrm{RH}) *(1.8 * \mathrm{~T}-26),
$$

where $\mathrm{T}$ is the temperature $\left({ }^{\circ} \mathrm{C}\right)$ and $\mathrm{RH}$ is the relative humidity $(\%)$. Based on the hourly THI the daily and monthly average, minimum and maximum THI were calculated for all six meteorological stations. For the average THI values four different THI classes were defined: $<40, \geq 40$ to $<50, \geq 50$ to $<60$, and $\geq 60$.

\section{Records of veterinary treatments}

Records of all veterinary-treated cases from the years 2003 and 2005 were evaluated using the standard receipts, which have to be documented for each veterinary treatment according to the European regulation (EC) 178/2002 (OFFICIAL JOURNAL OF THE European COMMUNITIES, 2002), which is also connected to national regulations (e.g. German regulation concerning veterinary medicine chest (GERMAN FEDERAL MINISTRY OF JustiCE, 2006)). Repeated disease treatments were counted if coded as new cases. A total 
of 8,569 treatments were analyzed. The different diagnoses were summarized into the following diagnostic keys: metabolism (e.g. disorders of metabolism, lack of mineral nutrients and vitamins, milk fever, diseases of the digestive organs, and displaced abomasum), udder (e.g. mastitis, delayed milk flow), fertility (e.g. ovarial cysts, abnormal estrous, endometritis, retained placenta), and foot/leg (e.g. panaritium, mortellaro, lameness, arthritis). Other treatments including those that are primarily dependent on management and independent on climate such as antiparasitics, antibiotics for dry cow therapy, and vaccinations were excluded from the analysis $(\mathrm{N}=3,022)$. After exclusion a final number of 5,547 treatments remained for further analysis. For each year and farm the number of monthly treatments was calculated. In order to enable comparability, the number of monthly treatments was related to the herd size of the different farms. Finally, these monthly treatment rates for the four diagnostic keys were related to the monthly average THI of the nearest meteorological station.

\section{Statistical analysis}

Data were analyzed with the MIXED procedure of the statistical package SAS 9.2 (SAS INSTITUTE INC, 2008). Seasons were defined according to the CLINO reference of Lower Saxony (German Meteorological Service, 2012) in the following way: winter (December to February), spring (March to May), summer (June to August), and autumn (September to November). The following model was used in order to compare percentage of udder, metabolic, fertility, or foot/leg treatments in the 4 THI classes:

$$
\mathbf{Y}_{\mathrm{ijklm}}=\mu+\mathbf{T H I}_{\mathrm{i}}+\mathrm{S}_{\mathrm{j}}+\mathbf{Y r}_{\mathrm{k}}+\mathbf{F}_{\mathrm{l}}+\mathbf{e}_{\mathrm{ijklm}}
$$

$\mathrm{Y}_{\mathrm{ijklm}}=$ observed value for udder, metabolic, fertility or foot/leg incidences;

$\mu \quad=$ mean effect;

$\mathrm{THI}_{\mathrm{i}}=$ fixed effect of the THI class ( $\left.\mathrm{i}=<40, \geq 40-<50, \geq 50-<60, \geq 60\right)$;

$\mathrm{S}_{\mathrm{j}} \quad=$ fixed effect of the season $(\mathrm{j}=$ spring, summer, autumn, winter $) ;$

$\mathrm{Yr}_{\mathrm{k}} \quad=$ fixed effect of year $(\mathrm{k}=2003,2005)$;

$\mathrm{F}_{1} \quad=$ random effect of the farm $(1=1$ to 8$)$;

$\mathrm{e}_{\mathrm{ijklm}}=$ random error.

The significance of the fixed effects was analyzed by using the Tukey test $(P \leq 0.05)$. In order to satisfy the assumptions of ANOVA, the monthly treatment rates were $\sqrt{\arcsin }(\mathrm{x})$ transformed prior to analysis. 


\section{RESULTS}

\section{Temperature-humidity index}

Courses of daily mean THI values averaged over all meteorological stations from the years 2003 and 2005 are presented in Figure 1.

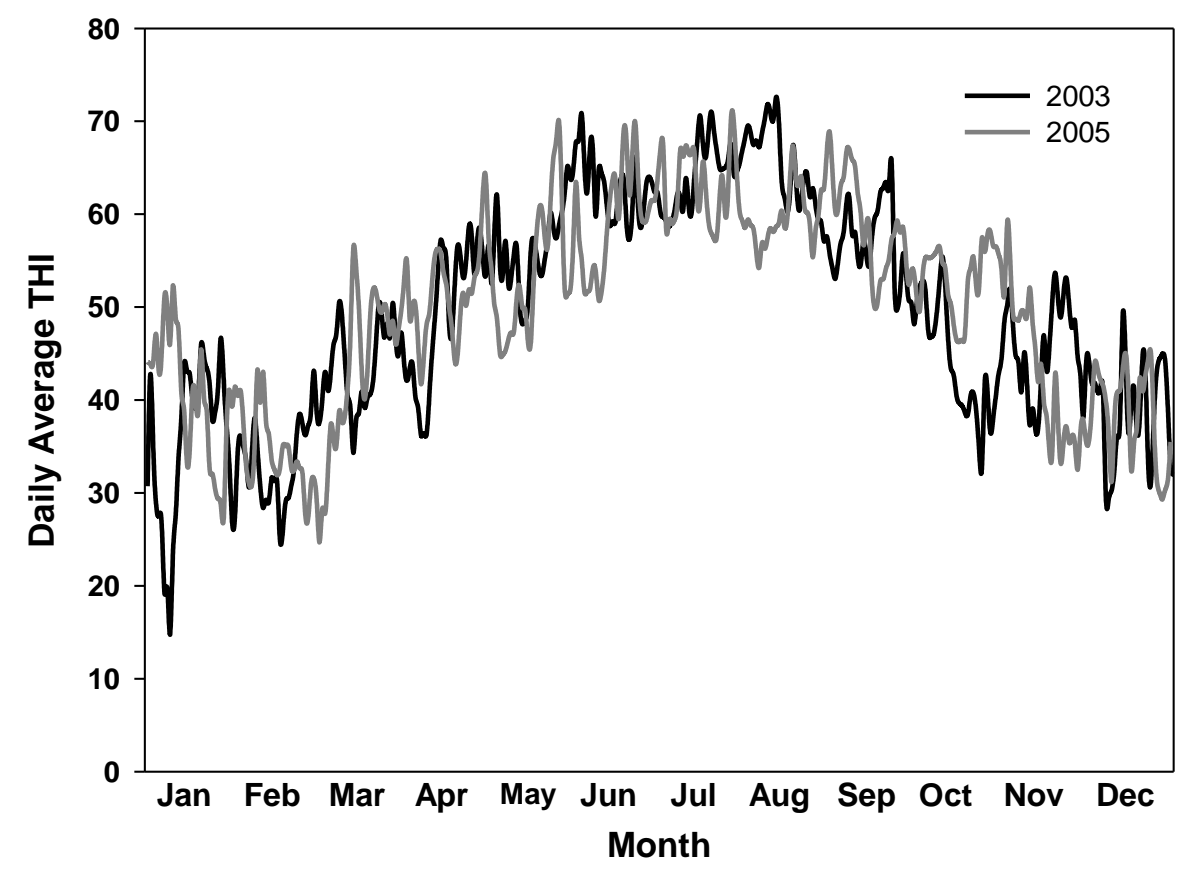

Figure 1. Course of the daily mean temperature-humidity index (THI) values averaged over six meteorological stations from Lower Saxony, Germany, from the years 2003 and 2005.

Beside a cold wave in January 2003 and a heat wave in June and August 2003 differences of the THI gradients between the two years were small. Monthly mean ( \pm standard deviation), minimum, and maximum THI are summarized in Table 1. Average yearly temperature, relative humidity, and THI averaged over all meteorological stations were 9.6 $\pm 7.7^{\circ} \mathrm{C}, 78.2 \pm 12.1 \%$, and $49.5 \pm 12.1$ for 2003 and $9.8 \pm 6.8^{\circ} \mathrm{C}, 80.6 \pm 10.1 \%$, and $49.9 \pm$ 10.9 for 2005, respectively. In winter the THI varied between 32.6 (February 2003) and 40.3 (January 2005), while the THI increased by 13 THI units from March to May. During summer months averages were constantly above 60. During autumn, the THI values decreased from around 58 to 45 in both years. The difference between daily minimum and maximum THI was most pronounced during winter months. In January minima of 10 and maxima of 48 were calculated. 
Table 1. Monthly mean \pm standard deviation (SD), minimum, and maximum temperaturehumidity index (THI) averaged over six meteorological stations from Lower Saxony, Germany, from the years 2003 and 2005 and the CLINO knowlegde (1961-1990; GERMAN MeteOROLOGICAL SERVICE, 2012).

\begin{tabular}{lccccccc}
\hline & \multicolumn{7}{c}{ THI } \\
\cline { 2 - 8 } Month & Mean \pm SD & Max & Min & Mean \pm SD & Max & Min & Mean \pm SD \\
\cline { 2 - 8 } Jan & $35.4 \pm 8.9$ & 48.2 & 10.2 & $40.3 \pm 7.0$ & 53.8 & 23.9 & $35.3 \pm 5.3$ \\
Feb & $32.6 \pm 4.2$ & 42.7 & 21.2 & $35.1 \pm 4.5$ & 45.5 & 20.7 & $36.0 \pm 4.4$ \\
Mar & $43.4 \pm 4.6$ & 52.4 & 31.7 & $41.8 \pm 8.8$ & 58.0 & 18.5 & $41.3 \pm 3.5$ \\
Apr & $49.2 \pm 7.4$ & 60.4 & 34.5 & $50.5 \pm 4.1$ & 58.8 & 40.0 & $47.2 \pm 1.7$ \\
May & $56.1 \pm 4.4$ & 66.9 & 46.0 & $54.3 \pm 7.4$ & 72.2 & 42.7 & $54.8 \pm 2.0$ \\
Jun & $63.0 \pm 3.5$ & 72.4 & 55.1 & $59.2 \pm 5.7$ & 71.1 & 49.5 & $59.4 \pm 1.7$ \\
Jul & $64.2 \pm 3.6$ & 72.6 & 58.1 & $63.1 \pm 3.9$ & 71.5 & 55.4 & $62.0 \pm 2.1$ \\
Aug & $64.7 \pm 4.8$ & 73.9 & 54.5 & $59.9 \pm 3.2$ & 68.6 & 53.0 & $61.7 \pm 1.6$ \\
Sep & $56.7 \pm 4.6$ & 70.0 & 46.8 & $58.8 \pm 5.3$ & 70.5 & 47.3 & $56.8 \pm 1.7$ \\
Oct & $43.9 \pm 6.1$ & 56.7 & 30.3 & $53.3 \pm 3.8$ & 59.4 & 42.0 & $50.3 \pm 2.0$ \\
Nov & $45.6 \pm 5.3$ & 56.2 & 31.5 & $43.2 \pm 7.7$ & 60.0 & 29.1 & $42.5 \pm 2.4$ \\
Dec & $38.8 \pm 5.5$ & 50.6 & 26.2 & $38.2 \pm 5.1$ & 46.7 & 28.1 & $37.4 \pm 4.0$ \\
\hline Year & $49.5 \pm 12.1$ & 73.9 & 10.2 & $49.9 \pm 10.9$ & 72.2 & 18.5 & $48.7 \pm 10.2$ \\
\hline
\end{tabular}

The number of days with hourly THI values above 60 was observed on more than 155 days per year, respectively, whereas during summer months this threshold was exceeded nearly every day. The daily maximum THI exceeded 65 and 70 on 106 and 40 days in 2003 and on 158 and 38 in 2005, respectively. In July the highest number of days with daily maximum THI values above 65 (2003: 27 days; 2005: 24 days) and 70 (2003: 17 days; 2005: 12 days) were recorded.

\section{Veterinary treatments}

The incidence of the treatments according to the different diagnostic clusters is given in Table 2. Out of the 5,547 treatments analyzed $37.4,32.9,21.6$, and $8.1 \%$ belonged to the complexes metabolism, udder, fertility, and foot/leg, respectively. Disorders of metabolism, deficiency of minerals and vitamins, and milk fever were found as the dominating diagnoses of the metabolism complex, whereas udder treatments were mainly related to mastitis. The most frequent causes of fertility treatments were ovarian cycsts, abnormal estrous, and endometritis. Among foot/leg therapies panaritium and mortellaro were most prevalent. Regarding the management-dependent and climate-independent treatments, which accounted for more than 3,000 treatments, antiparasitics (40\%) were 
dominating and followed by antibiotics for dry cow therapy (27\%), and vaccinations $(13 \%)$.

Table 2. Incidence of veterinary-treated cases according to four different diagnostic keys and different diagnoses using 5,547 records from eight dairy herds distributed over Lower Saxony, Germany, from the years 2003 and 2005.

\begin{tabular}{|c|c|c|}
\hline Diagnostic key and diagnosis & $\%$ & $\%$ \\
\hline Metabolism & 37.4 & \\
\hline Disorders of metabolism (ketosis, acidosis) & & 14.4 \\
\hline Lack of mineral nutrients and vitamins & & 7.6 \\
\hline Milk fever & & 7.6 \\
\hline Diseases of the digestive organs & & 5.5 \\
\hline Displaced abomasum & & 2.3 \\
\hline Udder & 32.9 & \\
\hline Mastitis & & 27.9 \\
\hline Delayed milk flow & & 4.5 \\
\hline Fertility & 21.6 & \\
\hline Ovarial cysts, abnormal estrous & & 10.5 \\
\hline Endometritis & & 7.8 \\
\hline Retained placenta & & 2.5 \\
\hline Birth & & 0.8 \\
\hline Foot/Leg & 8.1 & \\
\hline Panaritium, mortellaro & & 5.6 \\
\hline Lameness, arthritis & & 2.5 \\
\hline
\end{tabular}

The udder, fertility, metabolism, and foot/leg incidences were neither affected by the year $(P>0.05)$ and the season $(P>0.05)$ nor by the THI class $(P>0.05)$. There were nonsignificant trends of increasing incidence of metabolic treatments with increasing THI and increasing udder treatments with decreasing THI (Figure 2). As shown in Figure 3 nonsignificant seasonal trends of the four different diagnostic treatments were apparent. In tendency metabolic therapies rose in summer and udder treatments declined in summer and peaked in winter. Between 2003 and 2005 for none of the disease complexes differences were found. 


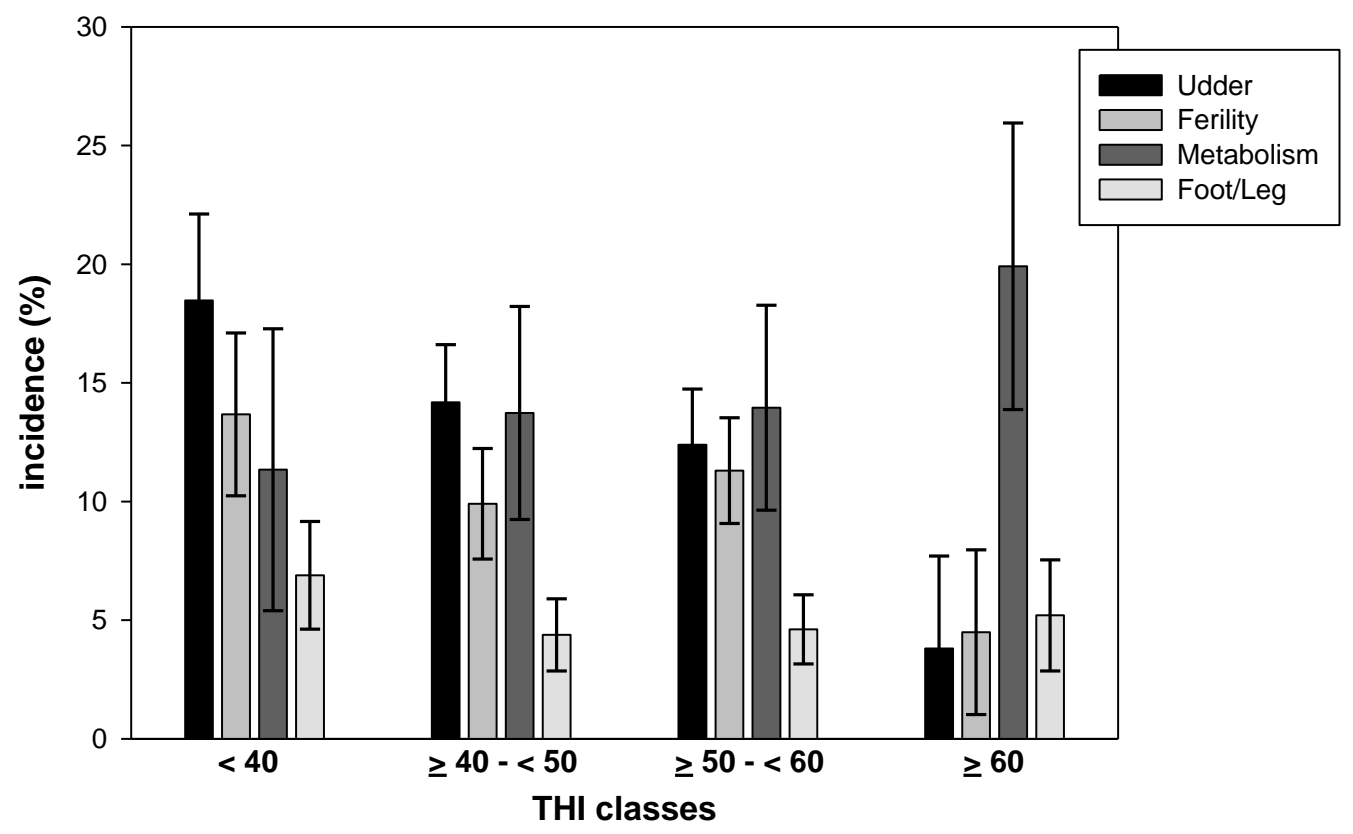

Figure 2. Least square means ( \pm standard error) of udder, fertility, metabolic, and foot/leg incidence $(\mathrm{N}=5,547)$ from eight dairy herds distributed over Lower Saxony, Germany, from the years 2003 and 2005 according to four THI-classes.

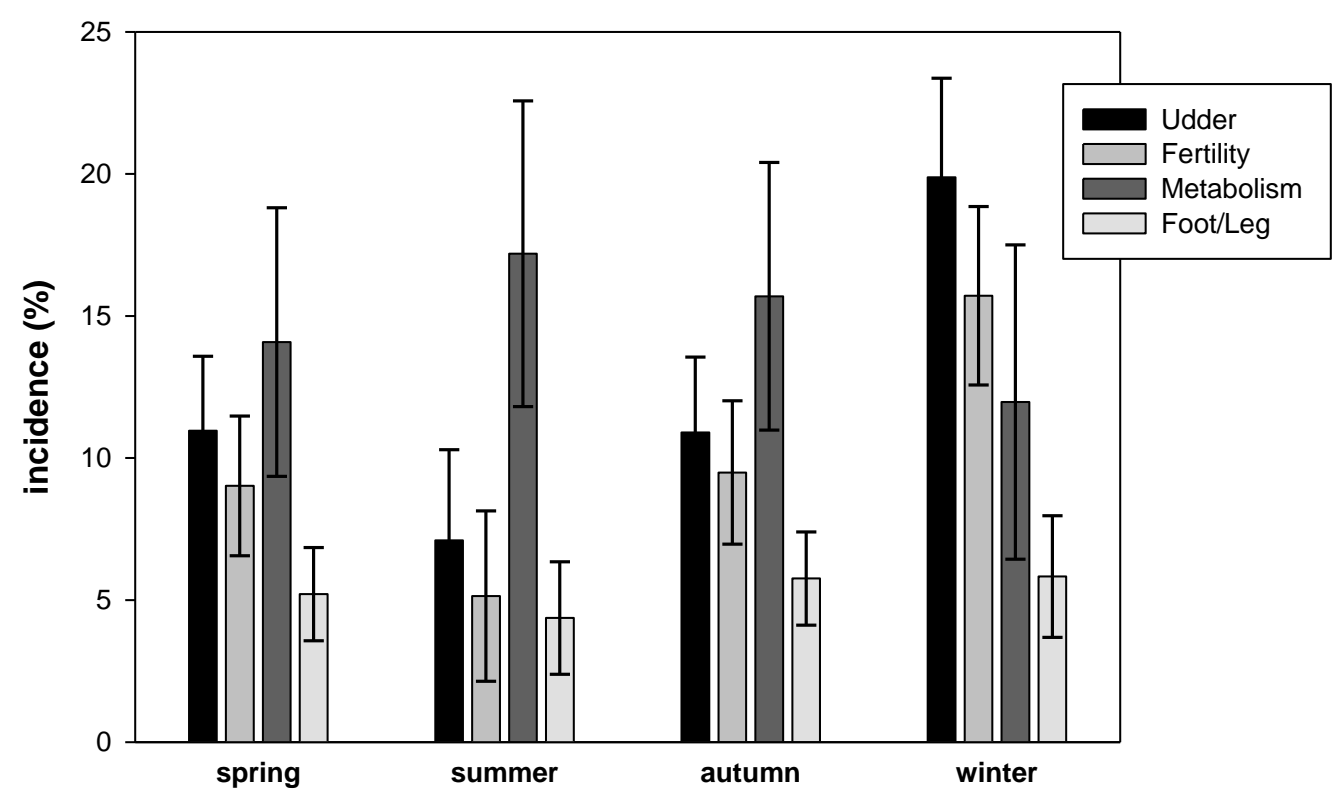

Figure 3. Seasonal effects of udder, fertility, metabolic, and foot/leg incidences (Least square means \pm standard error; $N=5,547$ ) from eight dairy herds distributed over Lower Saxony, Germany, from the years 2003 and 2005 . 


\section{DISCUSSION}

The quantification of heat stress effects on the health of dairy cows is complicated by the fact that performance, welfare, and health of the animals depend on various factors. Exposure to prolonged periods of extreme heat and humidity conditions induces physiological changes (BEATTY et al., 2006). BERMAN (2005) stated that heat stress relief is influenced by environmental factors including temperature, humidity, wind speed, and direction, and by animal characteristics such as body weight, exposed body surface, milk production, and hair coat. As in regions of intensive dairy production in general, heat stress is of increasing concern in Central Europe. Rising milk yields result in an increased production of metabolic heat by the animals. This effect might be potentiated by changing climatic conditions. The overall warming resulting in the proposed increase of warm extremes will enhance heat loads of the animals during summer months (KLEIN TANK AND KÖNNEN, 2003).

In the present study the relationship between incidences of veterinary treatments as an indicator for health and the THI as in indicator for heat stress was investigated. Though widely used as an important indicator of heat stress in dairy cows, factors such as wind speed and thermal radiation are not accounted for in the index. GAUGHAN et al. (2008) proposed that wind speed is a major factor influencing heat loads. As found by AMUNDSON et al. (2006) it has a positive effect on the pregnancy rate. The present study is compared to other studies using THI, wind speed as a climate factor was not included in the present study. Another factor that could not be taken into account on the farms is the exposure to solar radiation. This is another additional indicator for heat stress (BOHMANOVA et al., 2007).

However, the effect of environmental warmth on cattle is commonly predicted by including humidity, which mainly affects the potential for evaporative heat loss from the body. Due to the various temperature and humidity conditions found around the world, several THI formula are known. Accordingly, thresholds of heat stress vary between the different indices (BOHMANOVA et al., 2007). BRÜGEMANN et al. (2010) concluded that the THI of the NRC (1971) is more suitable than the index proposed by RAVAGNOLO AND MiszTAL (2000) for the environmental conditions found in the studied region of Lower Saxony, Germany. The threshold of THI $=60$ was identified for the various regions characterized as a coastal region, a pasture-based region, and a region of intensive crop production. Above this threshold heat stress effects on milk and protein yield were found 
(BRÜGEMANN et al., 2010; 2012). Whenever environmental stressors in dairy cows are discusses, their remarkable adaptive ability to mobilize mechanisms against environmental stressors has to be considered (NIENABER AND HAHN, 2007). As a consequence, the full impact of climatic variables on production, and likewise, on health parameters is delayed and may be related to altered dry matter intake, a delay between intake and utilization of consumed nutrients, or changes in the endocrine status of the cow (WEST, 2003). Especially heat waves, which are common in summer months under European conditions, expose dairy cows to long-term challenges due to the fact, that physiological homeorhetic adaptations require weeks rather than days (COLLIER et al., 2006). Findings of the present study could not underline the high exposure of dairy cows to extreme THI values above 60 during considerable periods in summer months under Central European conditions. However, the THI threshold of 60 was exceeded on more than 155 days per year and almost every day in summer months. It has to be mentioned here, that in the present study climate data of meteorological stations covering the whole region of Lower Saxony were averaged. The number of extreme THI values was calculated for each location and were finally averaged. Therefore, even a higher number of extreme THI values is expected when single locations are considered.

Despite the influence on production traits, studies evaluating the effect of heat stress on the animal health of dairy cows are lacking (KADZERE et al., 2002). Especially the effect on the frequency of ailments is not found in the literature to the author's knowledge. Nevertheless, widely-studied is the effect of thermal stress before insemination on the reproductive efficiency, commonly measured as conception, non-return, or pregnancy rate. VILLA-MANCERA et al. (2011) and GARCIA-ISPIERTO et al. (2007) indicated decreasing conception rates with increasing THI. Rising body temperatures one day before artificial insemination may influence oocytes, and thus, results in reduced conception rates (ROTH, 2008). Furthermore, different climate variables, such as temperature, humidity, wind speed, and rainfall, during the two days preceding the insemination had the greatest influence on the conception rate. A negative effect of high daily THI on the non-return rate was reported by RAVAGNOLO AND MiszTAL (2002). Compared to other periods before and after insemination, the THI on the day of insemination showed the highest effect. AMUNDSON et al. (2006) found that the negative associations of temperature and THI with pregnancy rate are most pronounced during the first 21 days of the breeding season. In the present study no significant effects of the THI classes and seasons on the incidence of fertility treatments were found. In tendency the incidence was higher in THI classes below 
50 than in classes above this value. This trend is contrary to DuBoIS AND WILLIAMS (1980), who found higher incidences of retained placenta and postpartum metritis during warm months than during cold months. Accordingly, heat stress was stated to shorten the gestation period and enhancing the incidence of retained placenta and postpartum metritis. In the present study, an influence of breeding season can be excluded, because the calvings were equally distributed throughout the whole year and a seasonal pattern was not observed in any of the farms. Nevertheless, the monitoring of the animals (e.g. estrus) may vary with the work load of the farmer during the course of the year.

Although effects of THI on the metabolism are well-known (WEST, 2003), studies evaluating this effect are rarely found in the literature. Heat stress effects on feeding behaviour of dairy cows including lower feed intake, selective consumption of concentrates, and minimal intake of forages predispose dairy cows to metabolism diseases, e.g. acidosis (STAPLeS AND THATCHER, 2011; Collier et al., 2006). As presented here, influences of THI and season on the incidence of metabolism treatments were not found.

Regarding the other disease complexes, studies evaluated different results about the relationship between mastitis treatments and climatic conditions. SHATHELE (2009) mentioned high clinical mastitis incidence occurring when the ambient temperature fell below $21^{\circ} \mathrm{C}$ during cold months. However, differences in the occurrence of the different organisms causing mastitis throughout the year may affect the incidence. Findings showed that streptococcal mastitis pathogens were more prevalent than coliform pathogens during periods of high ambient temperature (HARMON, 1994). In the present study udder treatments were not affected by THI and season. A trend of increasing udder incidences with increasing THI values, as it was expected in other studies could not be observed.

The low variation of foot/leg treatments between months indicated a relative independence on the THI. According to the present results, an effect of heat stress is not expected on this disease complex.

\section{CONCLUSIONS}

In the present study it was shown that under the environmental conditions of Lower Saxony, Germany, dairy cows are exposed to heat stress during summer months. However, effects of heat stress on the incidence of medical treatments were found for neither of the metabolism, udder, fertility and foot/leg complexes. 


\section{REFERENCES}

Amundson J.L., T.L. Mader, R.J. Rasby AND Q.S. Hu 2006. Environmental effects on pregnancy rate in beef cattle. J. Anim. Sci. 84: 3415-3420.

Beatty D.T., A. Barnes, E. Taylor, D. Pethick, M. McCarthy and S.K. Maloney 2006. Physiological responses of Bos taurus and Bos indicus cattle to prolonged, continuous heat and humidity. J. Anim. Sci. 84: 972-985.

BERMAN A. 2005. Estimates of heat stress relief needs for Holstein dairy cows. J. Anim. Sci. 83: 1377-1384.

Bohmanova J., I. MiszTal AND J.B. Cole 2007. Temperature-humidity indices as indicators of milk production losses due to heat stress. J. Dairy Sci. 90: 1947-1956.

BRÜGEMANN K., S. KÖNIG AND E. GERNAND 2010. Assessment of heat stress in dairy cows by applying random regression test day models. In Book of abstracts of $61^{\text {st }}$ annual meeting of the European association for animal production, Heraklion, Greece, p.195. Wageningen Academic Publishers, Wageningen, Netherlands.

BRÜGEMANN K., E. GeRnAND, U. KÖNIG VON BORSTEl AND S. KÖNIG 2012. Defining and evaluating heat stress thresholds in different dairy cow production systems. Arch. Tierz. 55: 13-24.

Collier R.J., G.E. DAHL AND M.J. VAnBAale 2006. Major advances associated with environmental effects on dairy cattle. J. Dairy Sci. 89: 1244-1253.

DuBoIS P.R. AND D.J. WILLIAMS 1980. Increased incidence of retained placenta associated with heat stress in dairy cows. Theriogenology 13: 115-121.

Gaughan J.B., T.L. Mader, S.M. Holt And A. Lisle 2008. A new heat load index for feedlot cattle. J. Anim. Sci. 86: 226-234.

GeRman Federal Ministry of Justice 2006. Verordnung über Nachweispflichten der Tierhalter für Arzneimittel, die zur Anwendung bei Tieren bestimmt sind (Tierhalter-Arzneimittel-Nachweisverordnung) article 2 of the regulation from December 20, 2006. Retrieved August 21, 2011, from http://www.gesetze-iminternet.de/anthv/BJNR345300006.html

German Meteorological Service 2012. Personal communication.

García-Ispierto I., F. López-Gatius, G. Bech-Sabat, P. Santolaria, J.L. YÁniz, C. NogaredA, F. De RENSIS AND M. LÓPEZ-BÉJAR 2007. Climate factors affecting conception rate of high producing dairy cows in northeastern Spain. Theriogenology 67: 1379-1385.

HANSEN P.J. 2007. Exploitation of genetic and physiological determinants of embryonic resistance to elevated temperature to improve embryonic survival in dairy cattle during heat stress. Theriogenology 68 Suppl. 1: S242-S249.

HARMON R.J. 1994. Physiology of mastitis and factors affecting somatic cell counts. J. Diary Sci. 77: 2103-2112. 
Hollweg H.D., U. Böhm, I. Fast, B. Hennemuth, K. Keuler, E. Keup-Thiel, M. Lautenschlager, S. LegutKe, K. Ratke, B. Rockel, M. Schubert, M. WoldT AND C. WUNRAM 2008. Ensemble simulations over Europe with the Regional Climate Model CLM forced with IPCC AR4 Global Scenarios. M and D Technical Report 3, Hamburg, Germany.

Intergovernmental Panel ON Climate Change 2007. Climate change 2007: the physical science basis. Contribution of working group I to the fourth assessment report of the Intergovernmental Panel on Climate Change. IPCC, Cambridge University Press, Cambridge, New York, USA.

Kadzere C.T., M.R. Murphy, N. Silanikove and E. Maltz 2002. Heat stress in lactating dairy cows: a review. Livest. Prod. Sci. 77: 59-91.

KLEIN TANK A.M.G. AND G.P. KÖNNEN 2003. Trends in indices of daily temperature and precipitation extremes in Europe, 1946-99. Journal of Climate 16: 3665-3680.

NATIONAL RESEARCH COUNCIL 1971. A guide to environmental research on animals. NRC, National Academy of Sciences, Washington, DC, USA.

NIENABER J.A. AND G.L. HAHN 2007. Livestock production system management responses to thermal challenges. Int. J. Biometeorol. 52: 149-157.

OfFicial Journal of the EuROPEAN COMMUNities 2002. Regulation (EC) No 178/2002 of the European Parliament and the Council of 28 January 2002 laying down the general principles and requirements of food law, establishing the European Food Safety Authority and laying down procedures in matters of food safety. Retrieved August 21, 2011, from http://eurlex.europa.eu/LexUriServ/site/de/oj/2002/1_031/1_03120020201de00010024.pdf

Pegorer M.F., J.L.M. Vasconcelos, L.A. Trinca, P.J. HANSEn And C.M. Barros 2007. Influence of sire and sire breed (Gyr versus Holstein) on establishment of pregnancy and embryonic loss in lactating Holstein cows during summer heat stress. Theriogenology 67: 692-697.

Ravagnolo O. AND I. MiszTal 2000. Genetic component of heat stress in dairy cattle, parameter estimation. J. Dairy Sci. 83: 2126-2130.

RAVAGNOLO O. AND I. MisZTAL 2002. Effect of heat stress on nonreturn rate in Holsteins: fixed-model analyses. J. Dairy Sci. 85: 3101-3106.

Rотн Z. 2008. Heat stress, the follicle, and its enclosed oocyte: mechanisms and potential strategies to improve fertility in dairy cows. Reprod. Domestic Anim. 43: 238-244.

SAS InSTITUTE InC. 2008. SAS/STAT® 9.2. User’s Guide. Cary, NC, SAS Institute Inc.

SHATHELE M.S. 2009. Weather effect on bacterial mastitis in dairy cows. International J. Dairy Sci. 4 Suppl 2: 57-66.

StAPles C.R. AND W.W. THATCHER 2011. Heat stress: effects on milk production and compostion. In Encyclopedia of Dairy Science (eds JW Fuquay, PF Fox, PLH McSweeney), 2nd Edition, pp. 561-566. Academic Press - Elsevier Science Ltd, Oxford, UK. 
Villa-Mancera A., M. MéndeZ-Mendoza, R. Huerta-Crispín, F. VÁZQuez-Flores AND A. CÓRDOVA-IZQUIERDO A 2011. Effect of climate factors on conception rate of lactating dairy cows in Mexico. Trop. Anim. Health Prod. 43: 597-601.

WEST J.W. 2003. Effects of heat-stress on production in dairy cattle. J. Dairy Sci. 86: 2131-2144. 


\section{KAPITEL IV}

CLIMATIC EFFECTS ON LACTATING HOLSTEIN COWS IN DIFFERENT HUSBANDRY SYSTEMS:

I. BULK MILK COMPONENTS AND SOMATIC CELL COUNT 


\begin{abstract}
The aim of this study was to compare the effect of temperature-humidity index (THI) on fat and protein percentage, and somatic cell count (SCC) in bulk milk of dairy cows raised in four different housing systems: (1) warm loose-housing with access to pasture; (2) warm loose-housing without access to pasture; (3) cold loose-housing with access to pasture; and (4) cold loose-housing without access to pasture. This study was conducted for four farms of each housing system located in Lower Saxony, Germany. Air temperature and relative humidity were recorded by data loggers in these farms over a period of 12 months. Maximum THI values (averaged about three days) were calculated. Bulk milk samples (SCC, fat and protein percentage) were taken four to six times per month. Data were analyzed with a mixed model and a regression analysis. In July in each housing system heat stress conditions were found with maximum temperatures above $30^{\circ} \mathrm{C}$ and maximum THI above 80. In the warm loose-housing systems the highest environmental data (mean air temperature and THI) was recorded. With increasing 3-days maximum THI the fat percentage decreased by $0.0123 \%$ and $0.0099 \%$ in the pasture-based and indoor warm loose-housing system, respectively. In the cold loose-housing systems the fat percentages decreased by $0.0043 \%$ per THI unit with access to pasture and by $0.0078 \%$ per THI unit without pasturing. In the warm loose-housing systems a higher decline of protein percentages with increasing 3-days maximum THI was recorded than in the cold loosehousing system. A significant increase of bulk milk SCC between winter and summer $(215,400 \pm 74,400$ somatic cells $/ \mathrm{ml}$ vs. $270,600 \pm 91,600$ somatic cells $/ \mathrm{ml} ; P<0.001)$ was observed. In conclusion, the effect of heat stress conditions on bulk milk components and SCC differed between husbandry systems. With increasing THI the highest decreases in bulk milk components and increases in bulk milk SCC were recorded in the warm loosehousing system.
\end{abstract}

\title{
INTERPRETIVE SUMMARY
}

Global warming is one of the most important topics in the near future for livestock production, especially the impact of heat stress on high producing dairy cows. The direct effects of heat stress on milk production are well-known, but it has to be considered that dairy cows are kept in substantially different husbandry systems. Thus, the aim of this study was to assess the impact of heat stress in terms of temperature and temperature- 
humidity index on bulk milk somatic cell count, fat and protein percentage in regard to the housing system.

\section{INTRODUCTION}

Livestock production and welfare is affected by various factors. This results from the complex interaction between the individual animal and the environment with its different factors such as the climate (outdoor or indoor) and housing conditions. According to the predictions of the Intergovernmental Panel on Climate Change (IPCC, 2007) global warming becomes an important topic in the world. It projected an increasing number and intensity of extreme climate situations and heat waves. The predicted increase of the global air temperature ranges from $1.8^{\circ} \mathrm{C}\left(\mathrm{B} 1\right.$ scenario, low) to $4.0^{\circ} \mathrm{C}(\mathrm{A} 1 \mathrm{Fl}$ scenario, high) until the end of the 21 st century. Under subtropical and tropical climatic conditions several studies demonstrated the impacts of environmental factors on the efficiency and productivity of beef and dairy cattle. Cattle are homoiotherm animals with a thermoneutral zone. In this zone the thermoregulation requires least expenditure of energy. Temperatures above this zone are associated with declines in productivity such as decreasing dry matter intake, milk production and reproduction (MCDOwELL et al., 1976; BEEDE AND COLLIER, 1986; BERMAN, 2005; WEST, 2003; RHOADES et al., 2009). The ability to adapt to climatic conditions is based on different heat dissipation mechanisms like conduction, convection, radiation, and evaporation (KADZERE et al., 2002). However, the thermoregulation mechanisms are limited. Stress is induced by exceeded heat production above the heat release of the animals (WEST, 2003). According to FUQUAY (1981) heat stress occurs above the thermoneutral zone with the upper critical temperature for dairy cows ranging between 24 and $27^{\circ} \mathrm{C}$. YOUSEF (1987) mentioned that the critical temperature depends on the rate of production, degree of acclimatization, pregnancy status, air movement, and relative humidity. Thus a representative measure of thermal environment cannot be the air temperature alone. Other environmental factors like the relative humidity, solar radiation, and wind movement have to be considered as well (RENAUDEAU et al., 2012).

Furthermore, scientists developed various indices from meteorological measurements, which represent the influence of direct and indirect heat exchanges between the animal and its environment. As a widely used indicator of thermal conditions and the degree of heat stress the temperature-humidity index (THI) is used. It incorporates the effects of ambient temperature as well as relative humidity (YOUSEF, 1987; HuBBARD et al., 1999). ST- 
PIERRE et al. (2003) calculated an immense annual economic loss of $\$ 897$ million caused by heat stress for the US dairy industry and mentioned as the main heat stress-related problems increased mortality and decreased feed intake, growth, milk production, and reproduction.

Generally, the performance of dairy cows suffers from hot climates. According to RHOADES et al. (2009) the dry matter intake and milk yield is lower in heat-stressed cows than in cows which are kept in a thermal neutral environment. Beside the declines in feed intake and milk production, there are significant changes in milk components (protein and fat) and increases in somatic cell counts (SCC) in the hottest months (BOURAOUI et al., 2002; RoDRIGUEZ et al., 1985). Stated by QUIST et al. (2008) significant seasonal depressions in fat and protein yield only appear in the first lactation. As an indicator of the udder health the SCC is widely used, because it indicates subclinical mastitis (DOHOO AND MEEK, 1982). As already pointed out for the milk components a seasonal pattern exists for SCC, too. Generally, SCS increases during the summer months (SALSBERG et al., 1984; NORMAN et al., 2000; BourAOUi et al., 2002; OLDE RIEKERINK et al., 2007).

Worldwide dairy cows are kept in various production and housing systems. In order to quantify the degree of heat stress on production, it has to be differentiated between these systems (NARdone et al., 2010; SCHNIER et al., 2003). According to NARDONE et al. (2010) production systems can be divided into three main categories:

i) grazing or pastoral systems,

ii) mixed agro-zootechnical or crop-livestock systems, and

iii) industrial or landless systems.

Mixed livestock systems are the dominating system in Central and Eastern Europe, whereas grazing systems are only found in distinct areas of Europe. SCHNIER et al. (2004) divided loose housing systems into warm and cold loose-housing systems according to the climatic conditions inside the barn. If the micro-climatic conditions inside the barn are similar to the macro-climatic conditions outside the barn, it is defined as a cold loosehousing system (SCHNIER et al., 2003). The warm loose-housing system is characterized by relatively constant indoor climatic conditions throughout the year (SCHNIER et al., 2004). Another important factor is grazing. In Lower Saxony grazing systems play a major role. In 2009 almost $68.5 \%$ of the 783,000 dairy cows were kept on pasture for an average of 24 weeks per year (German Federal Statistical OfFice, 2010). Based on increasing temperatures and the availability of different housing systems the objective of this study 
was to assess the effect of barn temperature and THI in four different husbandry systems on the bulk milk components (fat and protein percentage) and SSC.

\section{MATERIAL AND METHODS}

\section{Animals and housing system}

The study was conducted on 16 dairy farms distributed over Lower Saxony, Germany. Herd sizes varied between 70 and 190 Holstein-Friesian cows and all cows were raised in loose-housing systems with cubicles. The housing systems varied between different pasturing systems and construction styles. Four different housing systems could be differentiated:

(1) warm loose-housing with access to pasture (WP),

(2) warm loose-housing without access to pasture (WI),

(3) cold loose-housing with access to pasture (CP), and

(4) cold loose-housing without access to pasture (CI).

In the two pasturing systems cows had access to pasture from May to October. Cold and warm loose-housing systems differed by the construction of the roofs. Warm loose-housing systems had isolated and cold systems not isolated roofs. Four farms belonged to each of the four different housing systems.

\section{Data recording}

Data of bulk milk samplings taken from April 2010 to March 2011 were included in the present study. During this period each farm was sampled four to six times per month. Bulk milk was analysed for fat and protein percentage and somatic cell count.

For the above mentioned period air temperature and relative humidity were recorded at 15 minute intervals by data logger (Tinytag Plus 2, TGP-4500, Gemini Data Loggers, England). In each farm four loggers were installed with two placed in the lying and two in the feeding area at a height of $3 \mathrm{~m}$ (measured from the slatted floor). The THI for every barn was calculated using hourly averages of the four data loggers as follows:

$$
\mathrm{THI}=(1.8 * \mathbf{T}+32)-(0.55-0.0055 * \mathbf{R H}) *(1.8 * \mathbf{T}-26),
$$

where $\mathrm{T}$ is the air temperature in ${ }^{\circ} \mathrm{C}$ and $\mathrm{RH}$ is the relative humidity in \% (NRC, 1971). The average and maximum environmental data (air temperature and THI) of the three days 
preceding the milk sampling were used for the statistical analysis (BRÜGEMANN et al., 2011; BOHMANOVA et al., 2008).

\section{Statistical models}

The data analysis was performed with the statistical package SAS 9.2 (SAS INSTITUTE INC., 2008). Environmental data were analyzed with the following linear model to compare air temperature or THI in the four housing systems:

$$
Y_{i j k l}=\mu+C_{i}+C_{i}\left(F_{j}\right)+M_{k}+e_{i j k l}
$$

$\mathrm{Y}_{\mathrm{ijk} \mathrm{l}}=$ observed value for barn temperature or THI;

$\mu \quad=$ mean effect;

$\mathrm{C}_{\mathrm{i}} \quad=$ fixed effect of the housing cluster ( $\left.\mathrm{i}=\mathrm{WP}, \mathrm{WI}, \mathrm{CP}, \mathrm{CI}\right)$;

$\mathrm{C}_{\mathrm{i}}\left(\mathrm{F}_{\mathrm{j}}\right)=$ fixed effect of the farm within the housing cluster $(\mathrm{j}=1$ to 16$)$;

$\mathrm{M}_{\mathrm{k}} \quad=$ fixed effect of month ( $\mathrm{k}=$ April to March);

$\mathrm{e}_{\mathrm{ijkl}}=$ random error.

The significance of the fixed effects was analyzed by using the Tukey test with a significance level of $P<0.05$.

The effects on the bulk milk components were analyzed with the following mixed model to compare fat and protein percentage or somatic cell count in the four housing systems:

$$
Y_{i j k l}=\mu+C_{i}+C_{i}\left(F_{j}\right)+M_{k}+e_{i j k l}
$$

$\mathrm{Y}_{\mathrm{ijkl}}=$ observed value for fat and protein percentage or somatic cell count;

$\mu \quad=$ mean effect;

$\mathrm{C}_{\mathrm{i}} \quad=$ fixed effect of the housing cluster $(\mathrm{i}=\mathrm{WP}, \mathrm{WI}, \mathrm{CP}, \mathrm{CI})$;

$\mathrm{C}_{\mathrm{i}}\left(\mathrm{F}_{\mathrm{j}}\right)=$ fixed effect of the farm within the housing cluster $(\mathrm{j}=1$ to 16$)$;

$\mathrm{M}_{\mathrm{k}} \quad=$ fixed effect of month ( $\mathrm{k}=$ April to March);

$\mathrm{e}_{\mathrm{ijkl}}=$ random error.

The significance of the fixed effects was analyzed by using the Tukey test with a significance level of $P<0.05$. 
In order to determine the relationship between climatic values and bulk milk components Pearson's correlations were analysed. Afterwards regression coefficients for the housing systems were estimated for:

i) 3-day average temperature on milk components (fat and protein percentage);

ii) 3-day maximum temperature on SCC;

iii) 3-day average THI on milk components (fat and protein percentage) and

iv) 3-day maximum THI on SCC.

Season was included as a fixed factor and farm as random factor. Season was defined in the following way: spring (February to April), summer (May to July), autumn (August to October), and winter (November to January).

\section{RESULTS AND DISCUSSION}

\section{Environmental data}

Monthly THI averaged over all barns from April 2010 to March 2011 are shown in Table 1. During 2010 it was particularly hot: in July maximum THI exceeded in every housing system 80 (WP: 85.7; WI: 83.3; CP: 85.2; CI: 83.9). In the warm loose-housing systems annual average THI values were significantly $(P<0.001)$ higher than of the cold

Table 1. Monthly mean and maximum barn THI by the four different housing clusters throughout the experimental period (April 2010 to March 2011).

\begin{tabular}{|c|c|c|c|c|c|c|c|c|}
\hline \multirow[b]{2}{*}{ Month } & \multicolumn{2}{|c|}{$\begin{array}{c}\text { warm loose- } \\
\text { housing with } \\
\text { pasturing }(N=4)\end{array}$} & \multicolumn{2}{|c|}{$\begin{array}{c}\text { warm loose- } \\
\text { housing without } \\
\text { pasturing }(\mathrm{N}=4)\end{array}$} & \multicolumn{2}{|c|}{$\begin{array}{l}\text { cold loose-housing } \\
\text { with pasturing } \\
(\mathbf{N}=4)\end{array}$} & \multicolumn{2}{|c|}{$\begin{array}{l}\text { cold loose-housing } \\
\text { without pasturing } \\
\qquad(\mathrm{N}=4)\end{array}$} \\
\hline & Mean & Max & Mean & Max & Mean & Max & Mean & Max \\
\hline Apr & 57.5 & 73.5 & 56.2 & 73.2 & 54.2 & 74.9 & 54.2 & 74.0 \\
\hline May & 57.5 & 73.2 & 57.7 & 72.4 & 55.6 & 75.8 & 56.2 & 76.1 \\
\hline Jun & 64.8 & 79.1 & 65.5 & 78.3 & 63.6 & 80.1 & 64.4 & 78.6 \\
\hline Jul & 69.6 & 85.7 & 71.0 & 83.3 & 69.1 & 85.2 & 69.9 & 83.9 \\
\hline Aug & 65.5 & 78.3 & 67.1 & 78.0 & 64.9 & 78.0 & 65.6 & 78.2 \\
\hline Sep & 60.9 & 73.5 & 61.5 & 74.7 & 59.9 & 75.2 & 60.1 & 73.8 \\
\hline Oct & 56.3 & 72.0 & 55.4 & 71.3 & 54.3 & 72.1 & 53.3 & 69.7 \\
\hline Nov & 51.5 & 64.3 & 49.8 & 63.6 & 46.5 & 61.7 & 47.0 & 62.6 \\
\hline Dec & 44.9 & 57.0 & 40.9 & 57.0 & 34.8 & 48.7 & 36.5 & 51.0 \\
\hline Jan & 49.4 & 62.1 & 47.4 & 62.7 & 42.6 & 57.9 & 44.2 & 59.0 \\
\hline $\mathrm{Feb}$ & 48.3 & 60.3 & 47.6 & 61.2 & 43.0 & 55.7 & 43.9 & 57.8 \\
\hline Mar & 53.3 & 67.4 & 51.5 & 65.5 & 47.7 & 65.7 & 49.0 & 65.5 \\
\hline Year & 56.9 & 85.7 & 56.0 & 83.3 & 53.4 & 85.2 & 53.8 & 83.9 \\
\hline
\end{tabular}

$\mathrm{N}=$ number of farms within cluster 
loose-housing systems. From June to September in all housing systems monthly mean THI values exceeded 60. From April to September maximum THI values above 72 were recorded. This threshold of 72 is the upper critical THI for lactating cows in tropical areas and is associated with decreasing milk yields (JOHNSON, 1987). Within different production systems in Lower Saxony, Germany, a THI value of 60 was calculated as upper critical THI for lactating cows associated with decreasing milk and protein yields (BRÜGEMANN et al., 2010 and 2012).

Throughout the experimental period July was the month with the highest mean as well as maximum barn environmental data (temperature and THI). Comparisons of the various housing systems indicated higher mean THI values in warm loose-housing systems than in cold loose-housing systems. According to SCHNIER et al. (2004) relatively constant climatic conditions characterised warm loose-housing systems. Due to its construction, especially the isolated roof, a rapid heating is prevented. This was reflected by the lower maximum temperatures in the warm loose-housing systems. Furthermore, isolated roof inhibits a rapid cooling. It needs more time until barn temperature decreases than in outdoor systems. Furthermore, in the pasture-based systems lower mean and maximum THI values were recorded than in the indoor systems. Previously it was assumed that cows spent more time outside and during this time they produced less metabolic heat in barn. This assumption is confirmed with the study of KROHN et al. (1992). The authors indicated that cows spent more time on pasture and stayed $28 \%$ of the day indoor, if the cows have a choose between access to pasture and indoor housing.

\section{Bulk milk fat percentage}

In figure 1 the course of the milk fat percentages is shown during the experimental period. It was affected by cluster $(P<0.001)$, farm within cluster $(P<0.001)$ and month $(P<0.001)$. According to various housing systems herds in the warm loose-housing system without access to pasture produced significantly higher milk fat percentages than herds in the pasture-based housing clusters (WI: $4.2 \pm 0.2 \%$, WP: $4.1 \pm 0.3 \%$, CP: $4.1 \pm 0.2 \%$; $P<0.01)$. Fat percentages were lower in the indoor cold loose housing system than in the other three systems $(\mathrm{CI}: 3.9 \pm 0.2 \% ; P<0.001)$. Between the two different pasturing systems no significant differences were found $(4.1 \pm 0.3 \%$ vs. $4.1 \pm 0.2 \%$ for WP and CP, respectively; $P>0.05$ ). GÜRTLER AND SCHWEIGERT (2000) summarized that the milk fat concentration and composition can vary in regard to feed composition, breed, stage of 
lactation, parity, and season. The most important factors of feed composition are type of roughage, roughage/concentrate ratio, composition of carbohydrates, amount of lipids, amount of feed intake, and feed intake frequency.

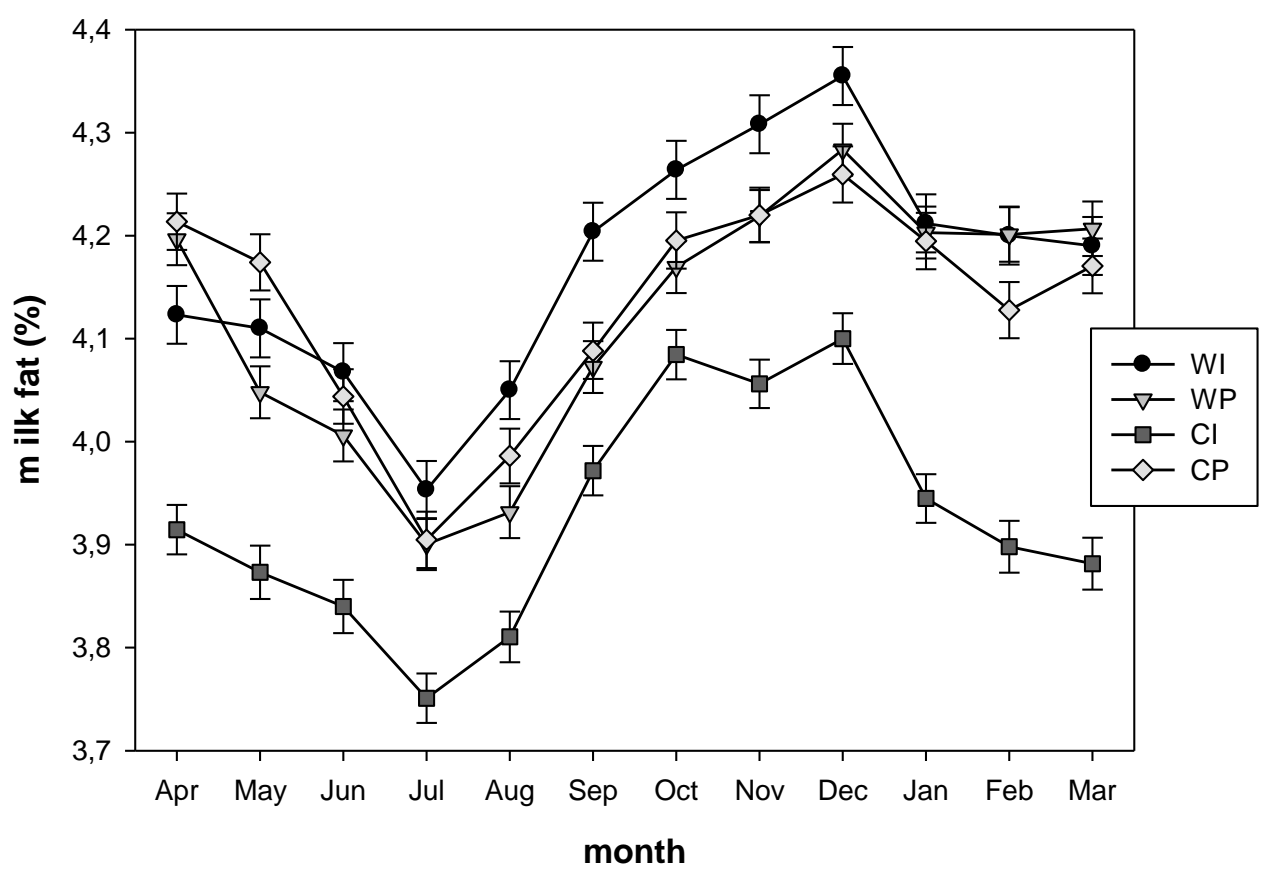

Figure 1. Monthly average bulk fat percentages with standard error for the warm loose-housing system without access to pasture (WI, $\mathrm{N}=4, \mathrm{n}=192$ ), warm loose-housing system access to pasture (WP, $N=4, n=228$ ), cold loose-housing system without access to pasture ( $\mathrm{CI}, \mathrm{N}=4, \mathrm{n}=$ 254 ) and cold loose-housing system with access to pasture ( $\mathrm{CP}, \mathrm{N}=4, \mathrm{n}=195)$ from April 2010 until March 2011 ( $\mathrm{N}=$ number of farms; $\mathrm{n}=$ number of records within cluster).

From April to July the bulk fat percentage decreased in all housing systems. In summer months (June, July and August) it was significantly lower than in the other months $(P<0.01)$. Throughout the year in all systems fat percentages varied about 0.3 to $0.4 \%$. In comparison of the coldest month (December) to the hottest month (July) there were highly significant differences (WI: $-0.41 \%$, WP: $-0.38 \%$, CI: $-0.34 \%$, CP: $-0.35 \%$; $P<0.001$ ). It is well known that milk production of dairy cows declines of cows during summer months. The decrease in bulk milk fat under heat stress conditions in the present study is well in agreement with previous reports (BOURAOUI et al., 2002; QUIST et al., 2008). QUIST et al. (2008) indicated a significant seasonal difference of $0.17 \mathrm{~kg} / \mathrm{d}$ in milk fat yield in the first lactation. 

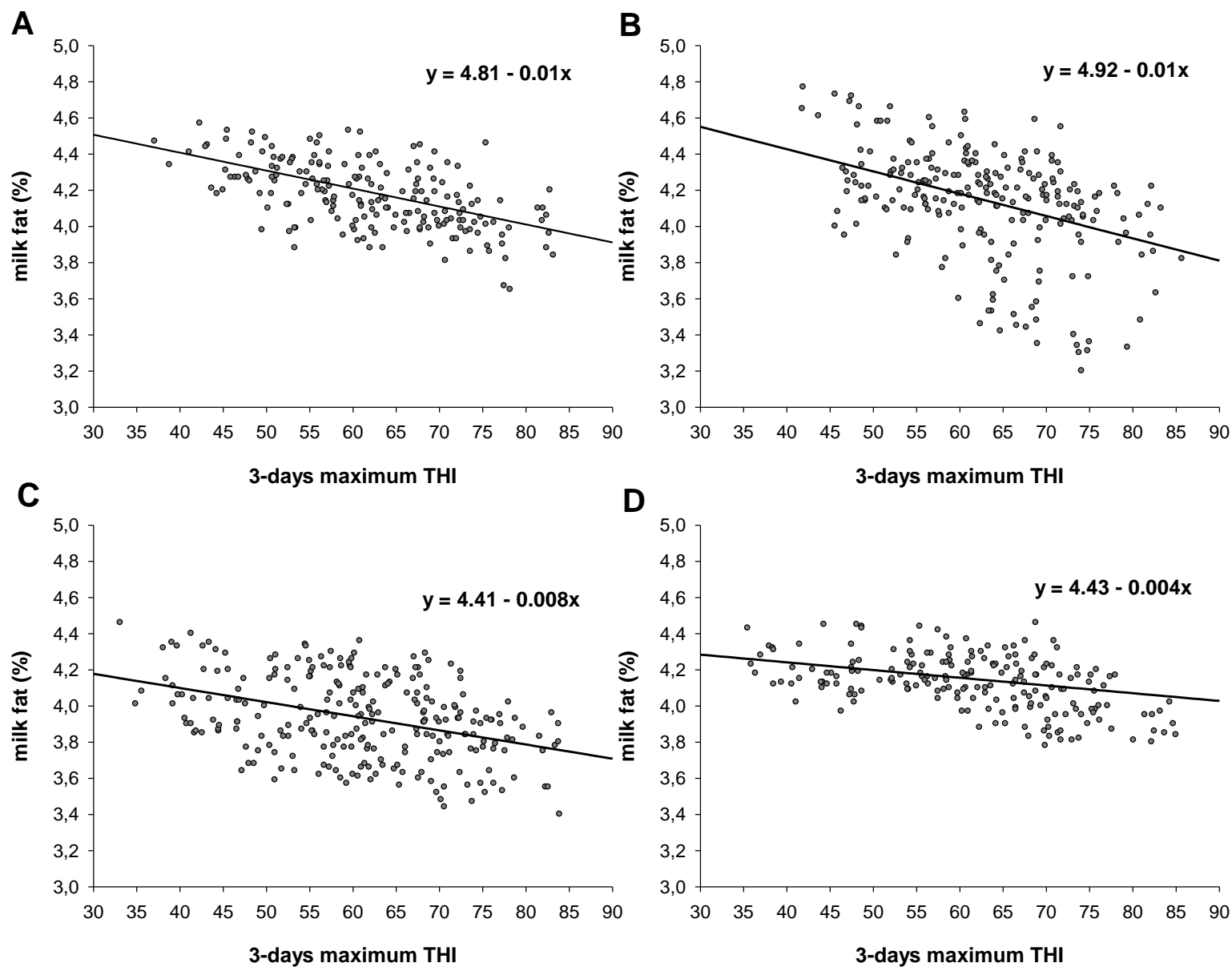

Figure 2. Relationship of maximum THI during the last 3-days preceding milk sampling to fat content for $\mathbf{A}$ warm loose-housing system without access to pasture $(\mathrm{N}=4)$, B warm loose-housing system with access to pasture $(\mathrm{N}=4), \mathbf{C}$ cold loose-housing system without access to pasture $(\mathrm{N}=4)$ and $\mathbf{D}$ cold loose-housing system with access to pasture $(\mathrm{N}=4)$.

Milk fat percentage was negatively correlated $(\mathrm{r}=-0.38, P<0.001)$ with the 3 -days maximum THI. Figure 2 illustrates the regression coefficients of the 3-days maximum THI for the different systems. In warm loose-housing systems the bulk fat percentage decreased at a higher rate than in cold loose-housing systems. This might be explained by the fact, that the warm loose-housing system exhibited higher climatic average values than the cold loose-housing cluster. Within the insulated system farms with pasturing showed a higher decline in bulk milk fat percentage for each increasing unit in 3-days maximum THI ($0.0099 \%$ vs. $-0.0123 \%$, respectively for WI and WP). Otherwise, within the open systems the system without pasturing indicated the higher decrease $(-0.0078 \%$ vs. $-0.0043 \%$, CI and $\mathrm{CP}$, respectively). The different assumptions related to the pasturing systems could be 
explained by the behaviour of the cows. Under environmental conditions of heat stress cows in the pasturing systems were able to choose whether to stay in the barn or to graze on pasture. The shade is one of these factors, which is an important management technique to reduce heat stress (BROWN-BRANDL et al., 2005). Furthermore, in the pasture-based warm loose-housing dairy cows could be outside during the summer months (KROHN et al., 1992), because insulated barns cooled down more slowly than the opened barns. Moreover, relations between feeding and milk components are well known. Milk components can be altered through the frequency of feeding and changes in the diet. Fat is very sensitive to these changes (SutTon, 1989; Jenkins And MCGuiRe, 2006). During the study period the farms didn't change their feeding techniques. One consequent of heat stress is a lower dry matter intake (COLLIER et al., 2006), which could affect the milk fat content. Lower feed intake, a selective consumption of concentrates and minimized intake of forages could predispose cows to ruminal acidosis and lower milk fat content (STAPLES AND THATCHER, 2011; COLLIER et al., 2006).

\section{Bulk milk protein percentage}

Similarly to milk fat, the concentration of milk proteins is affected by stage of lactation, breed, and feed ration. Primarily milk protein concentration is determined by energy absorption or energy content of feed, respectively. A non-effective energy supply leads to a decrease in milk protein percentage (GÜRTLER AND SCHWEIGERT, 2000). In the present study the bulk protein percentage ranged from 3.09 to $3.74 \%$ with a mean of $3.42 \pm 0.12 \%$ across all systems over the study period. It was affected by cluster $(P<0.001)$, farm within cluster $(P<0.001)$ and month $(P<0.001)$. Within the two pasture-based systems and within the two indoor systems no significant difference were found $(P>0.05)$. Bulk protein percentage was significantly lower in indoor systems than in pasture-based systems (WI: $3.39 \pm 0.14 \%$, CI: $3.39 \pm 0.10 \%$, WP: $3.44 \pm 0.11 \%$, CP: $3.44 \pm 0.12 \% ; P<0.001)$. The increase in protein content in milk after access to pasture is primarily due to an improvement of energy supply (GÜRTLER AND SCHWEIGERT, 2000). The bulk protein percentage reached the maximum in December and the minimum in July. This course is similar to the fat percentage. Monthly protein percentage decreased between December to July from 3.53 to $3.26 \%$ across all systems (WI: 3.51 to $3.23 \%$; WP: 3.55 to $3.29 \%$; CI: 3.50 to $3.25 \%$; CP: 3.56 to $3.29 \%$ ). Significantly lower protein percentage were recorded in summer months (June, July, August) than in other months (June $P<0.01$; July, August 
$P<0.001)$. The results in the present study are well in agreement with those reported by other authors, which indicated a decreased milk protein percentage under summer heat stress conditions (BOURAOUI et al., 2002; RHOAdES et al., 2009; SHWARTZ et al., 2009). RHOADES et al. (2009) described a milk protein content decrease of $0.13 \%$ (2.73\% vs. $2.6 \%$ ) during heat stress in comparison to thermal neutral conditions. The comparison of the hottest and the coldest month yielded in highly significant differences (WI: $-0.26 \%$, WP: $-0.26 \%$, CI: $-0.25 \%, \mathrm{CP}:-0.27 \%$; $P<0.001)$. These results showed heat stress depressions in each system, whereas no difference between the housing systems existed.

Bulk milk protein percentage were higher correlated to 3-days maximum THI $(r=-0.50$, $P<0.001)$ than to mean THI. Therefore, maximum values were used to test the effect of 3-days maximum THI on milk protein percentage. Figure 3 illustrates the negative relationships of 3-days maximum THI on bulk protein percentages for each cluster. RODRIGUEZ et al. (1985) and KNAPP AND GRUMMER (1991) suggested that with increasing maximum daily temperatures milk protein content decreases. The insulated system indicated a higher decrease in protein percentage than the open systems. As mentioned for fat percentage higher climatic average values were measured in the warm loose-housing systems compared to the cold loose-housing systems. Within the cold loose-housing systems similar declines were observed $(-0.004 \%$ vs. $-0.0039 \%$ per increasing unit of 3-days maximum THI in CI and CP, respectively). The protein percentage declined at a higher rate in indoor warm loose-housing than in pasture-based system (-0.0064\% vs. $-0.0052 \%$ per increasing unit of 3-days maximum THI, respectively WI and WP). Generally, decreases in milk protein due to heat stress were related to lowered microbial protein synthesis in the rumen and lowered protein and feed intake (STAPLES AND THATCHER, 2011). 

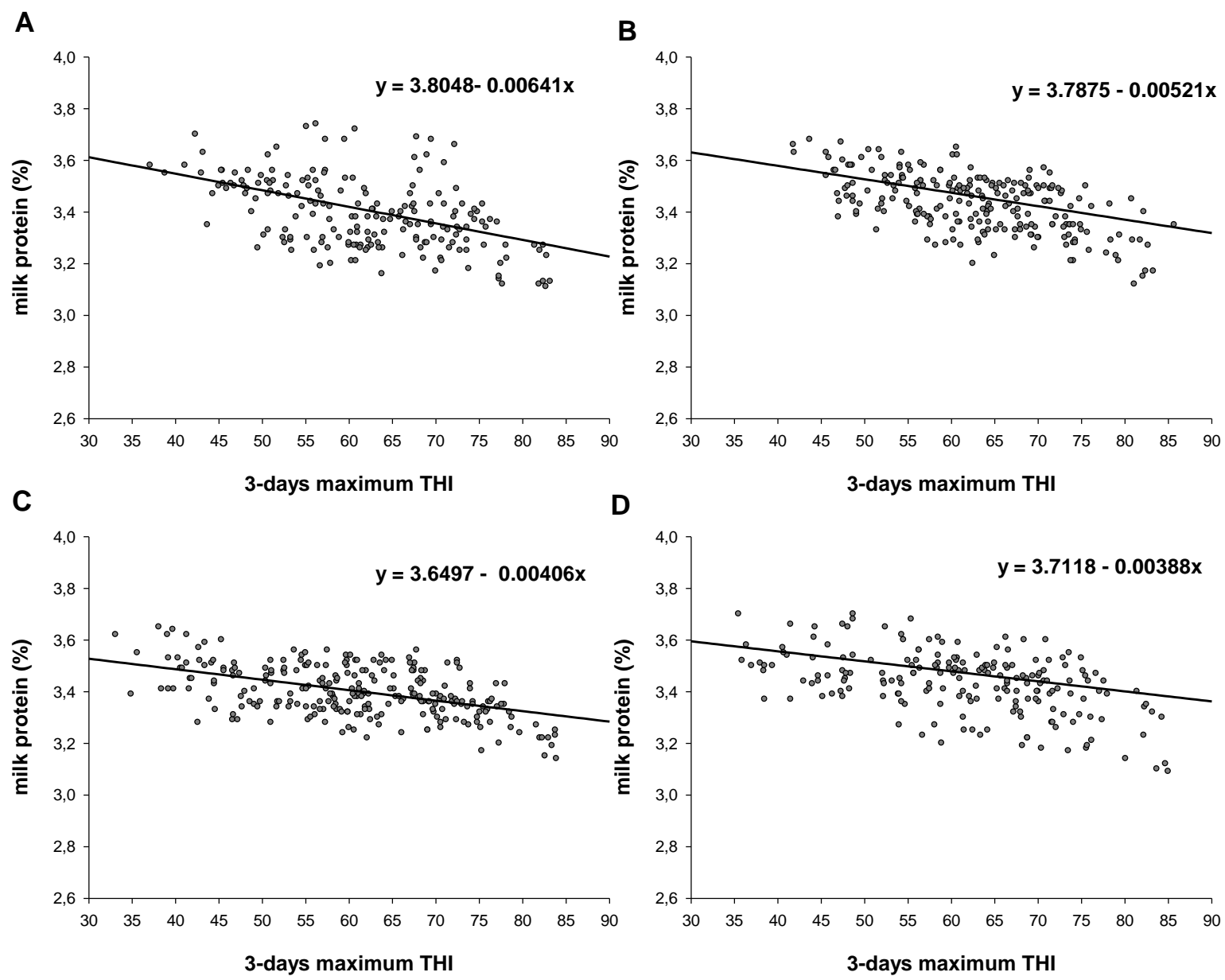

Figure 3. Relationship of 3-days maximum THI to milk protein content for A warm loose-housing system without pasturing $(\mathrm{N}=4), \mathbf{B}$ warm loose-housing system with pasturing $(\mathrm{N}=4), \mathbf{C}$ cold loose-housing system without pasturing $(\mathrm{N}=4)$ and $\mathbf{D}$ cold loose-housing system with pasturing $(\mathrm{N}=4)$.

\section{Bulk milk SCC}

Milk somatic cell count is the most important indicator for inflammation of the udder. 20,000 to 50,000 cells per ml milk are referred as a normal physiological cell content of milk from healthy gland complexes, whereas counts of diseased mammary gland cell complexes range between 100,000 and >10,000,000 cells/ml (KRÖMKER, 2007). In the present study bulk milk SCC ranged from 47,000 to 572,000 cells $/ \mathrm{ml}$ with a mean of $238,607 \pm 82,811$ cells $/ \mathrm{ml}$ across all systems over the study period. The bulk milk SCC was affected by cluster $(P<0.001)$, farm within cluster $(P<0.001)$ and month $(P<0.001)$. OLDE RIEKERINK et al. (2007) summarized that prevalence and incidence of subclinical and clinical mastitis influenced mainly the bulk milk SCC in a herd. Furthermore, it is 
depended on other factors like parity, stage of lactation, management, type of housing, access to pasture, and environmental data such as temperature, humidity and season. In the present study in the indoor systems the bulk milk SCC was significant lower than in the pasture-based systems (WI: 207,340 $\pm 105,793$ cells/ml; CI: 236,400 $\pm 65,379$ cells/ml vs. WP: $256,020 \pm 74,967$ cells $/ \mathrm{ml}$; CP: $254,480 \pm 75,855$ cells $/ \mathrm{ml} ; P<0.001)$. With regard to season a significantly higher bulk milk SCC was present in summer compared to winter $(270,600 \pm 91,600$ vs. $215,400 \pm 74,500$ cells $/ \mathrm{ml} ; P<0.001)$. This is well in agreement with several other investigations (e.g., BOURAOUI et al., 2002; OLDE RIEKERINK et al., 2007). BOURAOUI et al. (2002) described in their study an increase of 450,000 somatic cells from spring to summer. During spring and autumn months the bulk milk SCC was in-between summer and winter months $(230,000 \pm 81,700$ cells/ml vs. $238,100 \pm 73,900$ cells $/ \mathrm{ml})$. Referring to the housing systems a trend of increasing SCC between the hottest and coldest month in the cold loose-housing systems (CI: $260,880 \pm 83,800$ vs. $242,840 \pm 50,600$ cells/ml; CP: $269,150 \pm 47,700$ vs. $229,330 \pm 49,100$ cells $/ \mathrm{ml} ; P>0.05)$ and the warm loose-housing system with pasturing (WP: $279,700 \pm 62,000$ vs. $243,250 \pm 65,200$ cells $/ \mathrm{ml} ; P>0.05)$ was shown. In the indoor warm loose-housing systems bulk milk SCC increased significantly between December and July $(184,060 \pm 89,300$ vs. 279,940 \pm $136,300$ cells/ml; $P<0.001)$. SiMENSEN (1976) related seasonal pattern in SCC not only to environmental conditions, but also to effects of different husbandry systems. His study indicated a seasonal increase in milk SCC by cows kept on pasture, but not in cows in the indoor group. In the present study there was no clear effect of pasture and indoor systems. In all systems an increase was found with the highest increase in the indoor warm loosehousing. In the literature a consistent pattern of increased SCC during heat stress situations is not found. PAAPE et al. (1972) described characteristics of heat stress like enhanced body temperature, decreased milk yield and low circulating leucocytes and erythrocytes, but no rising milk somatic cells during the period of high ambient temperature. 

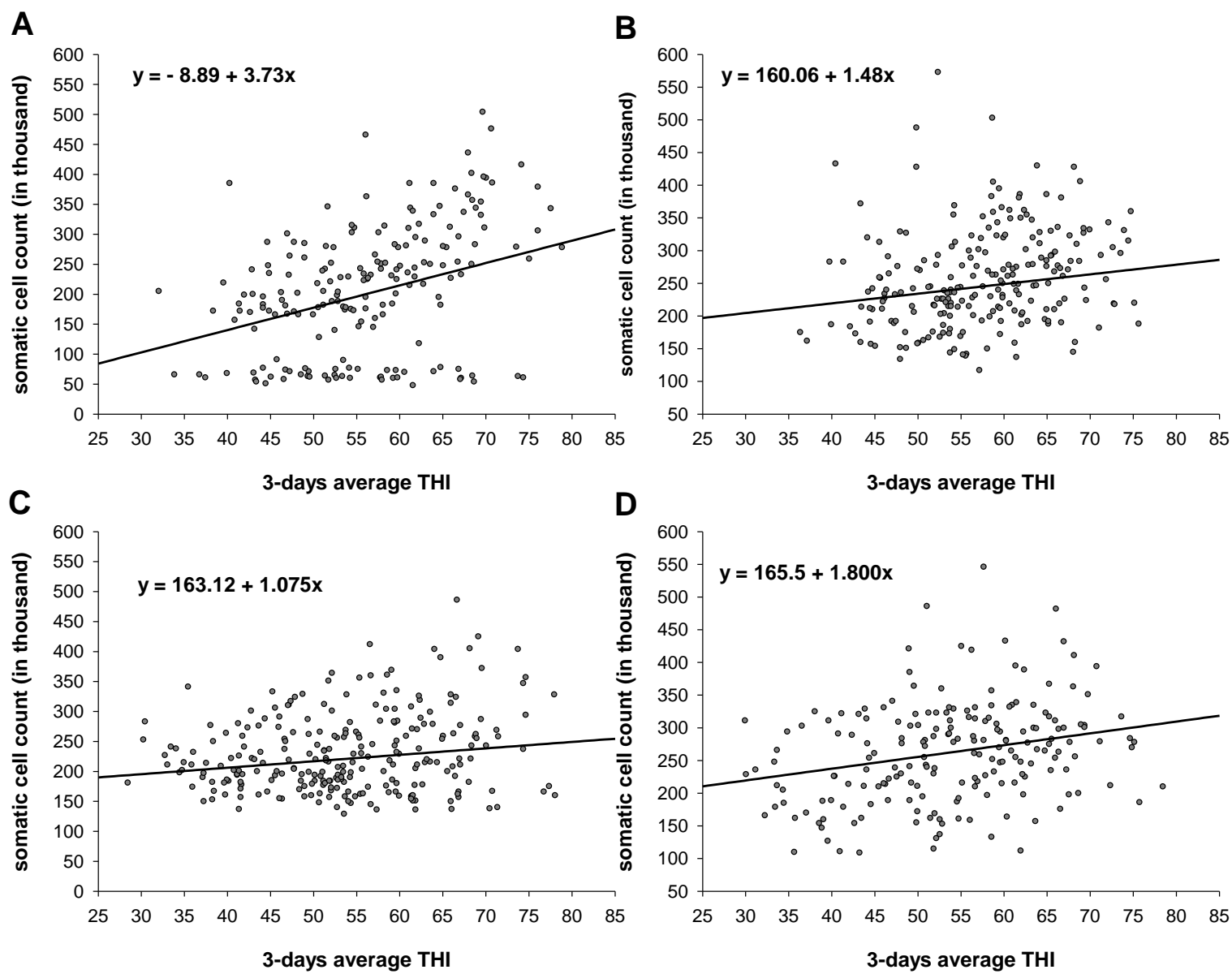

Figure 4. Relationship of 3-days average THI to bulk milk somatic cell count (in thousands) for A warm loose-housing system without access to pasture $(\mathrm{N}=4)$, B warm loose-housing system with access to pasture $(\mathrm{N}=4), \mathbf{C}$ cold loose-housing system without access to pasture $(\mathrm{N}=4)$, and $\mathbf{D}$ cold loose-housing system with access to pasture $(\mathrm{N}=4)$.

3-days average temperature as well as 3-days average THI were the environmental measures correlated with bulk milk SCC $(\mathrm{r}=0.27, P<0.001 ; \mathrm{r}=0.27, P<0.001)$. Therefore, the mean THI values were used to test the regression effect on bulk milk SCC. Figure 4 illustrates negative relationships of 3-days average THI on the SCC for each cluster. The highest increase in bulk milk SCC was found in the warm loose-housing system without access to pasture $(+3,730$ somatic cells $/ \mathrm{ml}$ for each unit rise in 3-days average THI). Within cold loose-housing cluster, bulk milk SCC increased at a higher rate in pasturebased system than in system without access to pasture $(+1,800$ vs. $+1,075$ somatic cells $/ \mathrm{ml}$ for CP and CI, respectively). The regression analysis showed same results as the mixed analyses. 


\section{CONCLUSIONS}

The environmental data of the present study indicated that dairy cows were exposed to heat stress conditions during summer months. Heat stress conditions resulted in significant decreases of bulk milk fat and protein percentages as well as increasing SCC. These effects differed between the analysed husbandry systems. Referring to warm loose-housing systems the highest decreases in bulk milk fat and protein percentages and highest increases in bulk milk SCC was observed with increasing environmental conditions. For pasture-based systems consistent trends were not found.

\section{REFERENCES}

BeEDE D.K. AND R.J. ColliER 1986. Potential nutritional strategies for intensively managed cattle during thermal Stress. J. Anim. Sci. 62: 543-554.

BERMAN A. 2005. Estimates of heat stress relief needs for Holstein dairy cows. J. Anim. Sci. 83: 1377-1384.

Bohmanova J., I. Misztal And J.B. Cole 2007. Temperature-humidity indices as indicators of milk production losses due to heat stress. J. Dairy Sci. 90: 1947-1956.

Bohmanova J., I. Misztal, S. Tsuruta, H.D. Norman and T.J. Lawlor 2008. Short communication: Genotype by environment interaction due to heat stress. J. Dairy Sci. 91:840-846.

Bouraoui R. M. Lahmar, A. Majdoub, M. Djemali And R. Belyea 2002. The relationship of temperature-humidity index with milk production of dairy cows in a Mediterranean climate. Anim. Res. 51: 479-491.

Brown-Brandl L.M., R.A. Eigenberg, J.A. Nienaber and G.L. Hahn 2005. Dynamic response indicators of heat stress in shaded and non-shaded feedlot cattle - Part 1: Analyses of indicators. Biosystems Engineering 90: 451-462.

BRÜGEMANN K., S. KÖNIG AND E. GERnAND 2010. Assessment of heat stress in dairy cows by applying random regression test day models. In Book of abstracts of $61^{\text {st }}$ annual meeting of the European association for animal production, Heraklion, Greece, p.195. Wageningen Academic Publishers, Wageningen, Netherlands.

BRÜGEMANN K., E. GERNAND, U.U. VON BORSTEL AND S. KÖNIG 2011. Genetic analyses of protein yield in dairy cows applying random regression models with time and temperature x humidity dependent covariates. J. Dairy Sci. 94: 4129-4139.

Brügemann K., E. GeRnAND, U. KÖNIG VON Borstel AND S. KÖNIG. 2012. Defining and evaluating heat stress thresholds in different dairy cow production systems. Arch. Tierz. 55: 13-24. 
COlliER R.J., G.E. DAHL AND M.J. VAN BAALE 2006. Major advances associated with environmental effects on dairy cattle. J. Dairy Sci. 89: 1244-1253.

Dohoo I.R. AND A.H. MeEk 1982. Somatic cell counts in bovine milk. Can. Vet. J. 23: 119-125.

FUQUAY J.W. 1981. Heat stress as it affects animal production. J. Anim. Sci. 52: 164-174.

German Federal Statistical OfFICE 2010. Retrieved January 01, 2012, from http://www.destatis.de/jetspeed/portal/cms/Sites/destatis/Internet/DE/Content/Publi kationen/Fachveroeffentlichungen/LandForstwirtschaft/Landwirtschaftzaehlung/Sta llhaltung_Weidehaltung2032806109004,property=file.pdf.

GÜRTLER, H. AND F. J. SchweIGERT 2000. Physiologie der Laktation. In Physiologie der Haustiere (eds W. VON ENGElHARDT AND G. BREVES), 2nd Edition, pp. 552-573. Enke Verlag in MVS Medizinverlage, Stuttgart, Germany.

Hubbard K.G., D.E. Stooksbury, G.L. Hahn And T.L. Mader 1999. A climatologic perspective on feedlot cattle performance and mortality related to the temperaturehumidity index. J. Prod. Agric. 12: 650-653.

Intergovernmental Panel on Climate Change (IPCC) 2007. Climate change 2007: the physical science basis. Contribution of working group I to the fourth assessment report of the Intergovernmental Panel on Climate Change. Cambridge University Press, Cambridge, New York, USA.

JENKInS T.C. AND M.A. MCGuIRE 2006. Major advances in nutrition: Impact on milk composition. J. Dairy Sci. 89: 1302-1310.

JOHNSON H.D. 1987. Bioclimate effects on growth, reproduction and milk production. In Bioclimatology and the Adaptation of Livestock, World Animal Science, B5, Chapter 5 (eds H.D. Johnson), pp. 35-57, Elsevier Science Publishers B.V., Amsterdam, The Netherlands.

Kadzere C.T., M.R. Murphy, N. Silanikove And E. Maltz 2002. Heat stress in lactating dairy cows: a review. Livest. Prod. Sci. 77: 59-91.

KNAPP D.M. AND R. GRUMMER 1991. Response of lactating dairy cows to fat supplementation during heat stress. J. Dairy Sci. 74: 2573-2579.

Krohn C.C., L. MunKSGAARD AND B. JonASEN 1992. Behaviour of dairy cows kept in extensive (loose housing/pasture) or intensive (tie stall) environments I. Experimental procedure, facilities, time budgets - diurnal and seasonal conditions. Appl. Anim. Beh. Sci. 34: 37-47.

KRÖMKER V. 2007. Kurzes Lehrbuch Milchkunde und Milchhygiene. Parey Verlag, Stuttgart.

McDowell R.E., N.W. Hooven AND J.K. Camoens 1976. Effect of climate on performance of holsteins in first lactation. J. Dairy Sci. 59: 965-971.

NARdone A., B. Ronchi, N. LaCETERA, M.S. RanieRI AND U. BeRnabUCCi 2010. Effects of climate changes on animal production and sustainability of livestock systems. Livest. Sci. 130: 57-69. 
NoRman H.D., R.H. MiLleR, J.R. Wright AND G.R. WigGans 2000. Herd and state means for somatic cell count from dairy herd improvement. J. Dairy Sci. 83: 2782-2788.

NATIONAL RESEARCH COUNCIL 1971. A guide to environmental research on animals. NRC, National Academy of Sciences, Washington, DC, USA.

Olde RieKERINK R.G.M., H.W. BARKEMA AND H. StRYhn 2007. The effect of season on somatic cell count and the incidence of clinical mastitis. J. Dairy Sci. 90: 17041715 .

PaApe M.J., W.D. Schultze, R.H. Miller And J.W: Smith 1972. Thermal stress and circulating erythrocytes, leucocytes, and milk somatic cells. J. Dairy Sci. 56: 84-91.

Quist M.A., S.J. LeBlanc, K.J. Hand, D. Lazenby, F. Miglior and D.F. Kelton 2008. Milking-to-Milking variability for milk yield, fat and protein percentage, and somatic cell count. J. Dairy Sci. 91: 3412-3423.

Renaudeau D., A. Collin, S. Yahav, V. De Basilio, J.L Gourdine and R.J. Collier 2012. Adaptation to hot climate and strategies to alleviate heat stress in livestock production. Animal 6: 707-728.

RhoAdes M.L., R.P. RhoAds, M.J. VAnBAale, R.J. Collier, S.R. SANDERS, W.J. Weber, B.A. Crooker AND L.H. BAumgard 2009. Effects of heat stress and plane of nutrition on lactating Holstein cows: I. Production, metabolism, and aspects of circulating somatotropin. J. Dairy Sci. 92: 1986-1997.

Rodriguez L.A., G. Mekonnen, C.J. Wilcox, F.G. Martin and W.A. Krienke 1985. Effects of relative humidity, maximum and minimum temperature, pregnancy, and stage of lactation on milk composition and yield. J. Dairy Sci. 68: 973-978.

SALSBERG E., A.H. MeEK AND S.W.MARTIN 1984. Somatic cell counts: associated factors and relationship to production. Can. J. Comp. Med. 48:251-257.

SAS InSTITUTE INC. 2008. SAS/STAT® 9.2. User’s Guide. Cary, NC, SAS Institute Inc.

SCHNiER C., S. Hielm AND H.S. SAlONIEMI 2003. Comparison of milk production of dairy cows kept in cold and warm loose-housing systems. Prev. Vet. Med. 61: 295-307.

SCHNiER C., S. Hielm AND H.S. SAlONIEMI 2004. Comparison of the breeding performance of cows in cold and warm loose-housing systems. Prev. Vet. Med. 62: 135-151.

Shwartz G., M. L. Rhoads, M. J. VanBaAle, R. P. RhoAds And L. H. Baumgard 2009. Effects of a supplemental yeast culture on heat-stressed lactating Holstein cows. J. Dairy Sci. 92:935-942.

SIMENSEN E. 1976. Milk somatic cells in dairy cows kept on pasture or confined indoors during the summer. Nord. Vet. Med. 28: 603-609.

St-PierRe N.R., B. CobANOV AND G. SchnitKey 2003. Economic losses from heat stress by US livestock industries. J. Dairy Sci. 86(E. Suppl.): E52-E77.

STAPLES C.R. AND W.W. THATChER 2011. Heat stress: effects on milk production and compostion. In Encyclopedia of Dairy Sciences (eds J.W. FUQUAY, P.F. FOX, P.L.H. MCSWEENEY), 2nd Edition, pp. 561-566. Academic Press - Elsevier Science Ltd, Oxford, UK. 
SUTTON J.D. 1989. Altering milk composition by feeding. J. Dairy Sci. 72: 2801-2814.

YOUSEF M.K. 1987. Priniciples of bioclimatology and adaptation. In Bioclimatology and the Adaptation of Livestock, World Animal Science, B5, Chapter 3 (eds H.D. JOHNSON), pp.17-31, Elsevier Science Publishers B.V., Amsterdam, The Netherlands.

WEST J.W. 2003. Effects of heat-stress on production in dairy cattle. J. Dairy Sci. 86: 2131-2144. 


\section{KAPITEL V}

CLIMATIC EFFECTS ON LACTATING HOLSTEIN COWS IN DIFFERENT HUSBANDRY SYSTEMS:

II. INDIVIDUAL MILK YIELD, MILK COMPONENTS AND SOMATIC CELL SCORE 


\begin{abstract}
The objective of this study was to compare the effect of the temperature-humidity index (THI) on milk yield, milk components (milk fat and protein yield) and somatic cell score (SCS) of dairy cows in four different husbandry systems: (1) warm loose-housing with access to pasture (WP); (2) warm loose-housing without access to pasture (WI); (3) cold loose-housing with access to pasture (CP); and (4) cold loose-housing without access to pasture (CI). For each of the four housing systems five farms in Lower Saxony (Germany, Central Europe) were studied. Environmental data (temperature and relative humidity) were recorded hourly by data logger for each barn. THI values (averaged over three days) were calculated. The performance data included 21,546 test-day records for milk, fat and protein yield and SCS. Data were recorded from April 2010 to March 2011 and were analyzed with a mixed model and regression analysis. In each of the housing systems monthly THI values above 60 indicating heat stress were recorded between June and September. Compared to cold loose-housing systems average annual THI values were higher in warm loose-housing systems (WI: $56.3 \pm 0.7$, WP: $56.8 \pm 0.7$ vs. CI: $53.9 \pm 0.7$, CP: $54.7 \pm 0.7 ; P<0.001)$. Averaged over all housing systems, a significant decrease of $0.78 \mathrm{~kg}, 0.04 \mathrm{~kg}$, and $0.03 \mathrm{~kg}$ in milk, fat and protein yield was calculated from the lowest to the highest THI class. For SCS a significant increase of 0.15 from THI class 60-65 to $\geq 65$ was calculated. In pasture-based housing systems the highest milk, fat, and protein yield was observed in THI class 55-65. Above THI values of 65 yields decreased. Regarding SCS, indoor systems had significantly higher values in the THI class $\geq 65$ compared to THI classes $<65$. However, for pasture-based systems high THI values did not affect SCS. The regression analysis was carried out for THI values above 60 and showed similar results of decreasing yields with increasing THI. Regression coefficients of fat corrected milk yield (FCM) on THI were $-0.12 \mathrm{~kg}$ for indoor, $-0.11 \mathrm{~kg}$ for pasture-based warm loose-housing systems, and $-0.21 \mathrm{~kg}$ for indoor and pasture-based cold loosehousing systems. In indoor systems the regression coefficients of SCS on THI were +0.03 for warm loose-housing $(P<0.05)$ and +0.07 for cold loose-housing $(\mathrm{P}<0.001)$. In conclusion, the effect of THI on milk production treatments differed between housing systems.
\end{abstract}




\section{INTERPRETIVE SUMMARY}

Global warming is one of the most important problems impairing livestock production, especially the impact of heat stress on high yielding dairy cows. Although the direct effects of heat stress on milk production are well-known, the effect of the substantially different husbandry systems for dairy cows under conditions of heat stress is widely unknown. Thus, the aim of this study was to assess the impact of heat stress in terms of temperaturehumidity index on milk production (milk, fat and protein yield) and somatic cell score in regard to housing system.

\section{INTRODUCTION}

Predictions of the Intergovernmental Panel on Climate Change (IPCC, 2007) regarding the warming of air temperature range from 1.1 to $2.9^{\circ} \mathrm{C}$ (B1 scenario, low) and 2.4 to $6.4^{\circ} \mathrm{C}$ (A1Fl scenario, high) until the end of the 21 st century. Furthermore, a higher frequency of hot extremes and heat waves is expected. Thus, heat stress impacting dairy production is not only expected in subtropical or tropical regions, but worldwide. Several studies under subtropical and tropical climatic conditions demonstrated the impacts of environmental factors (temperature, relative humidity, solar radiation, and wind) on productivity and efficiency of dairy cows. Dairy cows are able to adapt to climatic conditions. However the thermoregulation mechanisms are limited. Stress is induced when heat production of the animals exceeds heat release (WEST, 2003). Heat stress occurs above the thermal neutral zone with the upper critical temperature for dairy cows ranging between 24 and $27^{\circ} \mathrm{C}$ (FUQUAY, 1981). According to YOUSEF (1987) the critical temperature depends on rate of production, degree of acclimatization, pregnancy status, air movement, and relative humidity. The temperature-humidity index (THI) incorporates effects of ambient temperature as well as relative humidity and is widely used as an indicator of the thermal conditions and the degree of stress in dairy cows (YOUSEF, 1987; HUBBARD et al., 1999). The negative impacts of heat stress on production results in massive economic losses for farmers. ST-PIERRE et al. (2003) calculated an annual economic loss of $\$ 897$ million for the US dairy industry caused by heat stress and mentioned increased mortality and decreased feed intake, growth, milk production and reproduction as the main heat stressrelated problems. SCHNEIDER et al. (1988) and RHOADES et al. (2009) mentioned that heatstressed cows show a lower dry matter intake and a lower milk yield when compared to 
cows in a thermal neutral environment. JOHNSON (1987) reported a milk yield decline of $0.26 \mathrm{~kg}$ per THI unit. In Tunisia a negative correlation of 0.89 between milk yield and THI values three days prior to the measurement were calculated. The authors mentioned a milk decline of $0.41 \mathrm{~kg} / \mathrm{THI}$ above THI values of 69 (BOURAOUI et al., 2002). In Germany BRÜGEMANN et al. (2012) indicated a milk yield decline between $0.08 \mathrm{~kg}$ and $0.26 \mathrm{~kg}$ per THI unit depending on the region.

Beside a decreased feed intake and milk production, the study of BOURAOUI et al. (2002) indicated a significant change of milk composition and somatic cell count (SCC) between spring and summer season (milk fat: 3.58 vs. $3.24 \%$; and milk protein: 2.96 vs. $2.88 \%$ ). The SCC is widely used as an indicator of the udder health, because it indicates subclinical mastitis (DOHOO AND MEEK, 1982). There is a seasonal pattern on the SCC with increasing SCC in summer months (NORMAN et al., 2000; BOURAOUI et al., 2002; OLDE RIEKERINK et al., 2007).

In dairy production different production and husbandry systems are common. According to NARDONE et al. (2010) production systems can be divided into three main categories:

i) grazing or pastoral based systems,

ii) mixed agro-zootechnical or crop-livestock systems, and

iii) industrial or landless systems.

In Central and Eastern Europe mixed livestock systems are dominating, whereas grazing systems are only found in distinct areas. In Lower Saxony one third of the cattle farms keep their cows in tied stables and two thirds in loose-housing systems (GERMAN FEDERAL STATISTICAL OfFICE, 2010), whereas the number of loose-housing systems is increasing (ZÄHNER et al., 2004). Loose housing systems can be further divided according to the climatic conditions inside the barn into: warm and cold loose-housing systems (SCHNIER et al., 2004). In cold loose-housing system micro-climatic conditions in the barn are similar to macro-climatic conditions outside the barn (SCHNIER et al., 2003). The warm loose-housing system is characterized by relatively constant indoor climatic conditions throughout the year (SCHNIER et al., 2004). Thus, housing system has an important impact on climatic conditions in barns. In addition to other factors, e.g. nutrition, health status, parity, stage of lactation and season of calving, the microclimatic conditions affect the performance of animals (ZIEGLER AND WENIGER, 1990; GADER et al., 2007). Depending on environmental conditions dairy cows show different preferences for access to pasture or access to indoor housing (LEGRAND et al., 2009; KROHN et al., 1992). In Lower Saxony 
grazing systems are widely used. About two thirds of 783,000 dairy cows in Lower Saxony were kept on pasture for an average of 24 weeks per year in 2009 (GERMAN FEDERAL STATISTICAL OfFice, 2010).

The extent of heat stress has to be differentiated by production and husbandry systems (NARDONE et al., 2010; SCHNIER et al., 2003). BRÜGEMANN et al. (2012) showed different extents of heat stress on milk production of German Holsteins for three various production regions. Earlier NG-KWAI-HANG et al. (1984) concluded that milk yield and composition is influenced by environmental conditions. Considering rising temperatures and the availability of different housing systems the aim of this study was to evaluate the impact of barn THI on test-day records for production traits (milk, fat and protein yield) and SCS for four different husbandry systems in Lower Saxony, Germany.

\section{MATERIAL AND METHODS}

\section{Animals and housing system}

The study was conducted on 20 dairy farms distributed over Lower Saxony, Germany. Herd sizes varied between 70 and 200 Holstein-Friesian cows. All cows were raised in cubicles in loose-housing systems. Four different housing systems could be differentiated:

(1) warm loose-housing with access to pasture (WP),

(2) warm loose-housing without access to pasture (WI),

(3) cold loose-housing with access to pasture (CP), and

(4) cold loose-housing without access to pasture (CI).

In the two pasturing systems cows had access to pasture during day time or day and night from May to October. Five farms belonged to each of the four different housing systems. Warm and cold loose-housing systems differed by construction of the roofs with warm loose-housing systems having isolated roofs. The data set included a total of 21,546 testday records for milk yield, fat and protein percentage, and somatic cell count (SCC). According to the husbandry systems the data set comprised 5,070 test-day records from WI, 4,106 from WP, 6,824 from CI and 5,546 from CP. Milk yield and milk fat percentage was used to calculate fat-corrected milk (FCM, 4\%). Fat and protein yield were calculated from milk yield and fat and protein percentage. SCC was used to calculate somatic cell score (SCS) with SCS $=\log 2(\mathrm{SCC} / 100,000)+3$. The upper and lower one percent of the FCM, fat and protein yield, and SCS values were deleted. Lactation was divided into three 
stages: early (0-100 DIM; 7,689 test-day records), mid (101-200 DIM; 7,276 test-day records), and late (201-305 DIM; 6,580 test-day records); and parity into 3 classes: first lactation, second lactation, and $\geq 3$ lactations. Season of calving were defined as follows: spring (March to May), summer (June to August), autumn (September to November), and winter (December to February).

\section{Environmental data}

For the above mentioned period (April 2010 to March 2011) air temperature and relative humidity were recorded every 15 minutes by data logger (Tinytag Plus 2, TGP-4500, Gemini Data Loggers, England). In each farm four loggers were installed with two placed in the lying and two in the feeding area at a height of $3 \mathrm{~m}$ from the slatted floor. The THI for every barn was calculated using hourly averages of the four data logger as follows:

$$
\mathrm{THI}=(1.8 * \mathrm{~T}+32)-(0.55-0.0055 * \mathrm{RH}) *(1.8 * \mathrm{~T}-26),
$$

where $\mathrm{T}$ is the air temperature in ${ }^{\circ} \mathrm{C}$ and $\mathrm{RH}$ is the relative humidity in \% (NRC, 1971). For the statistical analysis the average and maximum THI of three days preceding the test day were used (BRÜGEMANN et al., 2011; BohmANOVA et al., 2008). For the following calculations the 3-days average THI was divided into six groups: <45, 45-50, 50-55, 55-60, 60-65, and $\geq 65$, whereas 3,344 test-day records belonged to the first class, 3,828 to the second, 4,954 to the third, 3,950 to the fourth, 2,881 to the fifth and 2,589 to the class $\geq 65$.

\section{Statistical models}

Data were analyzed with the statistical package SAS 9.2 (SAS InSTITUTE INC., 2008).

Environmental data were analyzed with the following mixed model:

$$
Y_{i j k l}=\mu+C_{i}+C_{i}\left(F_{j}\right)+M_{k}+e_{i j k l}
$$

$\mathrm{Y}_{\mathrm{ijkl}} \quad=$ observed value for barn THI;

$\mu \quad=$ mean effect;

$\mathrm{C}_{\mathrm{i}} \quad=$ fixed effect of the housing cluster ( $\left.\mathrm{i}=\mathrm{WP}, \mathrm{WI}, \mathrm{CP}, \mathrm{CI}\right)$;

$\mathrm{C}_{\mathrm{i}}\left(\mathrm{F}_{\mathrm{j}}\right)=$ fixed effect of the farm within the housing cluster $(\mathrm{j}=1$ to 20$)$;

$\mathrm{M}_{\mathrm{k}} \quad=$ fixed effect of month $(\mathrm{k}=$ April to March);

$\mathrm{e}_{\mathrm{ijkl}}=$ random error. 
The significance of the fixed effects was analyzed by using the Tukey test with a significance level of $P<0.05$.

In order to compare FCM, milk fat and protein yield, or SCS, respectively the following mixed model was used:

$$
\begin{aligned}
& \mathrm{Y}_{\mathrm{ijklmnop}}=\mu+\mathrm{SL}_{\mathrm{i}}+\mathrm{PA}_{\mathrm{j}}+\mathrm{SC}_{\mathrm{k}}+\mathrm{C}_{\mathrm{l}}+\mathrm{C}_{\mathrm{l}}\left(\mathrm{F}_{\mathrm{m}}\right)+\mathrm{cTHI}_{\mathrm{n}}+\mathrm{F}_{\mathrm{m}}\left(\mathrm{COW}_{\mathrm{o}}\right)+\mathrm{e}_{\mathrm{ijklmnop}} \\
& \mathrm{Y}_{\mathrm{ijklmnop}}=\text { observed value for FCM, milk fat and protein yield, or SCS; } \\
& \mu \quad=\text { mean effect; } \\
& \mathrm{SL}_{\mathrm{i}} \quad=\text { fixed effect of the stage of lactation ( } \mathrm{i}=\text { early, mid, late); } \\
& \mathrm{PA}_{\mathrm{j}} \quad=\text { fixed effect of the parity }(\mathrm{j}=\text { first, second, and } \geq 3 \text { lactations }) ; \\
& \mathrm{SC}_{\mathrm{k}} \quad=\text { fixed effect of season of calving ( } \mathrm{k}=\text { spring, summer, autumn, winter); } \\
& \left.\mathrm{C}_{1} \quad=\text { fixed effect of the housing cluster ( }=\mathrm{WP}, \mathrm{WI}, \mathrm{CP}, \mathrm{CI}\right) \text {; } \\
& \left.\mathrm{C}_{1}\left(\mathrm{~F}_{\mathrm{m}}\right) \quad=\text { fixed effect of the farm within the housing cluster ( } \mathrm{m}=1 \text { to } 20\right) \text {; } \\
& \text { cTHI }_{n} \quad=\text { fixed effect of the THI classes }(n=<45 ; 45-50 ; 50-55 ; 55-60 ; 60-65 ;>65) \text {; } \\
& \mathrm{F}_{\mathrm{m}}\left(\mathrm{COW}_{\mathrm{o}}\right)=\text { repeated effect of the cow within farm; } \\
& \text { e } \mathrm{e}_{\mathrm{ijklmnop}}=\text { random error. }
\end{aligned}
$$

The significance of the fixed effects was analyzed by using the Tukey test with a significance level of $P<0.05$.

To determine the effect of interactions between THI classes and clusters on FCM, milk fat and protein yield, or SCS, respectively, the following mixed model was used:

$$
\begin{aligned}
& \mathbf{Y}_{\mathrm{ijklmnop}}=\mu+\mathrm{SL}_{\mathrm{i}}+\mathrm{PA}_{\mathrm{j}}+\mathrm{SC}_{\mathrm{k}}+\mathrm{C}_{\mathrm{l}}+\mathrm{C}_{\mathbf{l}}\left(\mathrm{F}_{\mathrm{m}}\right)+(\mathrm{C} \times \mathrm{c} \text { THI })_{\mathrm{ln}}+\mathrm{F}_{\mathrm{m}}\left(\mathrm{COW}_{\mathrm{o}}\right)+\mathrm{e}_{\mathrm{ijklmnop}} \\
& \mathrm{Y}_{\mathrm{ijklmnop}} \quad=\text { observed value for FCM, milk fat and protein yield, or SCS; } \\
& \mu \quad=\text { mean effect; } \\
& \mathrm{SL}_{\mathrm{i}} \quad=\text { fixed effect of the stage of lactation ( } \mathrm{i}=\text { early, mid, late); } \\
& \mathrm{PA}_{\mathrm{j}} \quad=\text { fixed effect of the parity }(\mathrm{j}=\text { first, second, and } \geq 3 \text { lactations }) ; \\
& \left.\mathrm{SC}_{\mathrm{k}} \quad=\text { fixed effect of season of calving ( } \mathrm{k}=\text { spring, summer, autumn, winter }\right) \text {; } \\
& \mathrm{C}_{1} \quad=\text { fixed effect of the housing cluster }(1=\mathrm{WP}, \mathrm{WI}, \mathrm{CP}, \mathrm{CI}) \text {; } \\
& \mathrm{C}_{1}\left(\mathrm{~F}_{\mathrm{m}}\right) \quad=\text { fixed effect of the farm within the housing cluster ( } \mathrm{m}=1 \text { to } 20 \text { ); }
\end{aligned}
$$


$(\mathrm{C} x \mathrm{cTHI})_{\mathrm{ln}} \quad=$ fixed effect of interactions between the housing clusters and the THI classes $(\mathrm{n}=\langle 45 ; 45-50 ; 50-55 ; 55-60 ; 60-65 ;>65)$;

$\mathrm{F}_{\mathrm{m}}\left(\mathrm{COW}_{\mathrm{o}}\right) \quad=$ repeated effect of the cow within farm;

e $\quad=$ random error.

The significance of the fixed effects was analyzed by using the Tukey test with a significance level of $P<0.05$.

The relationship between climatic values (3-days average and 3-days maximum THI) and milk parameters (FCM, milk fat and protein yield, and SCS) were analysed with Pearson's correlation. Due to the fact that FCM, milk fat and protein yield, and SCS were higher correlated to the 3-day average THI (FCM: $r=-0.07$, milk fat yield: $r=-0.10$, milk protein yield: $\mathrm{r}=-0.08$, SCS: $\mathrm{r}=0.06 ; P<0.001)$ than to the 3 -days maximum THI. Therefore, the 3-days average THI were used to test regression effects of THI on milk parameters.

Regression coefficients for housing systems were estimated for:

i) 3-days average THI on milk yield (FCM),

ii) 3-days average THI and stage of lactation on milk yield (FCM),

iii) 3-days average THI on milk components (milk fat and protein yield),

iv) 3-days average THI and stage of lactation on milk components (milk fat and protein yield),

v) 3-days average THI on SCS, and

vi) 3-days average THI and stage of lactation on SCS.

Season of calving and farm as fixed factor and cow within farm as random factor were included into the models.

\section{RESULTS AND DISCUSSION}

\section{Environmental conditions}

Average annual THI values of the warm loose-housing systems were significantly higher when compared to the cold loose-housing systems $(\mathrm{LSM} \pm \mathrm{SE}$; WI: $56.3 \pm 0.7$, WP: $56.8 \pm$ 0.7 vs. CI: $53.9 \pm 0.7, \mathrm{CP}: 54.7 \pm 0.7 ; P<0.001)$. JOHNSON (1987) indicated the threshold of 72 as the upper critical THI for lactating cows associated with decreasing milk yields. Other studies defined a THI threshold of 60 as the upper critical THI for lactating cows 
associated with decreasing milk and protein yields with regard to different production systems in Lower Saxony (BRÜGEMANN et al., 2010; 2012). In the present study monthly averages exceeded the threshold of 60 from June to September (Figure 1) and maximum THI values exceeded 72 from April to September in indoor housing systems and from April to October in pasture-based housing systems. These values indicated heat stress conditions during the summer months in the present study. Throughout the experimental period July was the month with the highest mean as well as maximum THI values in the barn. Pasture-based systems had lower mean and maximum THI than the indoor systems. Previously a lower heat production in the barn during the grazing time was assumed, because metabolic heat of cows is not released into the barn. In a Danish study, dairy cows could choose between access to pasture and indoor housing. During the summer cows spent more time on pasture and stayed indoor only for $28 \%$ of the day (KROHN et al., 1992).

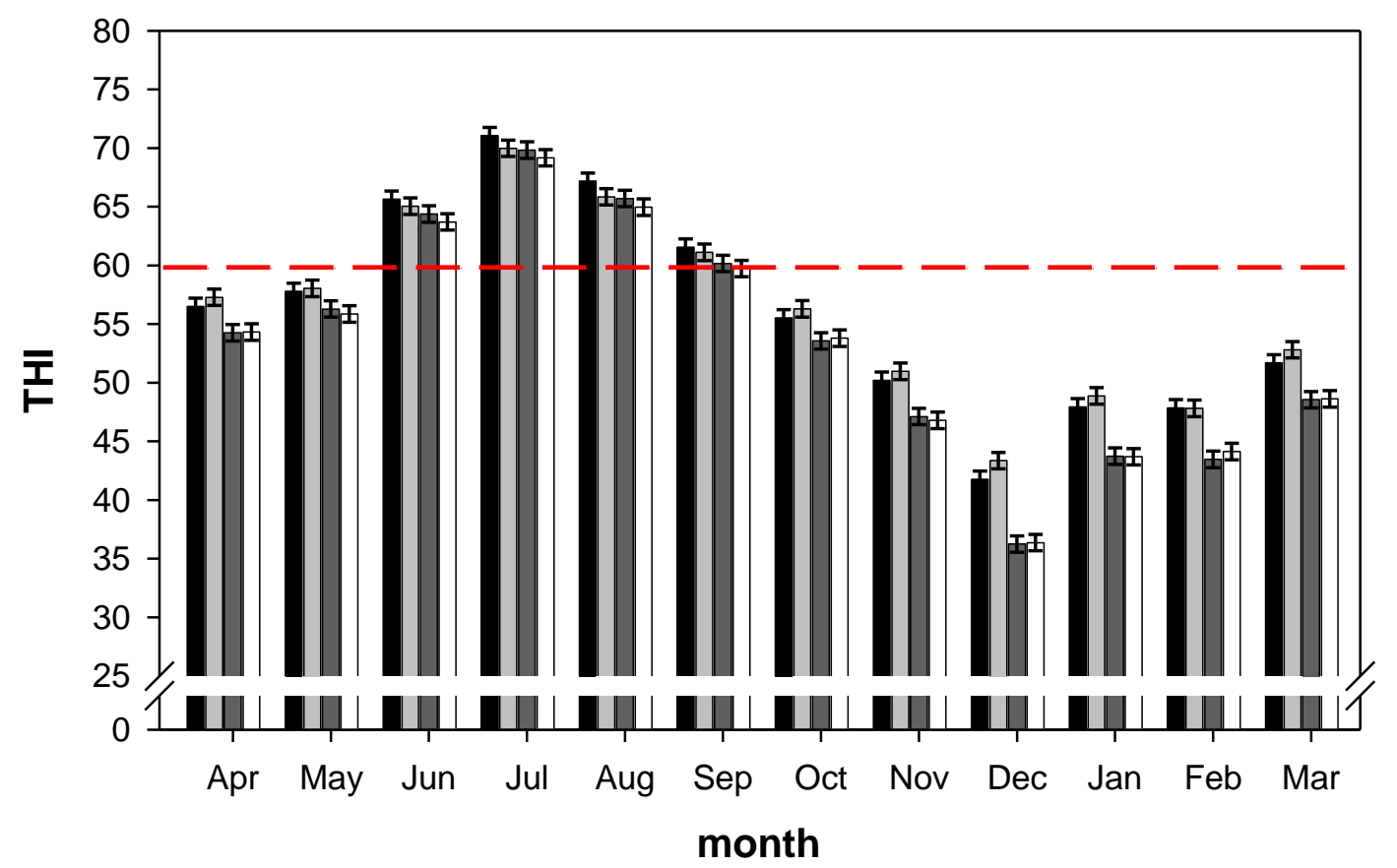

Figure 1. Least square means ( \pm standard errors) for barn temperature-humidity index (THI) in warm loose-housing system without pasturing (black column), warm loose-housing system with pasturing (light grey column), cold loose-housing system without pasturing (dark grey column) and cold loose-housing system with pasturing (white column) from April 2010 to March 2011 (dashed line: heat stress threshold by BRÜGEMANN et al., 2010). 
According to housing system the mean THI of warm loose-housing systems were higher than of cold loose-housing systems. Indicated by SCHNIER et al. (2003) warm loosehousing systems are characterised by relatively constant climatic conditions due to its construction (e.g., isolation, airflow, natural ventilation). Compared to cold loose-housing systems insulated construction of warm loose-housing systems prevents a rapid heating. Therefore, warm loose-housing systems are characterized by lower maximum temperatures. Otherwise isolation inhibits a rapid cooling. Generally, it takes longer until barn temperature decreases in indoor than in outdoor systems. On 187 and 180 days in warm loose-housing systems with and without pasturing and on 169 and 175 in cold loosehousing systems with and without pasturing, respectively, hourly THI values above 60 were observed. From June to September this threshold was exceeded nearly every day. The accordant number of days with daily maximum THI exceeding 70 was 66 and 74 in warm loose-housing systems with and without pasturing and 68 and 70 in cold loose-housing systems with and without pasturing, respectively. In July the highest number of days with daily maximum THI values above 70 were recorded (WP: 26 days; WI: 28 days; CP: 25 days; CI: 26 days). In the present study average THI for three days preceding the test day was used, because it was widely shown that climatic conditions during three days preceding the day of measurement were higher correlated with milk yield and composition than the values of the same day or of one and two days prior to the measurement (WEST, 1999; BOURAOUI et al., 2002).

\section{Effects on milk production and milk composition}

FCM, fat and protein yield, and SCS were affected by stage of lactation $(P<0.001)$, parity $(P<0.001)$, season of calving $(P<0.001)$, housing cluster $(P<0.001)$, farm within cluster $(P<0.001)$, and THI class $(P<0.001)$. Averaged over the four housing systems, a significant decrease of $0.78 \mathrm{~kg}, 0.04 \mathrm{~kg}$ and $0.03 \mathrm{~kg}$ in milk, milk fat, and milk protein yield was calculated from the lowest to the highest THI class. SCS increased by 0.15 from THI class 60-65 to THI class $\geq 65(P<0.05)$ over all systems. Different thresholds indicating heat stress conditions of lactating cows were proposed mostly under hot humid conditions. JOHNSON (1987) calculated a threshold of 72, whereas BRÜGEMANN et al. (2010) specified a threshold of 60 under Central European conditions. Considering the latter threshold cows were exposed to heat stress in the present study during summer months. The decrease in FCM, fat and protein yield under heat stress conditions is well in agreement with previous reports (BOURAOUI et al., 2002; QUIST et al., 2008). 
The FCM ranged between 13.4 and $56.0 \mathrm{~kg}$ with a mean $( \pm \mathrm{SD})$ of $32.1 \pm 8.3 \mathrm{~kg}$ across all systems over the whole study period. In indoor systems FCM was significantly higher than in pasture-based systems (WI: $32.5 \pm 0.10 \mathrm{~kg}$; CI: $32.4 \pm 0.08 \mathrm{~kg}$ vs. WP: $30.0 \pm 0.10 \mathrm{~kg}$; CP: $31.9 \pm 0.09 ; P<0.001)$. Indoor systems provide the possibility for a balanced and performance-adapted feeding ration. For pasture-based systems this is difficult due to the unpredictable feed intake on pasture. Nevertheless, a study on preferences for pasture versus free-stall housing indicated that cows with access to pasture spent one hour per day less time feeding TMR and thereby the dry matter intake decreased by $2.9 \mathrm{~kg} / \mathrm{d}$ (LEGRAND et al., 2009).

Environmental factors such as temperature, relative humidity, solar radiation, and air flow and their interactions often limit the performance of dairy cows (WEST, 2003). BOURAOUI et al. (2002) reported in their study a heat stress decline of $-4.58 \mathrm{~kg}$ FCM from the spring period (THI 68) to the summer period (THI 78) for mid-lactating Holstein cows in a Mediterranean climate. In the present study cows in warm loose-housing systems did not show significantly negative effects of increasing THI on FCM throughout the whole study period (Table 1). In each system daily milk production increased from the low THI class $(\leq 45)$ to the mid THI classes.

Table 1. Least square means (standard error) of $4 \%$ fat-corrected milk for temperature-humidity index (THI) classes in four different housing systems from April 2010 to March 2011.

\begin{tabular}{lcccc}
\hline \multirow{2}{*}{ THI classes } & $\begin{array}{c}\text { warm loose- } \\
\text { housing without } \\
\text { pasturing (N=5) }\end{array}$ & $\begin{array}{c}\text { warm loose- } \\
\text { housing with } \\
\text { pasturing (N=5) }\end{array}$ & $\begin{array}{c}\text { cold loose- } \\
\text { housing without } \\
\text { pasturing (N=5) }\end{array}$ & $\begin{array}{c}\text { cold loose- } \\
\text { housing with } \\
\text { pasturing (N=5) }\end{array}$ \\
\hline$\leq 45$ & $31.4(0.3)^{\mathrm{a}}$ & $29.5(0.4)^{\mathrm{a}}$ & $32.3(0.2)^{\mathrm{ab}}$ & $32.1(0.2)^{\mathrm{ab}}$ \\
$45-50$ & $32.2(0.2)^{\mathrm{ab}}$ & $29.4(0.3)^{\mathrm{a}}$ & $32.3(0.2)^{\mathrm{ab}}$ & $31.8(0.2)^{\mathrm{ab}}$ \\
$50-55$ & $32.5(0.2)^{\mathrm{ab}}$ & $30.2(0.2)^{\mathrm{a}}$ & $32.5(0.2)^{\mathrm{ab}}$ & $32.7(0.2)^{\mathrm{b}}$ \\
$55-60$ & $32.0(0.2)^{\mathrm{ab}}$ & $29.8(0.2)^{\mathrm{a}}$ & $32.9(0.2)^{\mathrm{a}}$ & $32.0(0.2)^{\mathrm{ab}}$ \\
$60-65$ & $33.7(0.2)^{\mathrm{c}}$ & $30.8(0.3)^{\mathrm{a}}$ & $32.4(0.2)^{\mathrm{ab}}$ & $31.4(0.2)^{\mathrm{ca}}$ \\
$\geq 65$ & $32.8(0.2)^{\mathrm{bc}}$ & $29.9(0.2)^{\mathrm{a}}$ & $31.6(0.2)^{\mathrm{b}}$ & $30.5(0.3)^{\mathrm{c}}$ \\
\hline
\end{tabular}

Least squares means within the same column with the same letter are not significantly different $(P>0.05)$; $\mathrm{N}=$ number of farms within cluster.

In the warm loose-housing systems with access to pasture an insignificant decline of $0.9 \mathrm{~kg}$ from THI class $60-65$ to $\geq 65$ was calculated. An according decline of $0.85 \mathrm{~kg}$ was recorded in indoor warm loose-housing systems. Cows in cold loose-housing systems showed a considerable decrease in milk production with increasing THI. Without access to pasture 
the highest FCM was found for THI values between 55 and 60 and the lowest FCM above values of 65 . A significant difference of $1.3 \mathrm{~kg}$ between these two classes $(P<0.05)$ was recorded. With pasturing there were significant decreases of $1.6,1.3,2.2$ and $1.5 \mathrm{~kg}$ between the THI classes $\leq 45,45$ - 50, 50 - 55, and 55 - 60 and the highest THI class $(\geq 65$; $P<0.01)$. This milk yield decrease may be explained by a lower dry matter intake and a lower efficiency of conversion of feed into milk (kg FCM per kg DMI) for heat-stressed cows as reported by BouraOUI et al. (2002). A study in Scandinavia compared milk production in cold and warm loose-housing systems (SCHNIER et al., 2003).

In agreement to the present study the authors indicated a lower milk production in the cold loose-housing system. However, this effect was not statistically significant. The authors concluded that for Ayrshire and Black and White cows, the micro-climatic conditions in combination with farm management allows milk production in a cold loose-housing to equal production in a warm loose-housing. According to the environmental data of the present study the system with the lower average THI values showed the highest milk yield declines. Thus, it should be considered that not only the temperature and relative humidity affect the level of heat stress effects, but also wind movement and solar radiation (RENAUdEAU et al., 2012). Otherwise, cold loose-housing systems showed the highest maximum temperatures.

In the present study, the milk fat yield showed a mean \pm SD of $1.28 \pm 0.34 \mathrm{~kg}$ and ranged from 0.54 to $2.38 \mathrm{~kg} /$ day across all systems and over the whole study period. Herds in warm loose-housing systems without access to pasture produced significantly lower fat yields than in the other loose-housing systems (WP: $1.20 \pm 0.004 \mathrm{~kg}$ vs. WI: $1.30 \pm 0.004$ $\mathrm{kg}$; CI: $1.27 \pm 0.003 \mathrm{~kg}$; CP: $1.27 \pm 0.004 ; P<0.001)$. Between the two cold loose-housing systems no significant differences were found $(P<0.05)$.

A study of heat stress under Mediterranean climatic conditions indicated a decline of milk fat percentage by $0.34 \%$ from spring to summer (BOURAOUI et al., 2002). In agreement other studies in heat-stressed environments associated heat stress with declines in milk fat percentages (RODRIGUEZ et al., 1985). In contrast, KNAPP AND GRUMMER (1991) found no significant depressions in milk fat percentages for heat-stressed cows. The analysis of the climatic effects on milk fat yield showed similar results as mentioned above for FCM. Accordingly no significant effects of THI classes on the milk fat yield were recorded in pasture-based warm loose-housing systems (Table 2). Cows kept in indoor warm loosehousing systems had the highest fat yields in the THI class from 60 to $65(P<0.05)$. In 
comparison a significant decrease of $0.05 \mathrm{~kg}(P<0.05)$ was found in the THI class $\geq 65$. Cows in cold loose-housing systems showed significant declines in milk fat yields between

Table 2. Least square means (standard error) of milk fat yield $(\mathrm{kg} / \mathrm{d})$ for temperature-humidity index (THI) classes in four different housing systems from April 2010 to March 2011.

\begin{tabular}{lcccc}
\hline \multirow{2}{*}{ THI classes } & $\begin{array}{c}\text { warm loose- } \\
\text { housing without } \\
\text { pasturing (N=5) }\end{array}$ & $\begin{array}{c}\text { warm loose- } \\
\text { housing with } \\
\text { pasturing (N=5) }\end{array}$ & $\begin{array}{c}\text { cold loose- } \\
\text { housing without } \\
\text { pasturing (N=5) }\end{array}$ & $\begin{array}{c}\text { cold loose- } \\
\text { housing with } \\
\text { pasturing (N=5) }\end{array}$ \\
\hline$\leq 45$ & $1.27(0.01)^{\mathrm{a}}$ & $1.19(0.01)^{\mathrm{a}}$ & $1.29(0.01)^{\mathrm{a}}$ & $1.29(0.01)^{\mathrm{ab}}$ \\
$45-50$ & $1.30(0.01)^{\mathrm{ab}}$ & $1.19(0.01)^{\mathrm{a}}$ & $1.28(0.01)^{\mathrm{a}}$ & $1.29(0.01)^{\mathrm{ab}}$ \\
$50-55$ & $1.30(0.01)^{\mathrm{a}}$ & $1.22(0.01)^{\mathrm{a}}$ & $1.28(0.01)^{\mathrm{a}}$ & $1.31(0.01)^{\mathrm{a}}$ \\
$55-60$ & $1.28(0.01)^{\mathrm{a}}$ & $1.18(0.01)^{\mathrm{a}}$ & $1.30(0.01)^{\mathrm{a}}$ & $1.27(0.01)^{\mathrm{bd}}$ \\
$60-65$ & $1.35(0.01)^{\mathrm{b}}$ & $1.23(0.01)^{\mathrm{a}}$ & $1.26(0.01)^{\mathrm{ab}}$ & $1.24(0.01)^{\mathrm{cd}}$ \\
$\geq 65$ & $1.30(0.01)^{\mathrm{a}}$ & $1.18(0.01)^{\mathrm{a}}$ & $1.23(0.01)^{\mathrm{b}}$ & $1.20(0.01)^{\mathrm{c}}$ \\
\hline
\end{tabular}

Least squares means on the same column with the same letter are not significantly different $(P>0.05) ; \mathrm{N}=$ number of farms within cluster.

the lowest and highest THI classes $(P<0.05)$. In the indoor system the highest milk fat yield was found in the THI class from 55 to 60 . In comparison to the highest THI class a significant decrease of $0.07 \mathrm{~kg}(P<0.05)$ was found. In the cold loose-housing system with access to pasture the highest milk fat yields were recorded in THI class 55 to 60 and the lowest for $\mathrm{THI} \geq 65$. Between these THI classes milk fat yield decreased significantly by $0.11 \mathrm{~kg}(P<0.01)$. The cold loose-housing system exhibited higher maximum temperatures than the warm loose-housing system, which may explain the higher decrease in this system. The different assumptions regarding the pasturing systems may be explained by the behaviour of the cows. Under environmental conditions of heat stress cows in the pasturing systems were able to choose whether to stay indoor or to graze on pasture. Furthermore the barn provided shade, a widely used management technique to reduce heat stress (BROWN-BRANDL et al., 2005). Otherwise, in the warm loose-housing with pasturing more dairy cows could be on the pasture in the summer months (KROHN et al., 1992), because insulated barns cooled more slowly than open barns. Alike relations between feeding and milk components are well-known. Milk components can be altered through the frequency of feeding and changes in the diet. The fat percentage is very sensitive to these changes (JENKINS AND MCGuiRE, 2006; SuTTON, 1989). The farms of the present study did not change their diets during the study period. Therefore an effect on fat percentage by feed ration is not expected. Dry matter intake decreases as a consequence of heat stress (COLlier et al., 2006; BouraOu et al., 2002). This could have affected the milk fat content. Lower feed intake, selective consumption of concentrates and minimal intake of 
forages predisposes cows to ruminal acidosis and lower milk fat content (STAPLES AND THATCHER, 2011; COLLIER et al., 2006).

The milk protein yield ranged from 0.46 to $1.76 \mathrm{~kg}$ with a mean $\pm \mathrm{SD}$ of $1.09 \pm 0.26 \mathrm{~kg}$ across all systems over the study period. Herds in cold loose-housing systems without pasturing produced significantly higher protein yields and herds in warm loose-housing systems significantly lower protein yields than herds in other systems (CI: $1.12 \pm 0.003 \mathrm{~kg}$; WP: $1.02 \pm 0.003 \mathrm{~kg} ; P<0.001)$. No THI effects on milk protein yield were shown in indoor warm loose-housing system (Table 3). In pasture-based warm loose-housing system and cold loose-housing system with and without pasturing the lowest milk protein yields were found in the THI class above 65 . Cows in pasture-based warm loose-housing systems and cows in indoor cold loose-housing systems showed the similar decline of $0.04 \mathrm{~kg}$ from THI class 60-65 to THI class above 65 , whereas the decline in warm loose-housing was not significant. In pasture-based cold loose-housing system the highest milk protein yield was measured for THI values between 50 and 60. A decrease of $0.07 \mathrm{~kg}(P<0.001)$ was recorded from THI class 55 - 60 to THI class $\geq 65$.

Table 3. Least square means (standard error) of milk protein yield $(\mathrm{kg} / \mathrm{d})$ for temperature-humidity index (THI) classes in four different housing systems from April 2010 to March 2011.

\begin{tabular}{lcccc}
\hline \multirow{2}{*}{ THI classes } & $\begin{array}{c}\text { warm loose- } \\
\text { housing without } \\
\text { pasturing (N=5) }\end{array}$ & $\begin{array}{c}\text { warm loose- } \\
\text { housing with } \\
\text { pasturing (N=5) }\end{array}$ & $\begin{array}{c}\text { cold loose- } \\
\text { housing without } \\
\text { pasturing (N=5) }\end{array}$ & $\begin{array}{c}\text { cold loose- } \\
\text { housing with } \\
\text { pasturing (N=5) }\end{array}$ \\
\hline$\leq 45$ & $1.07(0.01)^{\mathrm{ab}}$ & $1.01(0.01)^{\mathrm{ab}}$ & $1.12(0.01)^{\mathrm{a}}$ & $1.10(0.01)^{\mathrm{a}}$ \\
$45-50$ & $1.08(0.01)^{\mathrm{ab}}$ & $1.03(0.01)^{\mathrm{ab}}$ & $1.11(0.01)^{\mathrm{a}}$ & $1.08(0.01)^{\mathrm{a}}$ \\
$50-55$ & $1.10(0.01)^{\mathrm{ab}}$ & $1.03(0.01)^{\mathrm{ab}}$ & $1.11(0.01)^{\mathrm{a}}$ & $1.10(0.01)^{\mathrm{a}}$ \\
$55-60$ & $1.07(0.01)^{\mathrm{a}}$ & $1.02(0.01)^{\mathrm{ab}}$ & $1.13(0.01)^{\mathrm{a}}$ & $1.10(0.01)^{\mathrm{a}}$ \\
$60-65$ & $1.10(0.01)^{\mathrm{b}}$ & $1.05(0.01)^{\mathrm{a}}$ & $1.13(0.01)^{\mathrm{a}}$ & $1.07(0.01)^{\mathrm{ab}}$ \\
$\geq 65$ & $1.10(0.01)^{\mathrm{ab}}$ & $1.01(0.01)^{\mathrm{b}}$ & $1.09(0.01)^{\mathrm{a}}$ & $1.03(0.01)^{\mathrm{b}}$ \\
\hline
\end{tabular}

Least squares means on the same column with the same letter are not significantly different $(P>0.05) ; \mathrm{N}=$ number of farm within cluster.

The results in the present study are well in agreement with those reported by BOURAOUI $e t$ al. (2002), RHOADES et al. (2009) and SHWARTZ et al. (2009), which indicated a decreased milk protein percentage under summer heat stress conditions. RODRIGUEZ et al. (1985) and KNAPP AND GRUMMER (1991) suggested that with increasing maximum daily temperatures the milk protein content decreases. Pasture-based systems indicated a higher decrease in milk protein yield than in indoor systems. As mentioned for FCM, the husbandry system has an impact on dry matter intake (LEGRAND et al., 2009). Pasture-based cows have a 
lower TMR intake. Generally heat stress decreases in milk protein were related to lowered microbial protein synthesis in the rumen and lowered protein and feed intake (STAPLES AND THATCHER, 2011).

The SCC ranged from 11,000 to $3,444,000$ with a mean of $210,252 \pm 389,689$. The SCS ranged from -0.18 to 8.1 with a mean of $2.92 \pm 1.67$ across all systems throughout the study period. The highest SCS were measured in herds of pasture-based warm loosehousing systems and the lowest SCS in herds of indoor warm loose-housing systems (WP: $3.08 \pm 0.03 ; \mathrm{WI}: 2.70 \pm 0.02 ; P<0.001)$. The analysis of the climatic effects on SCS showed no significant heat stress effects in the pasture-based housing systems (Table 4). In the indoor system cows had significantly higher SCS when THI values were above 65 . The lowest SCS was recorded in THI class $50-55$ and increased significantly by 0.33 to the highest THI class $(P<0.01)$ in the warm loose-housing system. In the cold loose-housing system the lowest SCS was recorded in THI class 60-65 and increased significantly by 0.32 to the highest THI class $(P<0.05)$. BouRAOUI et al. (2002) indicated negative effects of heat stress on SCC with significantly increasing SCC from spring to summer.

Table 4. Least square means (standard error) of somatic cell score for temperature-humidity index (THI) classes in four different housing systems from April 2010 to March 2011.

\begin{tabular}{lcccc}
\hline \multirow{2}{*}{ THI classes } & $\begin{array}{c}\text { warm loose- } \\
\text { housing without } \\
\text { pasturing(N=5) }\end{array}$ & $\begin{array}{c}\text { warm loose- } \\
\text { housing with } \\
\text { pasturing(N=5) }\end{array}$ & $\begin{array}{c}\text { cold loose- } \\
\text { housing without } \\
\text { pasturing(N=5) }\end{array}$ & $\begin{array}{c}\text { cold loose- } \\
\text { housing with } \\
\text { pasturing (N=5) }\end{array}$ \\
\hline$\leq 45$ & $2.70(0.06)^{\mathrm{ab}}$ & $3.25(0.09)^{\mathrm{a}}$ & $2.95(0.04)^{\mathrm{ab}}$ & $2.82(0.05)^{\mathrm{a}}$ \\
$45-50$ & $2.73(0.05)^{\mathrm{ab}}$ & $2.91(0.08)^{\mathrm{a}}$ & $2.94(0.04)^{\mathrm{ab}}$ & $2.89(0.05)^{\mathrm{a}}$ \\
$50-55$ & $2.59(0.05)^{\mathrm{b}}$ & $3.15(0.05)^{\mathrm{a}}$ & $2.84(0.04)^{\mathrm{ab}}$ & $2.88(0.05)^{\mathrm{a}}$ \\
$55-60$ & $2.67(0.05)^{\mathrm{ab}}$ & $3.11(0.06)^{\mathrm{a}}$ & $2.99(0.05)^{\mathrm{ab}}$ & $2.94(0.04)^{\mathrm{a}}$ \\
$60-65$ & $2.63(0.05)^{\mathrm{ab}}$ & $3.04(0.06)^{\mathrm{a}}$ & $2.71(0.06)^{\mathrm{a}}$ & $2.91(0.06)^{\mathrm{a}}$ \\
$\geq 65$ & $2.92(0.06)^{\mathrm{a}}$ & $2.99(0.06)^{\mathrm{a}}$ & $3.03(0.06)^{\mathrm{b}}$ & $2.94(0.08)^{\mathrm{a}}$ \\
\hline
\end{tabular}

Least squares means on the same column with the same letter are not significantly different $(P>0.05) ; \mathrm{N}=$ number of farm within cluster.

The results in the present study are opposed to those reported by SIMENSEN (1976). The author indicated a seasonal increase in SCC by cows kept on pasture, whereas no increase of SCC was recorded by indoor housing group. In agreement to these results, GOLDBERG et al. (1992) found in bulk milk of pasture-based dairy cows lower SCC than in milk of indoor kept dairy cows. Generally, the SCC is mainly influenced by prevalence and incidence of subclinical and clinical mastitis (DOHOO AND MEEK, 1982). 


\section{Relationship between THI and milk production}

The above mentioned analysis showed increases in milk, fat and protein yield and decreases in SCS from the lowest to the mid THI classes. From the mid THI classes to the highest THI classes in general, a significant decrease in milk, milk fat and protein was measured. Studies of BRÜGEMANN et al. indicated a THI of 60 as an upper critical THI for lactating cows associated with decreasing milk yields (2012) and protein yields (2010) in different production systems in Central Europe. Therefore, another approach was tested: different linear regressions between 3-days average THI and the tested parameters in four husbandry systems. This analysis was only done for THI values above 60 according to the threshold found by BRÜGEMANN et al. (2010, 2012). Over the whole lactation the regression coefficients of FCM on 3-days average THI values were $-0.21 \mathrm{~kg}$ for the cold loose-housing system and $-0.12 \mathrm{~kg}$ and $-0.11 \mathrm{~kg}$ for the indoor warm loose-housing system and pasture-based systems, respectively. The present results are comparable to the regression coefficients of BRÜGEMANN et al. (2012). The authors found milk declines per THI unit from $0.08 \mathrm{~kg}$ for regions with indoor systems (crop production regions) to $0.17 \mathrm{~kg}$ for pasture-based systems. THI formula and regions are comparable.

An important factor influencing the effects of heat stress on milk production is the stage of lactation. In Table 5 different linear regressions between 3-days average THI values and the tested parameters at different stages of lactations in the four husbandry systems are shown. Results of IGONO et al. (1992) and NOVAK et al. (2009) showed a higher decrease in the early lactation. NOVAK et al. (2009) mentioned that cows in early lactation are more sensitive to effects of heat than cows in late lactation. Alike, NARDONE et al. (2010) mentioned that mid-lactating dairy cows showed the highest milk losses. Compared to these results the highest decreases were indicated in the late lactation (201 to 305 DIM). Between the indoor systems higher regression coefficients were found in the warm loosehousing system, whereas the FCM significantly declined by $0.18 \mathrm{~kg}$ per cow per day in the late stage of lactation. Between pasture-based systems cold louse-housing system showed the highest regression coefficients. There was a significant decrease of $0.15 \mathrm{~kg}$ and $0.2 \mathrm{~kg}$ per cow per day in the mid and late stage of lactation.

Milk fat decreased by $-0.008 \mathrm{~kg} / \mathrm{THI}(P<0.01)$ in indoor, $-0.004 \mathrm{~kg} / \mathrm{THI}(P<0.01)$ and pasture-based warm loose-housing systems, and by $-0.007 \mathrm{~kg} / \mathrm{THI}(P<0.05)$ and -0.009 $\mathrm{kg} / \mathrm{THI}(P<0.01)$ in indoor and pasture-based cold loose-housing systems. In regard to the 
stage of lactation similar regression coefficients were indicated. Compared to FCM results the highest milk fat declines were indicated by late-lactating dairy cows.

Table 5. Linear Regression coefficients between THI (THI above 60) and milk production (FCM $\mathrm{kg} /$ day), milk components (milk fat and protein yield ( $\mathrm{kg} / \mathrm{day}$ )), and somatic cell score (SCS) at different stages of lactation (early: 0-100 DIM; mid: 101-200 DIM; late 201-305 DIM) in four loose-housing systems $(\mathrm{n}=5,470)$ from April 2010 to March 2011.

\begin{tabular}{|c|c|c|c|c|}
\hline & \multicolumn{4}{|c|}{ Cluster } \\
\hline & $\begin{array}{c}\text { warm loose- } \\
\text { housing without } \\
\text { pasturing }(\mathrm{N}=5)\end{array}$ & $\begin{array}{c}\text { warm loose- } \\
\text { housing with } \\
\text { pasturing }(N=5)\end{array}$ & $\begin{array}{c}\text { cold loose- } \\
\text { housing without } \\
\text { pasturing }(\mathrm{N}=5)\end{array}$ & $\begin{array}{c}\text { cold loose- } \\
\text { housing with } \\
\text { pasturing }(\mathrm{N}=5)\end{array}$ \\
\hline \multicolumn{5}{|l|}{ FCM $(4 \%, \mathrm{~kg})$} \\
\hline Intercept (SE) & $36.6(4.0)$ & $36.9(2.2)$ & $38.0(4.5)$ & $43.5(4.8)$ \\
\hline Early (SE) & $-0.042(0.06)$ & $+0.000(0.03)$ & $-0.004(0.07)$ & $-0.093(0.08)$ \\
\hline Mid (SE) & $-0.105(0.06)$ & $-0.072(0.03)^{*}$ & $-0.071(0.07)$ & $-0.149(0.07)^{*}$ \\
\hline Late (SE) & $-0.179(0.06)^{*}$ & $-0.123(0.03)^{*}$ & $-0.129(0.07)$ & $-0.197(0.07)^{*}$ \\
\hline \multicolumn{5}{|l|}{ Milk fat (kg) } \\
\hline Intercept (SE) & $1.69(0.2)$ & $1.40(0.1)$ & $1.49(0.2)$ & $1.78(0.2)$ \\
\hline Early (SE) & $-0.005(0.003) *$ & $+0.000(0.001)$ & $-0.000(0.003)$ & $-0.005(0.003)$ \\
\hline Mid (SE) & $-0.008(0.003) *$ & $-0.003(0.001)^{*}$ & $-0.003(0.003)$ & $-0.007(0.003) *$ \\
\hline Late (SE) & $-0.010(0.003) *$ & $-0.005(0.001)^{*}$ & $-0.005(0.003)$ & $-0.009(0.003)^{*}$ \\
\hline \multicolumn{5}{|c|}{ Milk protein (kg) } \\
\hline Intercept (SE) & $1.04(0.1)$ & $1.59(0.1)$ & $1.18(0.2)$ & $1.50(0.2)$ \\
\hline Early (SE) & $+0.000(0.002)$ & $-0.005(0.001)^{*}$ & $+0.001(0.002)$ & $-0.004(0.002)$ \\
\hline Mid (SE) & $-0.001(0.002)$ & $-0.006(0.001)^{*}$ & $-0.001(0.002)$ & $-0.005(0.002)$ \\
\hline Late (SE) & $-0.003(0.002)$ & $-0.008(0.001)^{*}$ & $-0.002(0.002)$ & $-0.006(0.002)^{*}$ \\
\hline \multicolumn{5}{|l|}{ SCS } \\
\hline Intercept (SE) & $1.74(0.9)$ & $3.56(0.6)$ & $-0.93(1.1)$ & $2.54(1.2)$ \\
\hline Early (SE) & $+0.027(0.01)^{*}$ & $-0.002(0.01)$ & $+0.051(0.02)^{*}$ & $+0.002(0.02)$ \\
\hline $\operatorname{Mid}(\mathrm{SE})$ & $+0.029(0.01)^{*}$ & $+0.003(0.01)$ & $+0.060(0.02)^{*}$ & $+0.006(0.02)$ \\
\hline Late (SE) & $+0.034(0.01)^{*}$ & $+0.007(0.01)$ & $+0.062(0.02)^{*}$ & $+0.017(0.02)$ \\
\hline
\end{tabular}

The highest declines of milk protein were calculated for dairy cows in pasture-based systems. Accordingly a decrease of $-0.007 \mathrm{~kg}$ per cow and THI $(P<0.001)$ was recorded for warm loose-housing system and a decline of $-0.006 \mathrm{~kg}$ per cow and THI $(P<0.05)$ for cold loose-housing system. In indoor systems decreases of $-0.001 \mathrm{~kg} / \mathrm{THI}$ (WI; $P>0.05$ ) and $-0.004 \mathrm{~kg} / \mathrm{THI}(\mathrm{CI} ; P<0.01)$ were indicated, respectively. In warm loose-housing system with pasturing a significant decline of $0.005 \mathrm{~kg}, 0.006 \mathrm{~kg}$ and $0.008 \mathrm{~kg}$ per cow and day in the early, mid and late stage of lactation was found, respectively.

These results are comparable to the results between 3-days average THI and SCS. The highest increases were found in the indoor systems. The regression coefficients were +0.03 SCS/THI $(P<0.05)$ for warm loose-housing and +0.07 SCS/THI $(P<0.001)$ for cold loosehousing systems, respectively. In cold loose-housing system the SCS increased by 0.05 , 
0.06 and 0.06 per cow and per day in the early, mid, and late stage of lactation and in the warm loose-housing system by 0.03 per cow and per day in each stage of lactation.

\section{CONCLUSIONS}

The present study demonstrated the effects of heat stress on production and udder health parameters in different housing and production systems. For the milk production the highest decreases were observed in cold loose-housing systems with increasing THI. The highest declines in milk protein were observed in pasture-based systems. For SCS the highest increases were found at highest THI values in the systems without access to pasture. Based on these results no system could be indicated to prevent heat stress effects over all. However, the most important parameter for an economic dairy production is milk yield. Consequently cold loose-housing system should be preferred towards warm loosehousing system.

\section{REFERENCES}

Bohmanova J., I. Misztal, S. Tsuruta, H.D. Norman and T.J. Lawlor 2008. Short communication: Genotype by environment interaction due to heat stress. J. Dairy Sci. 91:840-846.

Bouraoui R., M. Lahmar, A. Majdoub, M. Djemali And R. Belyea 2002. The relationship of temperature-humidity index with milk production of dairy cows in a Mediterranean climate. Anim. Res. 51: 479-491.

Brown-Brandl L.M., R.A. Eigenberg, J.A. Nienaber and G.L. Hahn 2005. Dynamic response indicators of heat stress in shaded and non-shaded feedlot cattle - Part 1: Analyses of indicators. Biosystems Engineering 90: 451-462.

BRÜGEMANN K., S. KÖNIG AND E. GERNAND 2010. Assessment of heat stress in dairy cows by applying random regression test day models. In Book of abstracts of $61^{\text {st }}$ annual meeting of the European association for animal production, Heraklion, Greece, p.195. Wageningen Academic Publishers, Wageningen, Netherlands.

BRÜGEMANN K., E. GERNAND, U.U. VON BORSTEL AND S. KÖNIG 2011. Genetic analyses of protein yield in dairy cows applying random regression models with time and temperature x humidity dependent covariates. J. Dairy Sci. 94: 4129-4139.

BRÜGEMANN K., E. GERnAND, U. KÖNIG VON BORSTEL AND S. KÖNIG 2012. Defining and evaluating heat stress thresholds in different dairy cow production systems. Arch. Tierz. 55: 13-24.

COLliER R.J., G.E. DAHL AND M.J. VAN BAALE 2006. Major advances associated with environmental effects on dairy cattle. J. Dairy Sci. 89: 1244-1253. 
Dohoo I.R. AND A.H. MeEK 1982. Somatic cell counts in bovine milk. Can. Vet. J. 23: 119-125.

FUQUAY J.W. 1981. Heat stress as it affects animal production. J. Anim. Sci. 52: 164-174.

Gader A.Z.A., M.K.A. Ahmed, L.M.A. Musa And K.J. Peters 2007. Milk yield and reproductive performance of Friesian cows under Sudan tropical conditions. Arch. Tierz. 50: 155-64.

German Federal Statistical OfFice. 2010. Retrieved January 01, 2012, from http://www.destatis.de/jetspeed/portal/cms/Sites/destatis/Internet/DE/Content/Publi kationen/Fachveroeffentlichungen/LandForstwirtschaft/Landwirtschaftzaehlung/Sta llhaltung__Weidehaltung2032806109004,property=file.pdf

Goldberg J.J., E.E. Wildman, J.W Pankey, J.R. Kunkel, D.B. Howard and B.M. MURPHY 1992. The influence of intensively managed rotational grazing, traditional continuous grazing, and confinement housing on bulk milk quality and udder health. J. Dairy Sci.75: 96-104.

Hubbard K.G., D.E. Stooksbury, G.L. Hahn And T.L. Mader 1999. A climatologic perspective on feedlot cattle performance and mortality related to the temperaturehumidity index. J. Prod. Agric. 12: 650-653.

IgOno M.O., G. BJotvedT AND H.T. SANFORD-Crane 1992. Environmental profile and critical temperature effects on milk production of Holstein cows in desert climate. Int. J. Biometeorol. 36: 77-87.

InTERgovernmental PANel on Climate Change (IPCC) 2007. Climate change 2007: the physical science basis. Contribution of working group I to the fourth assessment report of the Intergovernmental Panel on Climate Change. Cambridge University Press, Cambridge, New York, USA.

JENKINS, T.C. AND M.A. McGuiRE 2006. Major advances in nutrition: Impact on milk composition. J. Dairy Sci. 89: 1302-1310.

JOHNSON H.D. 1987. Bioclimate effects on growth, reproduction and milk production. In Bioclimatology and the Adaptation of Livestock, World Animal Science, B5, Chapter 5 (eds H.D. Johnson), pp. 35-57, Elsevier Science Publishers B.V., Amsterdam, The Netherlands.

KNAPP D.M. AND R. GRUMMER 1991. Response of Lactating Dairy Cows to Fat Supplementation During Heat Stress. J. Dairy Sci. 74: 2573-2579.

KROHN C.C., L. MunKSGAARD AND B. JonASEN 1992. Behaviour of dairy cows kept in extensive (loose housing/pasture) or intensive (tie stall) environments I. Experimental procedure, facilities, time budgets - diurnal and seasonal conditions. Appl. Anim. Beh. Sci. 34: 37-47.

LEGRAND A.L., M.A.G. von KeYSERLINGK AND D.M. WeARY 2009. Preference and usage of pasture versus free-stall housing by lactating dairy cattle. J. Dairy Sci. 92: 36513658. 
NARdone A., B. Ronchi, N. LACETERA, M.S. RANIERI AND U. BERnABUCCI 2010. Effects of climate changes on animal production and sustainability of livestock systems. Livest. Sci. 130: 57-69.

NATIONAL RESEARCH COUNCIL 1971. A guide to environmental research on animals. NRC, National Academy of Sciences, Washington, DC, USA.

NG-Kwai-Hang K.F., J.F. Hayes, J.E. Moxley And H.G. Monardes 1984. Variability of test-day milk production and composition and relations of somatic cell counts with yield and compositional changes of bovine milk. J. Dairy Sci. 67: 361-366.

NoRman H.D., R.H. MiLleR, J.R. Wright AND G.R. WigGans 2000. Herd and state means for somatic cell count from dairy herd improvement. J. Dairy Sci. 83: 2782-2788.

Novak P., J. Vokralova AND J. BROUCEK 2009. Effects of the stage and number of lactation on milk yield of dairy cows kept in open barn during high temperatures in summer months. Arch. Tierz. 52: 574-586.

Olde RiEKERINK R.G.M., H.W. BARKEMA AND H. STRYHn 2007. The Effect of Season on Somatic Cell Count and the Incidence of Clinical Mastitis. J. Dairy Sci. 90: 17041715 .

Quist M.A., S.J. LeBlanc, K.J. Hand, D. LaZenby, F. Miglior and D.F. Kelton 2008. Milking-to-Milking variability for milk yield, fat and protein percentage, and somatic cell count. J. Dairy Sci. 91: 3412-3423.

Renaudeau D., A. Collin, S. Yahav, V. De Basilio, J.L. Gourdine and R.J. Collier 2012. Adaptation to hot climate and strategies to alleviate heat stress in livestock production. Animal 6: 707-728.

RhoAdes M.L., R.P. RhoAds, M.J. VanBaAle, R.J. Collier, S.R. SANDERs, W.J. Weber, B.A. CROOKER AND L.H. BAUMGard 2009. Effects of heat stress and plane of nutrition on lactating Holstein cows: I. Production, metabolism, and aspects of circulating somatotropin. J. Dairy Sci. 92: 1986-1997.

Rodriguez L.A., G. Mekonnen, C.J. Wilcox, F.G. Martin and W.A. Krienke 1985. Effects of Relative Humidity, Maximum and Minimum Temperature, Pregnancy, and Stage of Lactation on Milk Composition and Yield. J. Dairy Sci. 68: 973-978.

SAS InSTITUTE InC. 2008. SAS/STAT® 9.2. User's Guide. Cary, NC, SAS Institute Inc.

SCHNEIDER P.L., D.K. BEEDE AND C.J. WILCOX 1988. Nycterohemeral patterns of acid-base status, mineral concentrations and digestive function of lactating cows in natural or chamber heat stress environments. J. Anim. Sci. 66: 112-125.

SCHNiER C., S. Hielm AND H.S. SAlONIEMI 2003. Comparison of milk production of dairy cows kept in cold and warm loose-housing systems. Prev. Vet. Med 61: 295-307.

SChNiER C., S. Hielm AND H.S. SAlONIEMI 2004. Comparison of the breeding performance of cows in cold and warm loose-housing systems. Prev. Vet. Med. 62: 135-151.

Shwartz G., M. L. Rhoads, M. J. VanBaAle, R. P. RhoAds And L. H. Baumgard 2009. Effects of a supplemental yeast culture on heat-stressed lactating Holstein cows. J. Dairy Sci. 92:935-942. 
SIMENSEN E. 1976. Milk somatic cells in dairy cows kept on pasture or confined indoors during the summer. Nord. Vet. Med. 28: 603-609.

St-Pierre N.R., B. Cobanov AND G. SchnitKey 2003. Economic losses from heat stress by US livestock industries. J. Dairy Sci. 86(E. Suppl.): E52-E77.

STAPLES C.R. AND W.W. THATCHER 2011. Heat stress: effects on milk production and compostion. In Encyclopedia of Dairy Sciences (eds J.W. FuQUAY, P.F. FoX, P.L.H. McSweEneY), 2nd Edition, pp. 561-566. Academic Press - Elsevier Science Ltd, Oxford, UK.

SUTTON J.D. 1989. Altering milk composition by feeding. J. Dairy Sci. 72: 2801-2814.

YOUSEF M.K. 1987. Priniciples of bioclimatology and adaptation. In Bioclimatology and the Adaptation of Livestock, World Animal Science, B5, Chapter 3 (eds H.D. JoHnson), pp.17-31, Elsevier Science Publishers B.V., Amsterdam, The Netherlands.

WEST J.W. 1999. Nutritional strategies for managing the heat-stressed dairy cows. J. Animal Sci. 14: 350-362.

WEST J.W. 2003. Effects of heat-stress on production in dairy cattle. J. Dairy Sci. 86: 2131-2144.

ZÄHNER M., L. Schrader, R. HAuser, W. LANGHANS, M. KeCK AND B. WeChSLER 2004. The influence of climatic conditions on physiological and behavioural parameters in dairy cows kept in open stables. Anim. Sci. 78: 139-47.

ZIEGLER H. AND WENIGER J.H. 1990. Leistungen, Thermoregulation und Energiehaushalt von Kühen der Rasse Deutsche Schwarzbunte unter Wärmebelastung. Züchtungskunde 62: 254-64. 
KAPITEL VI

ALLGEMEINE DISKUSSION 
Die in dieser Arbeit durchgeführten Analysen dienen der Darstellung von Hitzestressauswirkungen auf ausgewählte Parameter der Gesundheit und Leistung anhand des Temperatur-Humiditäts Indexes. In der folgenden Diskussion werden zunächst auf die unterschiedliche Verfahren zur Beurteilung von Klimaverhältnissen und auf das Klima in Niedersachsen eingegangen. Anschließend wird auf die untersuchten Leistungsparameter (4\%-fettkorrierte Milch, Milchfett und -protein) und ausgewählte Gesundheitsparameter (Mastitishäufigkeit, somatischer Zellgehalt bzw. Zellscore) eingegangen, um abschließend Schlussfolgerungen zu ziehen. Hierbei soll insbesondere auf die Eignung der einzelnen Haltungssysteme zur Reduzierung bzw. Milderung von Hitzestress induzierenden klimatischen Bedingungen eingegangen werden.

\subsection{THI-Formel und Schwellenwerte}

Temperatur und relative Luftfeuchtigkeit sind die Stallklimaparameter, welche am häufigsten gemessen werden und am einfachsten zu erfassen sind und anhand derer die klimatischen Bedingungen in einem Milchviehstall charakterisiert werden können (UNRATH, 2004). Hierbei sollte beachtet werden, dass die Umgebungstemperatur alleine keine repräsentative Maßeinheit ist, um die Produktionsumwelt von Milchkühen zu beschreiben. Neben der Temperatur sollten relative Luftfeuchtigkeit, Sonneneinstrahlung und Windgeschwindigkeit einbezogen werden. In den letzten Jahrzehnten wurden verschiedene Indices (vgl. Kapitel II Tabelle 3) entwickelt, anhand derer die Wechselwirkung zwischen dem Tier und der Umwelt beschrieben werden kann. Für die Definitionen der verschiedenen Indizes wurden unterschiedliche Kombinationen von meteorologischen Messwerten genutzt. $\mathrm{Zu}$ den Messwerten gehörten unter anderem die Temperatur, relative Luftfeuchtigkeit, Sonneneinstrahlung und Windgeschwindigkeit (Bohmanova et al., 2007; RenAudeau et al., 2012). Neben den unterschiedlichen Formeln zur THI Berechnung werden in der Literatur zusätzlich verschiedene THI Schwellenwerte beschrieben, ab denen mit Leistungseinbussen zu rechnen ist (WALTER UND LÖPMEIER, 2010). Für die vorliegenden Untersuchungen wurden insbesondere die Studien von BRÜGEMANN et al. (2010, 2011, und 2012) für die Auswahl der THI-Formel und der Schwellenwerte herangezogen. Für die Untersuchungen wurde die Formel von NRC (1971) genutzt, da diese Formel zum einen insbesondere in europäischen Regionen für Hitzestressuntersuchungen verwendet wurde (u.a. SPERONI et al., 2006; NOVAK et al., 2009; BRÜGEMANN et al., 2010) und zum anderen haben BRÜGEMANN et al. (2010) 
festgestellt, dass die THI Werte des NRC (1971) besser geeignet sind als die von RAVAGNOLO UND MiszTAL (2000), um die Umgebungsbedingungen in der untersuchten Region Niedersachsen zu beschreiben.

Wie bereits erwähnt gibt es neben den unterschiedlichen THI Formeln mehrere Schwellenwerte, die in der Forschung und Praxis zur Identifizierung von Hitzestresssituationen genutzt werden. Die Zusammenstellung von WALTER UND LÖPMEIER (2010) zeigt eindeutig, dass viele Schwellenwerte um den THI 70 liegen, wobei die Untersuchungen zur Ermittlung dieser Schwellenwerte nicht in klimatisch vergleichbaren Regionen durchgeführt wurden. Deshalb wurde in den vorliegenden Studien untersucht, ob Leistungsdepressionen und Auswirkungen auf die Gesundheit von Milchkühen ebenfalls bei einem Schwellenwert von 60 festgestellt werden können. Dieser spezifische Schwellenwert wurde von BRÜGEMANN et al. (2011, 2012) anhand von Leistungsminderungen in der Proteinmenge und der Milchleistung unter mitteleuropäischen Bedienungen ermittelt.

\subsection{Klimatische Werte in Deutschland}

Grundlage dieser Arbeit waren die Auswirkungen von Hitzestress auf das Leistungsvermögen und die Gesundheit von Milchkühen. Daher wird zunächst auf die Klimaverhältnisse in Deutschland eingegangen, um Rückschlüsse ziehen zu können, inwieweit mit Hitzestressauswirkungen in Deutschland zu rechnen ist. Den Ergebnissen der Modellierung von dem Intergovernmental Panel of Climate Change (IPCC, 2007) zufolge steigt global die Wahrscheinlichkeit von Hitzeereignissen, wobei sie in ihrer Anzahl wie Intensität zunehmen werden. Generell wird ein Anstieg der globalen mittleren Temperatur zwischen $1.8^{\circ} \mathrm{C}$ und $4.0^{\circ} \mathrm{C}$ (je nach Szenario) bis 2100 erwartet.

In Niedersachsen wird unter anderem mit einem Anstieg der Jahresmitteltemperatur bis 2100 von $2,5^{\circ} \mathrm{C}$ bis $3,5^{\circ} \mathrm{C}$ im Vergleich zu dem Zeitraum 1961-1990 gerechnet, wobei diese Anstiege regional als auch saisonal variieren und um $\geq 4^{\circ} \mathrm{C}$ ansteigen können. Des Weiteren wird mit einem in der Niederschlagsmenge etwa gleich bleibenden und jahreszeitlich verschobenen Jahresniederschlag (Sommer: Abnahme um bis zu 30\%; Winter: Zunahme um 10-30\%), einer Zunahme der Anzahl von Winterstürmen und Extremwetterereignisse (z.B. Starkregen, Stürme, Hitzewellen und Dürren) und einen Anstieg der Schneefallgrenze und des Meeresspiegels gerechnet (FRANCK UND Peithmann, 2010). 
In der vorliegenden Arbeit wurde der Temperatur-Humiditäts Index (THI) genutzt, um die thermische Umgebung von Milchkühen zu beschreiben und die Zusammenhänge zwischen der Leistung und des Stallklimas zu ermitteln. Deshalb wird in diesem Abschnitt nachfolgend nicht auf die Temperatur, sondern auf den THI eingegangen. Anhand der Abbildung 1 wird deutlich, dass sich die Außenklima THI-Werte von dem Versuchszeitraum 2010/2011 von den CLINO Referenzwerten (1961 - 1990; DWD, 2012b) von Niedersachsen unterscheiden.

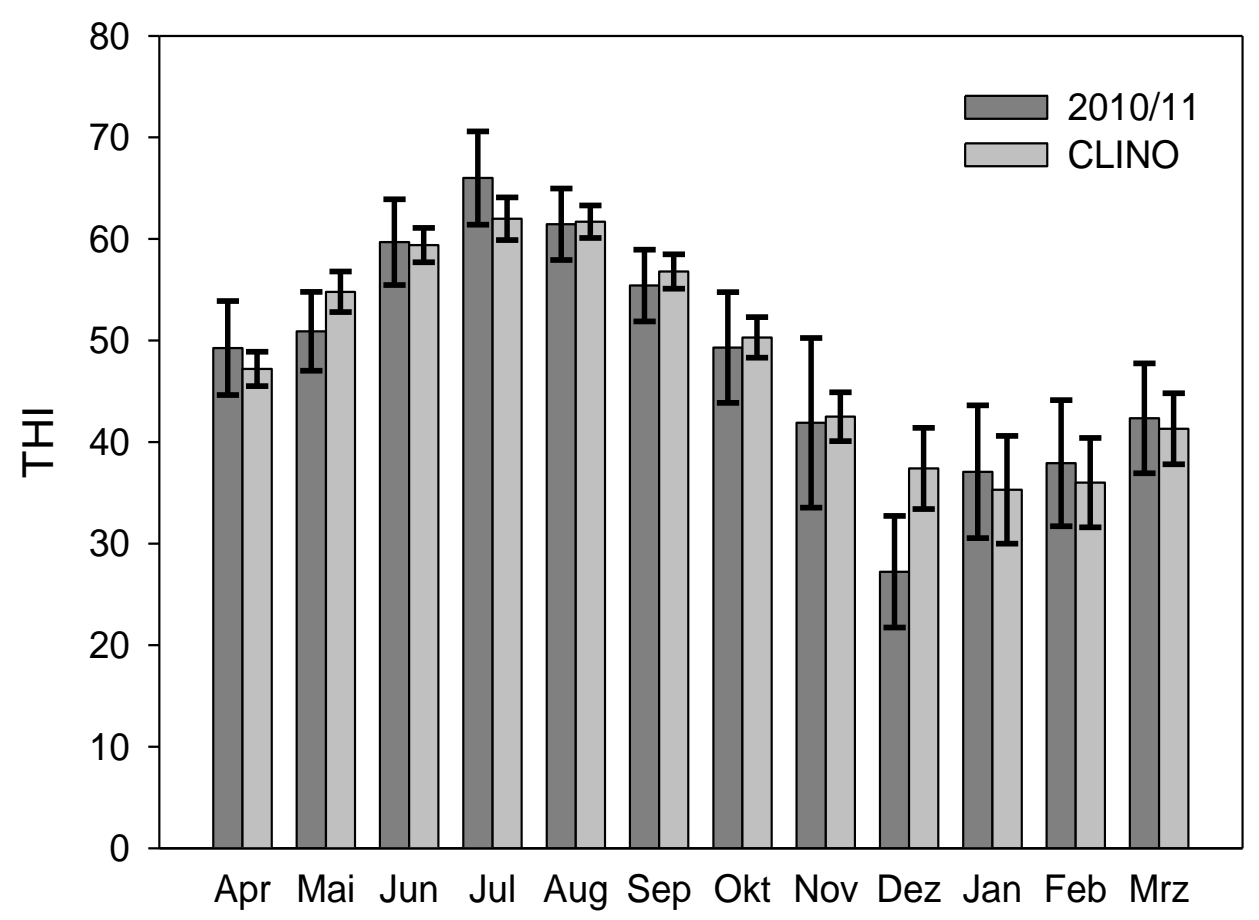

Abbildung 1. Monatliche Mittelwerte ( \pm Standardabweichung) des Temperatur-Humiditäts Index (THI) für den Versuchszeitraum 2010/2011 und den CLINO Referenzen (1961 - 1990) von Niedersachsen.

Entgegengesetzt der Klimaprojektionen zeigte sich im Dezember des Versuchsjahres ein niedrigerer Monatsmittelwert gegenüber der CLINO Referenz. Es zeigte sich zum einen eine Erhöhung der THI-Werte im Juli sowie im Zeitraum von Januar bis April. Im Juni und August des Versuchjahres wurden vergleichbare Mittelwerte gegenüber der CLINO Referenz ermittelt, wohingegen eine höhere Variabilität durch die größere Standardabweichung ersichtlich ist. Zum anderen ergaben sich im Dezember des Versuchsjahres deutlich niedrigere Mittelwerte gegenüber der CLINO Referenz. Der Deutsche Wetterdienst (DWD, 2012a) bewertete den Sommer 2010 als einen der zehn 
wärmsten Sommer in Deutschland seit 1881, wobei der Juni als eher mäßig und der Juli aufgrund der Hitzewelle als heiß bewertet wurde. Ebenfalls wurde in Abbildung 1 deutlich, dass die THI-Werte während der Versuchslaufzeit höhere waren als in den vorherigen Jahren, welches Berechnungen von Hitzestressauswirkungen bei Milchkühen ermöglichte. Bei einem anschließenden Vergleich der Abbildungen zu den Außenklimawerten (Kapitel VI, Abbildung 1) und zu den Stallklimawerten (Kapitel V, Abbildung 1) zeigten sich ähnliche Verläufe, wobei die Stall-THI-Werte im Laufe des Jahres deutlich über den Außen-THI-Werten lagen. Anhand der Außen-THI-Werte wäre nur im Juli der Schwellenwert nach BRÜGEMANN et al. $(2010,2012)$ überschritten worden, wobei die Untersuchungen des Stallklimas gezeigt haben, dass die Milchkühe in den Ställen während der gesamten Sommermonate Hitzestresssituationen ausgesetzt waren.

\subsection{Milchleistung}

Die Untersuchungen der Einflussfaktoren auf die Milchleistung (4\%-fettkorrigierte Milch, FCM) ergaben, dass diese von dem Laktationsstadium, der Parität, der Kalbesaison, dem Haltungssystem, dem Betrieb innerhalb des Haltungssystem und der THI Klasse beeinflusst wird (Kapitel V).

In dieser Arbeit standen insbesondere die klimatischen Faktoren, repräsentiert durch den THI, und die Haltungssysteme im Vordergrund. Die Analyse des THI Einflusses bei allen Haltungssystemen ergab einen signifikanten Rückgang von 0,78 kg FCM zwischen der niedrigsten $(\mathrm{THI} \leq 45)$ und der höchsten THI Klasse (THI $\geq 65)$. RHOADES et al. (2009) erwähnten, dass Hitzestress bei Milchkühen eine geringere Trockensubstanzaufnahme und eine geringere Milchleistung verursachte. In einer Studie unter mediterranen Klimabedingungen ermittelten die Autoren einen Milchleistungsrückgang von 4,58 kg FCM von den Frühjahrs- (THI 68) zu den Sommermonaten (THI 78) bei Holsteinkühen, die sich in der Mitte ihrer Laktation befanden (BouRAOUI et al., 2002).

Für die Zielstellung dieser Untersuchung ist insbesondere die Hitzstressauswirkungen zwischen den verschiedenen Haltungssystemen von Bedeutung. Bei dem Vergleich der Auswirkungen der Stall-THI Klassen zeigten sich in den gedämmten Laufstallsystemen keine signifikant negativen Auswirkungen eines zunehmenden THI auf die FCM (Kapitel $\mathbf{V}$, Tabelle 1). So ergaben sich tendenzielle Rückgange von 0,9 kg FCM mit Weidegang und 0,85 kg FCM ohne Weidegang bei einer Erhöhung der THI-Klasse von 60-65 auf $\geq 65$. Im Gegensatz dazu zeigten sich in den ungedämmten Systemen signifikante 
Leistungsdepressionen. In dem System ohne Weidehaltung ergaben sich Rückgänge von $1,24 \mathrm{~kg}$ FCM bei einem Anstieg von der THI Klasse 55-60 auf $\geq 65(P<0,05)$. Bei dem weidebasierenden System zeigten sich signifikante Leistungsabfälle von 1,35 kg FCM

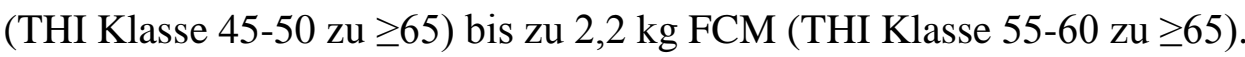

Bei der Regressionsanalyse wurden abschließend Regressionskoeffizienten zwischen dem Leistungsmerkmal FCM und den durchschnittlichen THI-Werten über drei Tage berechnet (bei THI Werten $\geq 60$ ), um die THI Effekte innerhalb der Systeme deutlicher darzustellen. Hierbei ergaben sich Regressionskoeffizienten von $-0,21 \mathrm{~kg}$ FCM/THI für die ungedämmten Systeme mit und ohne Weidegang und $-0,12 \mathrm{~kg}$ FCM/THI für die gedämmten Systeme ohne Weidegang sowie $-0,11 \mathrm{~kg}$ für weidebasierte Systeme. Die vorliegenden Ergebnisse sind vergleichbar mit den Regressionskoeffizienten von BRÜGEMANN et al. (2012), die Milchleistungsrückgänge von $-0,08 \mathrm{~kg} / \mathrm{THI}$ für ackerbaubetonte Regionen (Stallhaltung) und -0,17 kg/THI für weidebasierte Systeme bei identischer Berechnung der THI-Werte und vergleichbaren Regionen in Niedersachsen fanden. Es ist hierbei zu beachten, dass es sich bei den Klimadaten nicht um Stallklimasondern um Außenklimawerte handelte. In der vorliegenden Untersuchung wurden keine bzw. nur geringe Unterschiede zwischen Stallhaltungs- und weidebasierenden Systemen gefunden, sondern Unterschiede zwischen den Stallkonstruktionen. So zeigten sich in dem ungedämmten System höhere Leistungseinbussen mit steigendem THI als in dem gedämmten System. Untersuchungen in Regionen mit tropischen bzw. subtropischen Klimaverhältnissen berichtet JOHNSON (1987) von einem Milchleistungsrückgang von 0,26 kg Milch/THI ab einem THI >72. In einer tunesischen Studie zeigten sich Abfälle der Milchleistung von 0,41 kg FCM/THI über einen THI von 69 (BOURAOUI et al., 2002).

Eine skandinavische Studie, die eine vergleichende Analyse zwischen Warmställen und Außenklimaställen durchgeführt hat, zeigte keine signifikanten Unterschiede in der Milchproduktion zwischen den beiden Systemen. Die Autoren schlossen daraus, dass Milchkühe in Warmställen und Außenklimaställen unter Berücksichtigung der mikroklimatischen Bedingungen in Kombination mit dem Betriebsmanagement zu gleichen Leistungen fähig sind (SCHNIER et al., 2003). In der vorliegenden Untersuchung ergaben sich signifikant höhere Milchleistungsrückgänge in den ungedämmten Systemen. Unter Einbeziehung der Stallklimaauswertung zeigten diese Haltungssysteme wiederum die niedrigsten monatlichen THI Mittelwerten. Im Gegensatz dazu wurden in den ungedämmten Systemen die höchsten Maximaltemperaturen erfasst, was zum einen auf 
kurzfristig höhere Hitzestresssituationen in diesem System gegenüber dem gedämmten System hindeutet. Zum anderen weist dies darauf hin, dass milchleistungsbedingte Hitzestressauswirkungen nicht nur durch den THI erklärt werden können, sondern andere Faktoren diesen Bereich ebenfalls beeinflussen. So sollten bei Hitzestressbeurteilungen weitere Klimafaktoren mit berücksichtigt werden, wie z.B. die Windgeschwindigkeit und die Sonneneinstrahlung (RENAUDEAU et al., 2012).

\subsection{Milchinhaltsstoffe}

Neben den negativen Einflüssen auf die Milchleistung werden in der Literatur ebenfalls negative Auswirkungen auf den Gehalt der Milchinhaltsstoffe beschrieben (BOURAOUI et $a l ., 2002)$. In der vorliegenden Untersuchung wurde zum einen der prozentuale Anteil von Milchfett und Milchprotein (in \%) in der Tankmilch (Kapitel IV) und zum anderen die Milchfett- und Milchproteinleistung (in kg) anhand von Einzeltiererhebungen im Rahmen der Milchleistungsprüfung (Kapitel V) untersucht.

\section{Milchfett}

Der Milchfettgehalt und dessen Zusammensetzung können im Bezug auf die Futterrationsgestaltung, die Rasse, das Laktationsstadium, die Parität und die Saison variieren (GÜRTLER UND SCHWEIGERT, 2000). In der vorliegenden Untersuchung zeigte sich sowohl bei den Tankmilchproben, als auch bei den Einzeltierproben ein saisonaler und THI abhängiger Verlauf. In den Sommermonaten (Juni, Juli, August) war der Fettgehalt der Tankmilch signifikant niedriger als in den übrigen Monaten $(P<0,001)$. In der Studie von BOURAOUI et al. (2002) ergab sich neben der verminderten Futteraufnahme und Milchleistung ebenfalls ein um 0,34\% signifikant geringerer Milchfettgehalt zwischen den Sommer- und Frühjahrsmonaten. Gleich hohe Differenzen wurden in der vorliegenden Untersuchung ermittelt. Während der Versuchslaufzeit wurde zwischen dem wärmsten Monat (Juli) und dem kältesten Monat (Dezember) signifikante Differenzen von 0,41\% und $0,38 \%$ für die gedämmten Systeme ohne und mit Weidegang und 0,34\% und 0,35\% für die ungedämmten Systeme ohne und mit Weidegang ermittelt.

Bei der Regressionsanalyse zeigten sich bei dem prozentualen Fettgehalt der Tankmilch die höchsten Regressionskoeffizienten bei den gedämmten Haltungssystemen (Kapitel IV). Bei den Milchfetterträgen auf Basis der Einzeltierdaten ergaben sich die höchsten Regressionskoeffizienten bei den ungedämmten Haltungssystemen (Kapitel V). Da die 
Untersuchungen in den gleichen Betrieben und zum selben Zeitraum durchgeführt wurden, können Zeitraum und Betrieb als Einflussfaktoren ausgeschlossen werden. Vielmehr besteht bei prozentualen Werten das Problem, dass sie im Verhältnis zu anderen Werten ermittelt werden. Der Fettgehalt (in \%) wird in Relation zu der Milchmenge berechnet und wie zuvor erläutert wird die Milchmenge ebenfalls von hohen klimatischen Bedingungen beeinflusst. So dass die Ergebnisse aus dem Kapitel IV und V nicht 100\%ig vergleichbar sind. Bei der Betrachtung der Höhe der Auswirkungen auf den Fettgehalt zeigen sich nur geringe Unterschiede zwischen den Haltungssystemen.

\section{Milchprotein}

Die Untersuchungen des Milchproteins wurden vergleichbar aufgebaut wie die des Milchfetts und es zeigten sich tendenziell ähnliche Ergebnisse. In den Analysen stellten sich sowohl bei den Tankmilchproben (Kapitel IV), als auch bei den Einzeltierproben (Kapitel V) Saison und THI abhängige Verläufe dar. Während der Versuchslaufzeit wurde zwischen dem wärmsten Monat (Juli) und dem kältesten Monat (Dezember) eine durchschnittliche Differenz von 0,27\% ermittelt, wobei sich die Differenzen in den unterschiedlichen Haltungssystemen wie folgt darstellte: $0,28 \%$ und $0,26 \%$ für die gedämmten Systeme ohne und mit Weidegang sowie 0,25\% und $0,27 \%$ für die ungedämmten Systeme ohne und mit Weidegang $(P<0,001)$. Diese Leistungsdepressionen sind mit anderen Studien vergleichbar (BOURAOUI et al., 2002; RHOADES et al., 2009; SHWARTZ et al., 2009). In der Studie von RHOADES et al. (2009) ergaben sich um 0,13\% geringere Milchproteingehalte bei einem Vergleich von Hitzestress mit thermisch neutralen Bedingungen.

Bei der Regressionsanalyse zeigten sich bei den prozentualen Proteingehalten der Tankmilch, wie schon bei den Fettgehalten, die höchsten Regressionskoeffizienten bei den gedämmten Haltungssystemen (Kapitel IV). Bei den Milchproteinerträgen auf Basis der Einzeltierdaten ergaben sich die höchsten Regressionskoeffizienten bei den weidebasierten Haltungssystemen, sowohl bei den gedämmten als auch bei den ungedämmten Haltungssystemen (Kapitel V). Wie schon bei der Diskussion des Milchfettgehaltes erläutert wurde, haben die Untersuchungen in den gleichen Betrieben und zum selben Zeitraum statt gefunden, weshalb diese als Einflussfaktoren ausgeschlossen werden können. Wie auch der Fettgehalt wird der Proteingehalt (in \%) in Relation zu der Milchmenge berechnet. Da die Milchmenge ebenfalls vom THI beeinflusst wird, sind die Ergebnisse aus dem Kapitel IV und V nicht 100\%ig vergleichbar. Bei der Betrachtung der 
Auswirkungsintensität auf den Proteingehalt zeigten sich keine großen Unterschiede zwischen den Haltungssystemen.

\subsection{Eutergesundheit und somatischer Zellgehalt}

Der somatische Zellgehalt (SCC) ist der wichtigste Indikator, um die Eutergesundheit von Milchkühen bzw. von Milchviehherden zu beurteilen. Anhand dieses Parameters können klinische als auch subklinische Mastitiden quantifiziert werden, da der SCC von der Prävalenz und der Inzidenz dieser beeinflusst wird (KRÖMKER, 2007; OLDE RIEKERINK et al., 2007; DoHOO UND MEEK, 1982). In der vorliegenden Untersuchung wurde zunächst anhand von Arzneimittelbelegen von acht Betrieben Inzidenzen für vier verschiedene Behandlungskomplexe (Stoffwechsel, Fruchtbarkeit, Euter und Klauen/Gliedmaßen) berechnet (Kapitel III). Es zeigte sich, dass Mastitisbehandlungen den größten Behandlungskomplex darstellten. In der weiteren Analyse konnten aufgrund der Datengrundlage keine tierindividuellen Aussagen getroffen werden. Anhand der monatlichen Behandlungshäufigkeiten je Betrieb zeigten sich, entgegen der Literaturangaben, im Winter bzw. in der niedrigsten THI Klasse $(<40)$ tendenziell die höchsten Behandlungsinzidenzen $(P>0,05)$. Verschiedene Studien zeigten einen saisonalen Einfluss auf den somatischen Zellgehalt, wobei insbesondere ein SCC Anstieg in den Sommermonaten beschrieben wurde (NORMAN et al., 2000; BOURAOUI et al., 2002; OLDE RIEKERINK et al., 2007). Gleiche Beobachtungen konnten in dem Kapitel IV und V gemacht werden. Bei der Tankmilchbetrachtung ergaben sich Erhöhungen des somatischen Zellgehaltes mit steigendem 3-Tages THI Mittelwert von $1.075 \mathrm{SCC} / \mathrm{ml}$ (ungedämmtes Haltungssystem ohne Weidgang) bis $3.730 \mathrm{SCC} / \mathrm{ml}$ (gedämmtes Haltungssystem ohne Weidegang) (Kapitel IV). Im Kapitel $\mathbf{V}$ zeigten sich bei der Betrachtung der tierindividuellen Milchproben ebenfalls steigende somatische Zellscores (SCS) mit steigendem 3-Tages THI Mittelwert, wobei ebenfalls in dem gedämmten Haltungssystem ohne Weidegang die höchsten Anstiege gezeigt wurden. Anhand des somatischen Zellgehaltes könnten in der vorliegenden Arbeit negative Einflüsse auf die Eutergesundheit nachgewiesen werden, wobei diese in den Stallhaltungssystemen deutlicher sind als auf den weidebasierenden Systemen. Als Ursache könnten hier zum einen die höheren durchschnittlichen THI Werte und Temperaturen in dem gedämmten System angeführt werden und zum anderen könnte der Keimdruck in den Stallhaltungssystemen höher sein als in den weidebasierten Systemen. Im Zusammenhang mit den Behandlungsinzidenzen 
(Kapitel III) könnte eventuell der höhere SCC bzw. SCS mit steigendem THI auf eine höhere Gefahr für Eutererkrankungen hinweisen, wobei diese eher subklinisch verlaufen und aufgrund der fehlenden Klinik keine Behandlung durchgeführt wird. Bei dieser Vermutung sollte beachtet werden, dass die Untersuchungen der klimatischen Einflüsse auf die Behandlungsinzidenzen anhand des THI nicht in dem gleichen Zeitraum durchgeführt wurden, wie die zu den klimatischen Einflüssen auf den SCC bzw. SCS.

\subsection{Haltungssysteme}

Wie in den vorherigen Abschnitten schon erläutert wurde, war es unter anderem Ziel dieser Arbeit den Einfluss von Hitzestress auf Produktionsmerkmale in unterschiedlichen Haltungssystemen $\mathrm{zu}$ betrachten. In den Untersuchungen wurde hierbei zwischen gedämmten und ungedämmten Haltungssystemen unterschieden, wobei der Unterschied zwischen den Systemen in der Beschaffenheit des Daches bestand und nicht darin, ob es ein Warmstall bzw. Außenklimastall war. Bei dem gedämmten Stall war das Dach isoliert und bei dem ungedämmten System war das Dach nicht isoliert. Die gedämmten Systeme waren hierbei meistens zuvor Wärmställe, bei denen längere Zeit vor Beginn dieser Untersuchung die Seitenwände zum Teil eröffnet wurden. Die Stallklimauntersuchungen zeigten signifikante Unterschiede bei den Mittelwerten der Systeme. So ergaben sich signifikant höhere THI Monatsmittelwerte in den gedämmten gegenüber den ungedämmten Ställen. Im Gegensatz dazu zeigten sich in den ungedämmten Systemen die höchsten Monatsmaximaltemperaturen. Die Ergebnisse lassen die Vermutung aufkommen, dass die Dämmung des Daches eine vergleichbare starke Erhitzung des Stalles wie bei ungedämmten Systemen verhindert, wobei ebenso eine rasche Kühlung des Stalles verhindert wird, wodurch sich die höheren Monatsmittelwerte bei der Temperatur und dem THI erklären lassen. Bei den Leistungsmerkmalen zeigten sich insbesondere bei dem Parameter Milchleistung erhebliche Unterschiede zwischen den gedämmten und den ungedämmten Haltungssystemen. So ergaben sich trotz niedriger THI Mittelwerte stärkere Leistungsdepressionen in den ungedämmten Systemen. Um die Unterschiede zwischen den Systemen noch deutlicher herauszuarbeiten wurde auf Basis der Klimaergebnisse der einzelnen Haltungssysteme die tägliche Differenz zwischen dem THI Schwellenwert nach BRÜGEMANN et al. (THI $>60 ; 2010,2012)$ und dem Tages-THI Wert berechnet. Anschließend wurden die positiven Abweichungen summiert, wodurch die „Anzahl THI Punkte über 60“ errechnet wurden (Tabelle 1). Wie schon bei der Berechnung der „Anzahl 
Hitzetage“ deutlich wurde, zeigt ebenso der Parameter „Anzahl THI Punkte über 60“ höhere Werte in den gedämmten Systemen. Unter Berücksichtigung der einzelnen Milchleistungsdepressionen in den jeweiligen Haltungssystemen zeigten sich höhere jährliche Leistungsminderungen je Kuh in den ungedämmten Systemen. Am deutlichsten wurde dies in dem System ohne Weidegang, da in den Stallhaltungssystemen mehr Hitzetage und eine erhöhte „Anzahl THI Punkte über 60“ herrschten, als in den Systemen mit Weidegang. Wie schon in Kapitel IV und V angedeutet wurde, könnte dies durch den Aufenthalt der Kühe auf der Weide hervorgerufen worden sein. In einem dänischen Wahlversuch bei Milchkühen, die freie Wahl zwischen Weide und Stall hatten, zeigte sich, dass die Kühe vermehrt draußen waren und nur 28\% des Tages im Stall (KROHN et al., 1992).

Tabelle 1. Auswirkungen von Hitzestress auf die jährliche Milchleistung pro Kuh (4\%fettkorrigierte Milch) in den unterschiedlichen Haltungssystemen im Bezug auf die „Anzahl THI Punkte über den THI Schwellenwert (THI $\geq 60)$ “" während der Versuchslaufzeit vom 1. April 2010 bis 30. März 2011.

\begin{tabular}{|c|c|c|c|c|}
\hline \multirow[b]{2}{*}{ Parameter } & \multicolumn{4}{|c|}{ Cluster } \\
\hline & $\begin{array}{c}\text { gedämmtes } \\
\text { Haltungssystem } \\
\text { ohne Weidegang } \\
(\mathrm{N}=5) \\
\end{array}$ & $\begin{array}{c}\text { gedämmtes } \\
\text { Haltungssystem } \\
\text { mit Weidegang } \\
(\mathbf{N}=5) \\
\end{array}$ & $\begin{array}{c}\text { ungedämmtes } \\
\text { Haltungssystem } \\
\text { ohne Weidegang } \\
(\mathbf{N}=\mathbf{5}) \\
\end{array}$ & $\begin{array}{c}\text { ungedämmtes } \\
\text { Haltungssystem } \\
\text { mit Weidegang } \\
(\mathbf{N}=\mathbf{5}) \\
\end{array}$ \\
\hline $\begin{array}{l}\text { Anzahl } \\
\text { Hitzetage }^{1)}\end{array}$ & 180 & 187 & 175 & 169 \\
\hline $\begin{array}{l}\text { Anzahl THI } \\
\text { Punkte über } \text { 60²) }^{2}\end{array}$ & 859 & 757 & 694 & 654 \\
\hline $\begin{array}{l}\text { Leistungs- } \\
\text { depression je } \\
\text { Kuh/Tag }\end{array}$ & $-0.12 \mathrm{~kg} / \mathrm{THI}$ & $-0.11 \mathrm{~kg} / \mathrm{THI}$ & $-0.21 \mathrm{~kg} / \mathrm{THI}$ & $-0.21 \mathrm{~kg} / \mathrm{THI}$ \\
\hline $\begin{array}{l}\text { jährliche } \\
\text { Minderleistung } \\
\text { je Kuh }\end{array}$ & $103,1 \mathrm{~kg}$ & $83,3 \mathrm{~kg}$ & $145,7 \mathrm{~kg}$ & $137,3 \mathrm{~kg}$ \\
\hline
\end{tabular}

${ }^{1)}$ Anzahl Hitzetage $=$ Anzahl Tage mit THI-Tagesmaximum $\geq 60$

${ }^{2)}$ Anzahl THI Punkte über $60=\sum$ der positiven Differenzen aus (Tages THI Wert - THI Schwellenwert)

Die Ergebnisse verdeutlichen ebenso, dass die Unterschiede zwischen den Haltungssystemen nicht allein anhand des Stall THI zu erklären sind. Aufgrund der teilweisen bzw. ganz geöffneten Seitenwände der Ställe könnte die Windgeschwindigkeit noch einen weiteren wichtigen Einflussfaktor darstellen. Nach RENAUDEAU et al. (2012) ist 
die Windgeschwindigkeit neben der Temperatur und der relativen Luftfeuchtigkeit ein entscheidender Faktor der den Grad von Hitzestress beeinflusst.

Des Weiteren beeinflusst ebenfalls die Sonneneinstrahlung die Intensität des Hitzestresses, was insbesondere im Hinblick auf die Weidehaltung von Bedeutung ist, da die Kuh während der Weidezeit der direkten Sonneneinstrahlung ausgesetzt ist (TUCKER et al., 2008). Eine Untersuchung von Hitzestressauswirkungen bei Milchkühen, die auf der Weide gehalten wurden, zeigten sich eine deutliche Erhöhung der Oberflächentemperatur und der inneren Körpertemperatur bei Außentemperaturen von über $30^{\circ} \mathrm{C}$ (GASTEINER et al., 2007). Aus diesem Grund sind Schattenmöglichkeiten, die durch Bäume, Unterstände sowie dem Stallgebäude gewährleistet werden können, effektive Maßnahmen zur Reduzierung von Hitzestress bei weidebasierten Haltungssystemen (ARMSTRONG, 1994; BROWN-BRANDL et al., 2005).

\subsection{Schlussfolgerungen}

Allgemein kann anhand der Ergebnisse dieser Untersuchungen zu Außen- wie Stallklima zunächst geschlussfolgert werden, dass Milchkühe in Niedersachsen im Sommer Hitzestress ausgesetzt sind. In Bezug auf die einzelnen Teilbereiche dieser Arbeit können des Weiteren folgende Schlussfolgerungen gezogen werden:

- Im Außen- als auch im Stallklima konnten Hitzestresssituationen während der Versuchslaufzeit aufgezeigt werden, wobei sich insbesondere in den Stallsystemen höhere Klimawerte (Temperatur, THI) gegenüber den Außenklimawerten zeigten.

- Anhand der Untersuchungen mit der THI Formel nach NRC (1971) und dem Schwellenwert nach BRÜGEMANN et al. (2010, 2012) konnten Leistungsdepressionen bei der Milchleistung und der Milchinhaltsstoffen aufgrund von Hitzestress nachgewiesen werden.

- Im Bezug auf die Gesundheitsparameter konnten die Analysen keine signifikanten Effekte von den Außen THI Werten auf die Behandlungsinzidenzen aufweisen. Die Auswertung des somatischen Zellgehaltes (SCC) bzw. des somatischen Zellscores (SCS), die als Indikatoren für die Eutergesundheit genutzt werden, zeigte sich eine Erhöhung dieser mit steigendem Stall THI, wodurch deutlich wird, dass nachfolgende Analysen der Auswirkungen der Klimafaktoren auf die Gesundheit von Milchkühen sinnvoll sind. In diesen Betrachtungen ist es empfehlenswert 
Stallklimawerte und tierindividuelle Behandlungsdaten $\mathrm{zu}$ nutzen, um weitere Einflussfaktoren in den Analysen berücksichtigen zu können.

- Abschließend kann geschlussfolgert werden, dass in dem System mit ungedämmtem Dach die deutlichsten Leistungseinbussen aufgezeigt wurden. Für eine Empfehlung eines Haltungssystems bezüglich der Kompensationsfähigkeit von Hitzestress sollten zusätzliche Untersuchungen zum Einfluss von Windgeschwindigkeiten in gedämmten und ungedämmten Ställen durchgeführt werden.

\subsection{Literaturverzeichnis}

Armstrong D.V. 1994. Heat stress interaction with shade and cooling. J. Dairy Sci. 77: 2044-2050.

Bohmanova J., I. Misztal und J.B. COlE 2007. Temperature-humidity indices as indicators of milk production losses due to heat stress. J. Dairy Sci. 90: 1947-1956.

Bouraoui R., M. Lahmar, A. Majdoub, M. Djemali und R. Belyea 2002. The relationship of temperature-humidity index with milk production of dairy cows in a Mediterranean climate. Anim. Res. 51: 479-491.

Brown-Brandl L.M., R.A. Eigenberg, J.A. Nienaber und G.L. Hahn 2005. Dynamic response indicators of heat stress in shaded and non-shaded feedlot cattle - Part 1: Analyses of indicators. Biosystems Engineering 90: 451-462.

BRÜGEMANN K., S. KÖNIG UND E. GERNAND 2010. Assessment of heat stress in dairy cows by applying random regression test day models. In Book of abstracts of $61^{\text {st }}$ annual meeting of the European association for animal production, Heraklion, Greece, p.195. Wageningen Academic Publishers, Wageningen, Netherlands.

BRÜGEMANN K., E. GERNAND, U.U. VON BORSTEL UND S. KÖNIG 2011. Genetic analyses of protein yield in dairy cows applying random regression models with time and temperature x humidity dependent covariates. J. Dairy Sci. 94: 4129-4139.

BRÜGEMANn K., E. GeRnAND, U. KÖNIG VON Borstel und S. KÖNIG 2012. Defining and evaluating heat stress thresholds in different dairy cow production systems. Arch. Tierz. 55: 13-24.

DEUTSCHER WETTERDIENST (DWD) 2012a. Deutscher Wetterdienst - Wetter und Klima aus einer Hand: Deutschlandwetter im Sommer 2010 - Ein Sommer mit Hitze und Dürre sowie intensivsten Regenfällen, abgerufen am 20. Mai 2012 von http://www.dwd.de/bvbw/generator/DWDWWW/Content/Presse/Pressemitteilunge n/2010/20100830__DeutschlandwetterSommer2010,templateId=raw,property=publ icationFile.pdf/20100830_DeutschlandwetterSommer2010.pdf.

DEUTSCHER WETTERDIENST (DWD) 2012b. persönliche Auskunft.

DoHoo I.R. UND A.H. MeEK 1982. Somatic cell counts in bovine milk. Can. Vet. J. 23: 119-125. 
FRANCK, E. UND O. PEITHMANN 2010. Regionalplanung und Klimaanpassung in Niedersachsen. E-Paper der ARL, Nr. 9, Hannover.

Gasteiner J., D. Eingang, L. Sonnleitner und A. Steinwidder 2007. Hitzestress bei Milchkühen unter Weidebedingungen. Bautagung Raumberg-Gumpenstein, 23.-24. Mai 2007, Irdning.

GÜrTler, H. UND F. J. SChWEIGERT 2000. Physiologie der Laktation. In Physiologie der Haustiere (eds W. vON ENGELHARDT AND G. BREVES), pp. 552-573, 2. Auflage,. Enke Verlag in MVS Medizinverlage, Stuttgart, Germany.

Intergovernmental Panel on Climate Change (IPCC). 2007. Climate change 2007: the physical science basis. Contribution of working group I to the fourth assessment report of the Intergovernmental Panel on Climate Change. Cambridge University Press, Cambridge, New York, USA.

JOHNSON H.D. 1987. Bioclimate effects on growth, reproduction and milk production. In Bioclimatology and the Adaptation of Livestock, World Animal Science, B5, Chapter 5 (eds H.D. Johnson), pp. 35-57, Elsevier Science Publishers B.V., Amsterdam, The Netherlands.

Krohn C.C., L. MunKsgaARD Und B. JonASEN 1992. Behaviour of dairy cows kept in extensive (loose housing/pasture) or intensive (tie stall) environments I. Experimental procedure, facilities, time budgets - diurnal and seasonal conditions. Appl. Anim. Beh. Sci. 34: 37-47.

KRÖMKER V. 2007. Kurzes Lehrbuch Milchkunde und Milchhygiene. Parey Verlag, Stuttgart.

NAtional RESEARCH COUNCIL 1971. A guide to environmental research on animals. NRC, National Academy of Sciences, Washington, DC, USA.

NoRman H.D., R.H. MiLleR, J.R. WRight And G.R. Wiggans 2000. Herd and state means for somatic cell count from dairy herd improvement. J. Dairy Sci. 83: 2782-2788.

Novak P., J. Vokralova Und J. BROUCEK 2009. Effects of the stage and number of lactation on milk yield of dairy cows kept in open barn during high temperatures in summer months. Arch. Tierz. 52: 574-586.

Olde RiEKERINK R.G.M., H.W. BARKEMA Und H. STRYHn 2007. The Effect of Season on Somatic Cell Count and the Incidence of Clinical Mastitis. J. Dairy Sci. 90: 17041715 .

Ravagnolo O. Und I. MiszTal 2000. Genetic component of heat stress in dairy cattle, parameter estimation. J. Dairy Sci. 83: 2126-2130.

Renaudeau D., A. Collin, S. Yahav, V. De Basilio, J.L. Gourdine und R.J. Collier 2012. Adaptation to hot climate and strategies to alleviate heat stress in livestock production. Animal 6: 707-728.

RhoAdes M.L., R.P. RhoAds, M.J. VanBaAle, R.J. Collier, S.R. SANDERs, W.J. Weber, B.A. CROOKER UND L.H. BAUMGARD. 2009. Effects of heat stress and plane of nutrition on lactating Holstein cows: I. Production, metabolism, and aspects of circulating somatotropin. J. Dairy Sci. 92: 1986-1997. 
SCHNiER C., S. Hielm Und H.S. SAlONIEMI 2003. Comparison of milk production of dairy cows kept in cold and warm loose-housing systems. Prev. Vet. Med. 61: 295-307.

Shwartz G., M. L. Rhoads, M. J. VanBaAle, R. P. Rhoads Und L. H. Baumgard 2009. Effects of a supplemental yeast culture on heat-stressed lactating Holstein cows. J. Dairy Sci. 92:935-942.

SPERONi M., G. PIRLO UND S. LOLLI 2006. Effect of automatic systems on milk yield in a hot environment. J. Dairy Sci. 89: 4687-4693.

TUCKER C.B., A.R. RogERS UND K.E. SCHÜTZ 2008. Effect of solar radiation on dairy cattle behaviour, use of shade and body temperature in a pasture-based system. Appl. Anim. Behav. Sci. 109: 141-154.

UnRath J. 2004. Analyse und Bewertung von Parametern der Produktionsumwelt bei der Milchgewinnung mit automatischen Melksystemen (AMS). Dissertation an der Humboldt- Universität zu Berlin.

WALTER K. UND F.J. LÖPMEIER 2010. Fütterung und Haltung von Hochleistungskühen 5. Hochleistungskühe und Klimawandel. vTI Agriculture and Forestry Res. 60: 17-34. 


\section{Lebenslauf}

Name:

Geburtsdatum:

Geburtsort:

Staatsangehörigkeit:

Familienstand:

\section{Schulausbildung:}

1989 - 1993

1993 - 1999

1999 - 2002

\section{Studium:}

2003 - 2006

$2006-2008$

\section{Praktika:}

2002 - 2003

08/2005-09/2005

$11 / 2007-12 / 2007$

$01 / 2008-04 / 2008$

\section{Berufstätigkeit:}

2009 - 2012

Seit 2012
Christine Sanker

03.12.1982

Bünde

deutsch

ledig

Grundschule Belke-Steinbeck, Enger

Realschule Bünde-Mitte, Bünde

Gymnasium am Markt, Bünde

Studium der Agrarwissenschaften an der GeorgAugust Universität Göttingen, Studienschwerpunkt: Nutztierwissenschaften

Abschluss: Bachelor of Science

Studium der Agrarwissenschaften an der GeorgAugust Universität Göttingen, Studienschwerpunkt: Nutztierwissenschaften

Abschluss: Master of Science

Einjähriges landwirtschaftliches Praktikum auf dem Milchviehbetrieb der Familie Brokate, Uchte mit abschließender Praktikantenprüfung

Landwirtschaftliches Praktikum auf dem Veredlungsbetrieb (Zuchtsauen, Hähnchenmast) der Familie Bohnenkamp, Bad Salzuflen

Landwirtschaftliches Praktikum auf dem Milchviehbetrieb Westrup-Koch GbR, Bissendorf

Praktikum bei dem Rinderzuchtunternehmen MASTERRIND GmbH, Verden

Wissenschaftliche Mitarbeiterin an der Georg-August Universität Göttingen in der Abteilung Produktionssysteme der Nutztiere des Departments für Nutztierwissenschaften

Vermarktungsleiterin bei der Rinderunion BadenWürttemberg e.V. 